Discussion Paper No. 932

\title{
LOSING TRACK OF THE ASSET MARKETS: \\ THE CASE OF HOUSING AND STOCK
}

\author{
Kuang-Liang Chang \\ Nan-Kuang Chen \\ Charles Ka Yui Leung
}

\begin{abstract}
April 2015
The Institute of Social and Economic Research Osaka University

6-1 Mihogaoka, Ibaraki, Osaka 567-0047, Japan
\end{abstract}




\title{
Losing track of the asset markets: The case of housing and stock*
}

\author{
Kuang-Liang Chang Nan-Kuang Chen Charles Ka Yui Leung ${ }^{\dagger}$
}

April 17, 2015

*Acknowledgement: An earlier version of the paper was circulated as "Would some models please give me some hints?". The current version is revised after receiving helping comments from (alphabetical order) Gianni Amisano, Wing Hong Chan, Marcelle Chauvet, Andrew Filrado, Xu Han, Ivan Jaccard, Yuichiro Kawaguchi, Kyung-Hwan Kim, Fred Kwan, Rose Lai, Giovanni Lombardo, Thomas Lubik, Joe Ng, Liang Peng, Daniel Preve, John Quigley, Tim Riddiough, Douglas Rolph, Anna Samarina, Jim Shilling, Edward Tang, an anonymous referee, seminar participants at the Asian Econometric Society meeting, AsRES-AREUEA meeting, Bank of International Settlements, City University of Hong Kong, European Central Bank, European Real Estate Society meeting, NUS, and WEAI. Chen thanks the National Science Council (Taiwan) for financial support. The work in this paper was partially supported by a grant from the Research Grants Council of the Hong Kong Special Administrative Region, China [Project No. CityU 144709]. We are grateful for all their support. The usual disclaimer applies.

${ }^{\dagger}$ Correspondence: Chang: Department of Applied Economics, National Chiayi University, 580 Sinmin Road, Chiayi City 60054, Taiwan. Tel.: 886-5-2732852, E-mail: klchang@mail.ncyu.edu.tw. Chen: Department of Economics, National Taiwan University, 21 Shuchow Road, Taipei 10021, Taiwan. Tel.: 8862-2351-9641 ext. 471, E-mail: nankuang@ntu.edu.tw. Leung: Department of Economics and Finance, City University of Hong Kong, Kowloon Tong, Hong Kong. Tel.: 852-2788-9604, Fax: 852-2788-8806, E-mail: kycleung@cityu.edu.hk. 


\begin{abstract}
This paper revisits the relationships among macroeconomic variables and asset returns. Based on recent developments in econometrics, we categorize competing models of asset returns into different "Equivalence Predictive Power Classes" (EPPC). During the pre-crisis period (1975-2005), some models that emphasize imperfect capital markets outperform an $\mathrm{AR}(1)$ for the forecast of housing returns. After 2006, a model that includes both an external finance premium (EFP) and the TED spread "learns and adjusts" faster than competing models. Models that encompass GDP experience a significant decay in predictive power. We also demonstrate that a simulation-based approach is complementary to the EPPC methodology.

Key words: monetary policy, financial market variables, Uni-variate Single-regime Benchmark, Markov Regime Switching, forecasting

JEL classification: E50, G00, R00
\end{abstract}


"In view of the structural equality of explanation and prediction, it may be said that an explanation ... is not complete unless it might as well have functioned as a prediction."

Carl Hempel, 1942, The Function of General Laws in History.

\section{Introduction}

This paper contributes to the literature in a number of ways. First, it revisits the relationship between some macroeconomic variables and asset prices (housing and stock). On the one hand, based on the efficient market hypothesis (EMH), relevant information has been summarized in the asset prices and hence introducing macroeconomic variables should not improve our prediction for these asset prices. ${ }^{1}$ On the other hand, there is an emerging strand in the literature suggesting that there are non-trivial interactions among macroeconomic variables and asset prices, and therefore including macroeconomic variables would enhance our understanding of the asset prices. ${ }^{2}$ A simple way to distinguish these two bodies of theory above would be to set the asset prices as the dependent variables and introduce the macroeconomic variables as independent variables, in addition to including lagged asset prices. If the coefficients of the macroeconomic variables are statistically insignificant, then the efficient market hypothesis is confirmed. Conversely, if the coefficients of the macroeconomic variables are statistically significant, then the efficient market hypothesis is rejected and the macroeconomic variable-asset prices interactions are indeed important.

While such an approach is intuitive and easy to improve, there are several shortcomings. First, if the asset price movements indeed generate a wealth effect or collateral effect, ${ }^{3}$ then there is a feedback effect from asset prices to macroeconomic variables.

\footnotetext{
${ }^{1}$ Clearly, there are different views about the EMH and how we can test it. Among others, see Fama (1970), Darrat and Glascock (1989), LeRoy (1989).

${ }^{2}$ Among others, see Green (2002), Case, Quigley and Shiller (2005), Campbell and Cocco (2007) for a discussion of the wealth effect that can be created by the asset price fluctuations; Leung (2004), Chen and Leung (2008), Jin et al. (2012) and the reference therein for the interaction between housing prices and macroeconomic variables through the collateral effect.

${ }^{3}$ Since the aggregate consumption constitutes almost $70 \%$ of the total GDP of the USA, and since many countries target their export to the USA, the wealth effect generated by asset price swings can have important implications to the economies of both the U.S. and many of its trade partners. The
} 
Thus, an endogeneity bias may occur. The minimum model that can embed the potential feedback among asset prices and macroeconomic variables would be the vector autoregressive (VAR) models, ${ }^{4}$ but comparing VAR models is not always a trivial task. ${ }^{5}$ A common practice is to apply the test proposed by Diebold and Mariano (1995), which allows for a bilateral model comparison. In the context of asset price movements, we may want to compare more than two models as the rationale is quite clear. Different theories are "represented" by different econometric models, in the sense of different variables and different possible relationships among variables being highlighted. ${ }^{6}$ To compare which "theory" of asset price movements, it is important to employ an appropriate procedure to select the "best performing model" among competing ones. Our second major contribution of the literature thus combines the work on multi-model performance comparison by Mariano and Preve (2012) and the work on "model confidence set" by Hansen et al. (2011) in order to "eliminate" less competitive models sequentially. As a result, we can categorize models into several "Equivalence Predictive Power Classes" (EPPC).

collateral effect refers to the scenario that continuous declines in house prices can cause a quick decay of collateral quality and value, potentially leading to a credit crunch and subsequent rise in bankruptcy and foreclosures.

${ }^{4}$ Sims (1980b) makes a strong case why in a macroeconometric context, estimating a system of equations, especially in the context of a dynamically interacting system, is econometrically more sensible than single equation estimation.

${ }^{5}$ It is well known that under some conditions, we can view a VAR model as a collection of uni-variate regression. In fact, some standard computer packages deliver a separate $R^{2}$ measure for each of the equation within a multi-variate VAR. Therefore, it is possible that one VAR model produces a higher " $R$ " in the "stock price equation" and yet a lower " $R$ " in the "house price equation" than the other VAR. Yet both the "stock price equation" and "house price equation" are part of a dynamic system and hence it seems that reading the "individual equation $R^{2}$ " may not be sufficient.

${ }^{6}$ Notice that the reduced form dynamics of many dynamic, stochastic general equilibrium models (DSGE) have a VAR representation (for instance, see Kan et al., 2004; Leung, 2014). While identification can be an issue and we might not be able to recover the underlying DSGE model from estimated VAR, comparing the empirical performance of a collection of VAR models might still provide an indirect test for the models' capacity to account for the data. In the current context, a VAR at least could provide us some hints about whether regime-switching is important, which variables should be included in the DSGE, etc. See Kapetanios et al. (2007), among others, for more discussion on this point. See also Pagan and Robinson (2014) which show that some existing DSGE with imperfect capital market may not explain the data very well. 
Effectively, we may be able to provide indirect evidence about which theories have the same explanatory powers and which theories have a lower explanatory power than some rivals. Thus, the empirical results obtain herein might provide some reference for the future development of theoretical modeling. The method is very simple, can be applied to any finite number of models and very different contexts, and hence it may have some independent interests. ${ }^{7}$

This paper specifically focuses on U.S. aggregate data during the period $1975 Q 2-$ $2012 Q 1$ and studies various versions of Vector Auto-Regressive ( VAR) models, with and without regime-switching, which arguably represent different views on the driving force of the asset markets. ${ }^{8}$ While we have explained why VAR models should be used, our choice of regime switching model also seems non-controversial. First, the possibility of regime switching in the macroeconomic and financial time series has long been studied and verified. ${ }^{9}$ Among others, Chen and Leung (2008) show that in the presence of collateral constraints, bankruptcy possibility and asset price spillover, the relationship between aggregate output and the real estate price can be very non-linear (piece-wise continuous with different slopes in different segments) and hence may not be well captured by widely used linear VAR model. In addition, Chang, Chen and Leung (2011) argue that the regime switching model can be consistent with two stylized facts in the housing market: (1) short-run predictability, which has been repeatedly documented since Case and Shiller (1990), and (2) long-run non-profitability, which is a prerequisite of the long run efficiency of the housing market. ${ }^{10}$ The inclusion of some monetary policy variable would further justify the use of regime-switching model. ${ }^{11}$

\footnotetext{
${ }^{7}$ For instance, see Kwan et al. (2015) for an application of this model comparison method on structural models.

${ }^{8}$ The National Bureau of Economic Research, among others, has also admitted that an economic recession has started in the first quarter of 2008. When it will end, however, is still a topic for debate.

${ }^{9}$ Again, the literature is too large to be reviewed here. Among others, see Hamilton (1994), Maheu and McCurdy (2000).

${ }^{10}$ Notice that if the true model is single-regime, if short-run predictability holds, then we cannot have the long-run non-profitability at the same time. And there is a large literature on testing the housing market efficiency based on this simple relationship. Among others, see Chang et al. $(2012,2013)$ for more discussion.

${ }^{11}$ For instance, Sims and Zha (2006) find that the changes of monetary policy "were of uncertain
} 
In this paper we focus on the return stock price index $(S R E T)$ and the house price index (HRET), as well as variables that may affect the two asset returns. Our choices of variables are mainly guided by the previous literature on asset price dynamics and will be explained in further details in the following section. ${ }^{12}$ For a more balance understanding, we conduct both in-sample forecasting (ISF) and out-of-sample forecasting (OSF) herein. Our OSF takes two different approaches: conditional expectations and simulation-based methods. ${ }^{13}$ The merits of using the former approach have been widely discussed in the previous literature. On the other hand, the confidence intervals may not be available from the former approach. It is an important issue for the regime switching models, because the system not only receive shocks within a regime, but also experiences the stochastic switching from one regime to another. Following Sargent, Williams and Zha (2006), we adopt the simulation-based approach to calculate the median path and the confidence interval, with regular model updating.

There is clearly a large and recent literature on asset pricing. ${ }^{14}$ For instance, Maheu, McCurdy and Song (2012) study the daily returns of equity indices for 125 years and focus on the regime-dependence of the transition probability matrices. Grishchenko and

timing, not permanent, and not easily understood, even today" and that models which "treat policy changes as permanent, nonstochastic, transparent regime changes are not useful in understanding this history." Casual observation also suggests that the conduct of monetary policy has changed over time along changes in the chairman of the Fed and several episodes that dramatically affect inflation and economic activity (such as oil price shocks). Thus it may be appropriate to explicitly allow for regimeswitching behavior in the study of asset returns and monetary policy.

${ }^{12}$ For instance, there is a large class of dynamic equilibrium models suggesting that the house prices and stock prices should be correlated. Among others, see Leung (2007), Kwan et al. (2015) and the reference therein.

${ }^{13}$ We will provide more justifications on why this would be appropriate in later sections.

${ }^{14}$ For instance, Welch and Goyal (2008), among others, argue that most if not all models fail to predict equity premium. Recently, Phillips (2013) proves that the confidence intervals in some of the predictive regressions have zero converge probability and the corresponding statistics $\mathrm{Q}$ would indicate predictability even when there is none.

The focus of this paper is different. First, we emphasize on the model ability to account for both stock price and housing price, rather than the equity premium. Second, we emphasize on how different models "learn and adopt" since the 2006 housing price decline. Therefore, we will adopt a different approach, as it will be explained in later sections. 
Rossi (2012) employ the monthly data from Consumer Expenditure Survey from 1984 to 2012 to estimate the asset price model. Clark (2011) takes real-time data from 1985Q1 to 2009Q1 and shows that stochastic volatility improves the real time forecast of macroeconomic variables. There is also a strand of literature comparing the rate of returns of real estate versus the stock market from an investment perspective. ${ }^{15}$ This paper differs from the literature in several dimensions. First, this paper takes a "dynamical system approach". Our estimation is multivariate and when regime-switching occurs in our equation, it is actually the whole dynamical system switch from one regime to another. This clearly differs from, and hence complements, some of the literature taking a univariate approach. Second, we focus on aggregate data starting from 1975 and hence we can cover a longer period. Since the official, aggregate data of housing is in quarterly frequency, we adjust the frequency of other variables to quarterly frequency, and hence our work may complement earlier works that focus on the higher frequency movements of asset returns. Third, we focus on the application of classical econometrics. Perhaps more importantly, this paper compares not only how different models predict for the in-sample period (or, the "pre-crisis period"), but also how different model performances evolve as we recursively update the parameter estimates with new data in the out-of-sample period (or, the "post-crisis period"). To some extent, we examine the ability of different models to "learn and adopt" within changing asset markets. To our knowledge, these features are not emphasized by the previous literature and our paper can supplement that.

The rest of the paper is organized as follows. Section 2 describes the econometric model and gives a statistical summary of the data. Section 3 presents the empirical estimation results with the baseline model. Section 4 compare forecasting performances across models. Section 5 concludes.

\footnotetext{
${ }^{15}$ Among others, see Ibbotson and Siegel (1984), Quan and Titman (1997, 1999).
} 


\section{The Econometric Analysis}

\section{$2.1 \quad$ Data}

The analysis of this paper is based on the U.S. data covering the period 1975Q2-2012Q1. Limited by data availability, the dimensionality constraint of the econometric model, we focus on the returns of the stock price index $(S R E T)$ and the house price index (HRET), as stock and house are the most important assets for a typical household in the United States. Focus is placed on the asset return rather than the asset prices, because the latter tend to be non-stationary while the former may be mean-reverting. Figure 1 provides a visualization of these variables and clearly demonstrates two stylized facts: (1) the negativity of the housing return in the recent years, and (2) the high volatility of stock returns (relative to the housing returns).

(figure 1 about here)

The previous literature on asset price dynamics guides our choices of variables to be included, on top of the asset returns. They include: the (3-month) federal funds rates (hereafter FFR) which is a measure of the US monetary policy; the term spreads $(S P R)$ which is a measure of the difference between long-term and short-term interest rates ${ }^{16}$; external finance premium $(E F P)$, which is a measure of the degree of credit market imperfect from non-financial firms' perspective, ${ }^{17}$ the TED spread $(T E D)$, which is a

\footnotetext{
${ }^{16}$ In this paper, SPR is defined as the discrepancy of the long term (10 years) interest rate and the short term (3-month) counterpart.

${ }^{17}$ In this paper, EFP is defined as the spread between high-rating corporate bond and the low-rating one (Baa-Aaa).

There are a number of available series that have been used as the measure external finance premium. Among these are the prime spread (prime loan rate - federal funds rate) and the corporate bond spread (Baa-Aaa), and the high-yield bond spread (Bbb-Aaa). De Graeve (2007) argues that the prime loan spread provides a poor indication of financing conditions of firms which are typically considered vulnerable to credit market frictions, because it focuses on firms of the highest credit quality, to which financial constraints pertain the least. Gertler and Lown (1999) show that the high-yield bond spread is strongly
} 
measure of the degree of credit market imperfect from banks' perspective; ${ }^{18}$ and GDP growth rates $(G D P)$. The choices can be easily justified. For instance, our inclusion of monetary policy variable in the study of asset price dynamics is consistent with the literature. ${ }^{19}$ On the one hand, the monetary policy is widely perceived to be influential to both the stock and housing market. On the other hand, the Federal Reserve may react to the stock market movement in some instances (e.g. Rigobon and Sack, 2003). In this paper, we follow Sims (1980a) and choose FFR to represent the movement of the monetary policy. Similarly, the GDP growth rate $(G D P)$ seems to be a natural choice for a proxy of "economic fundamental." 20 The term spread $(S P R)$ is well-known to contain information about future inflation, future real economic activities as well as asset returns. ${ }^{21}$ Thus, it may be instructive to include the term structure as a (partly) "forward-looking variable" in the regression without taking any stand on the formation of future inflation or interest rate expectation. ${ }^{22}$ The external finance premium $(E F P)$ and

associated with both general financial conditions and the business cycle (as predicted by the financial accelerator). However, the series started only in the early 1980s. Therefore, we choose corporate bond spread (Baa-Aaa) to be our measure of the external finance premium.

${ }^{18}$ In this paper, the TED spread is defined as the difference between the 3-month Eurodollar deposit rate and the 3-month T-bill rate.

The widely-used BBA LIBOR, compiled by the British Bankers' Association, started only from January 1986. Therefore, we replace the 3-month LIBOR rate by 3-month Eurodollar deposit rate. These two series are highly correlated. Both the corporate bond spread and the 3-month Eurodollar deposit rate are from H.15 statistical release ("Selected Interest Rates") issued by the Federal Reserve Board of Governors.

${ }^{19}$ For instance, audiance in different occasions suggest us to adopt the "financial stress index" (FSI). However, FSI is available only from 1990 onwards, while other variables in our dataset are available since 1975. Using FSI will force us to lose much information, including how the system react to dramatic events such as the 1987 stock market crash. Furthermore, FSI may have higher predictive power with higher frequency data, while this paper focuses on the quarterly frequency where GDP data is available.

${ }^{20}$ In contrast, the aggregate consumption may be "too smooth" to account for the movement of stock return very well. Thus, we use the GDP instead. The literature is too large to be reviewed here. Among others, see Mehra and Prescott (2003).

${ }^{21}$ This statement has been confirmed by the data of the U.S. as well as other advanced countries. For a review of the more recent literature, see Estrella (2005), Estrella and Turbin (2006), among others.

${ }^{22}$ In the literature of term structure, a lot of efforts have been devoted to verify the "expectation hypothesis." However, Collin-Dufresne (2004) shows that there are several versions of the expectation hypothesis and they are not consistent with one another. Thus, the explicit formulation of the expecta- 
the TED spread (TED) are included in the analysis because some recent literature which highlights the role of imperfect capital market find these variables important proxies for the degree of capital market imperfection-ness. ${ }^{23}$ While EFP may capture the degree of capital market tightness faced by non-financial firms, TED spread, which is the difference between the interbank rate and the riskfree rate, can be interpreted as a proxy for the capital market tightness faced by banks. For instance, in a collateral-constrained economy such as Kiyotaki and Moore (1997) present, the borrowing constraint, which holds at the equilibrium, would take the following form,

$$
\text { debt } \leq E\left(\frac{\text { future col lateral value }}{\text { discount factor }}\right)
$$

Clearly, there are other variables that may be important in explaining the asset returns during the sampling period. Unfortunately, not every potentially important variable is available since 1975, and some other variable may not be as useful as it may seem. For instance, it has been suggested to us that the 30 year mortgage rate would improve the performance of our models. In the appendix, we provide empirical evidence it may not be the case, at least not for our sampling period. In addition, our "system approach" also limit the total number of variables that could be included in the empirical analysis. Thus, the current list tries to balance the economic validity and the data availability.

Our choice of sampling period is also constrained by data availability, as 1975 is the earliest date that the U.S. quarterly data of housing price is available. ${ }^{24}$ Given our selected group of VAR models, we examine the in-sample fitting for the period $1975 Q 1-$ tion may matter to the final empirical result.

${ }^{23}$ For instance, Jin et al (2012) show that the movement of EFP can be related to the housing returns in a DSGE model recently. In general, as surveyed by Bernanke and Gertler (1995), EFP is perceived as a measure of the "risk premium" and hence a reflection of the credit market conditions that faced by nonfinancial firms in the literature. For models which emphasize the role of imperfect capital market in the propagation of shocks over the business cycles, see Bernanke, Gertler and Gilchrist (1999), Christiano, Motto and Rostagno (2007), Davis (2010), among others. These papers did not explicitly model housing though.

${ }^{24}$ Another merit of choosing 1975 as the starting point is that it also avoids the first oil price crisis, which may be a period of "indeterminacy," especially in respect to the monetary policy, which will make the empirical identification difficult. Among others, see Lubik and Schorfheide (2004) for more analysis on this. 
2005Q4 and the out-of-sample forecasts for the period beginning with 2006Q1. We choose $2005 Q 4$ as the cut-off point, because the rise in the house price growth rate starting 1990s peaked around the end of $2005 .{ }^{25}$ Furthermore, we allow the models to "learn" in later sections in the sense that we would recursively re-estimate the model, for instance, from 1975 to 2006, and use it to predict the asset prices in 2007, and then re-estimate again by using the data from 1975 to 2007 in order to predict the asset prices in 2008, and so on. Thus, the in-sample we choose initially may not affect our results as much as some related studies.

To be compatible with the quarterly house price index provided by the Office of Federal Housing Enterprise Oversight (OFHEO), variables that are originally available in monthly are transformed into quarterly. The S\&P 500 stock price index is obtained from the DataStream. We compute stock and housing returns by taking the growth rates of the stock price index and housing price index respectively. Real GDP is taken from the Department of Commerce, Bureau of Economic Analysis. The federal funds rate is taken from H.15 statistical release ("Selected Interest Rates") issued by the Federal Reserve Board of Governors. As for the term spread, we follow Estrella and Trubin (2006) by choosing the difference between ten-year Treasury bond yield and three-month T-bill rate, both of which are released by the Federal Reserve Board of Governors. Since the constant maturity rates are available only after 1982 for 3-month T-bills, we use the secondary market three-month T-bill rate expressed on a bond-equivalent basis. ${ }^{26}$

While these time series have all been studied in the literature, it may nevertheless be instructive to present some "stylized facts" before any formal modeling. Table 1 gives a statistical summary for the variables in the data. The stock returns have a higher mean than housing returns (1.9 versus 1.1), and have an even larger volatility than the housing returns (8.2 versus 1.3). The simple correlation coefficients in Table 2 show that

\footnotetext{
${ }^{25}$ Clearly, there are substantial diversity in terms of when the asset price cycle ends. In this paper, we would experiment different end-dates in the robustness check section and the appendix also discusses the related literature in more details.

${ }^{26}$ The 3-month secondary market T-bill rate provided by the Federal Reserve System is on a discount basis. We follow Estrella and Trubin (2006) by converting the three-month discount rate $\left(r^{d}\right)$ to a bond-equivalent rate $(r): r=\frac{365 \times r^{d} / 100}{360-91 \times r^{d} / 100} \times 100$. They argue that this spread provides an accurate and robust measure in predicting U.S. real activity over long periods of time.
} 
some variables are indeed highly correlated. For instance, the correlation between the FFR and SPR is -0.6, that between the FFR and TED is 0.7, and that between EFP and TED is 0.6. On the other hand, some other correlations are close to zero. Thus, it is not clear which model will perform better a priori. To facilitate the comparison, models are constructed in some certain ways. As shown in Table 3a, for instance, Models A to E would have FFR involved, which can highlight the potential role of monetary policy in the asset return dynamics. ${ }^{27}$ Model $\mathrm{F}$ to $\mathrm{H}$ differ from the previous ones as the monetary policy variable FFR is replaced by a financial market variable. Thus, model $\mathrm{F}$ can be interpreted as model $\mathrm{C}$ with FFR replaced by EFP, model $\mathrm{G}$ as model $\mathrm{E}$ with FFR replaced by EFP, and model $\mathrm{H}$ as model E with FFR replaced by SPR. Thus, a comparison of the Model A to E on the one hand, and the Model F to $\mathrm{H}$ on the other hand would provide some information of the importance of monetary policy in the asset price dynamics. Table $3 b$ also shows how we choose the $\mathrm{AR}(1)$ as the Univariate, Single-regime Benchmark (USB). Obviously, if, for instance, econometric models that include EFP as a variable outperform other econometric models, it would provide indirect support that the firm financing problem is important in explaining asset market returns. On the other hand, if models that include TED spread outperform other models, it would suggest that the interbank market is important in explaining the asset market returns. Thus, by investigating the performance of different models we would be informed about which economic channels may be more important.

(Table 1, 2, 3a, 3b about here)

\subsection{The Econometric Model}

This paper takes a dynamical system approach in the sense that we estimate vector autoregressive (VAR) models which include both asset returns and other macroeconomic

\footnotetext{
${ }^{27}$ For the purpose of parsimony and model comparison, we set the lag period of all models to be one $(p=1)$. It turns out that most models with one lag period have the lowest value of $A I C$, compared with models having more than one lag periods. Details are available upon request.
} 
and financial variables and allow them to interact with one another. Some justifications have been discussed and we simply re-organize them here. First, much of the literature takes a univariate approach and hence this paper, which takes an alternative approach, is complementary. Second, it is well-known that when the regressors are not distinguishable from integrated processes, the conclusions about return predictability could be altered. ${ }^{28}$ Under the VAR approach, this issue would become less severe because it is less likely that the whole vector follows a unit root process than in the case of an individual variable. And as we argued in the introduction, the reduced form dynamics of some dynamic, stochastic general equilibrium models (DSGE) actually have a VAR representation. Hence, testing the ability of a class of VAR models may provide an indirect test for a class of DSGE models. Thus, the results in this paper could offer some hints for the future development of DSGE models. In addition, while some of the existing literature tends to take one of the returns as given and to use its movement to explain the other return, the $V A R$ approach naturally allows for dynamic interactions between the asset returns (housing and stock) and other variables, as well as the feedback effects among asset returns. In other words, it avoids assigning one of the asset returns as an "exogenous variable", which could lead to potential endogeneity bias. $^{29}$

Our econometric model is a regime-switching VAR, with lag length $p$ for a (vector) process $y_{t}$ :

$$
A_{0}\left(s_{t}\right) y_{t}=\gamma\left(s_{t}\right)+\sum_{i=1}^{p} A_{i}\left(s_{t}\right) y_{t-i}+u_{t}\left(s_{t}\right),
$$

where we allow for all parameters, including intercept coefficients, autoregressive coefficients, and covariance matrix of stochastic terms to be contingent on the unobservable state variable $s_{t} \in S$. The regime-dependent coefficients capture possible nonlinearities or time variation in the lag structure of the model. The stochastic volatility allows for possible heteroskedasticity of the stochastic terms.

The variables of interest $y_{t}=\left(y_{1, t}, y_{2, t}, . ., y_{m, t}\right)^{\prime}$ is a $m \times 1$ vector. The stochastic intercept term $\gamma\left(s_{t}\right)=\left(\gamma_{1}\left(s_{t}\right), \gamma_{2}\left(s_{t}\right), . ., \gamma_{m}\left(s_{t}\right)\right)^{\prime}$ captures the difference in the intercept

\footnotetext{
${ }^{28}$ Among others, see Torous et al (2004), Cochrane (2008).

${ }^{29}$ Among others, see Sims (1980a, b) for more discussion on these issues and the potential biases that could be eliminated by the VAR method.
} 
under different states. $A_{0}\left(s_{t}\right)$ is a $m \times m$ state-dependent matrix that measures the contemporaneous relationship between variables, and the econometric identification of the model is obtained through restrictions on $A_{0}\left(s_{t}\right)$. In addition, $A_{k}\left(s_{t}\right)$ is a $m \times m$ matrix with each element state-dependent $a_{k}^{(i j)}\left(s_{t}\right), i, j=1, . ., m, k=1, \ldots, p$. The stochastic error term $u_{t}$ will be explained below.

The corresponding reduced form of the above model can be obtained by pre-multiplying (1) by $A_{0}^{-1}\left(s_{t}\right)$, which yields:

$$
y_{t}=\delta\left(s_{t}\right)+\sum_{i=1}^{p} \Phi_{i}\left(s_{t}\right) y_{t-i}+\epsilon_{t}\left(s_{t}\right),
$$

where $\delta\left(s_{t}\right)=A_{0}^{-1}\left(s_{t}\right) \gamma\left(s_{t}\right), \Phi_{k}\left(s_{t}\right)=A_{0}^{-1}\left(s_{t}\right) A_{k}\left(s_{t}\right)$, and $\epsilon_{t}\left(s_{t}\right)=A_{0}^{-1}\left(s_{t}\right) u_{t}\left(s_{t}\right)$, $k=1,2, \ldots p . \Phi_{k}\left(s_{t}\right)$ is a $m \times m$ matrix with each element which is state-dependent $\phi_{k}^{(i j)}\left(s_{t}\right), i, j=1, . ., m, k=1, . ., p$. We further define

$$
\delta\left(s_{t}\right) \equiv c+\alpha\left(s_{t}\right),
$$

which will be explained below. The vector of stochastic error term $\epsilon_{t}$ can be further expressed as

$$
\epsilon_{t}=A_{0}^{-1}\left(s_{t}\right) u_{t}=\Lambda\left(s_{t}\right) H^{1 / 2} v_{t}\left(s_{t}\right),
$$

where $H$ is a $m \times m$ diagonal matrix with diagonal elements $\sigma_{j}^{2}, j=1, . ., m, \Lambda\left(s_{t}\right)$ is a $m \times m$ diagonal matrix with diagonal elements $\lambda_{j}\left(s_{t}\right), j=1, . ., m$,

$$
\Lambda\left(s_{t}\right)=\left[\begin{array}{cccc}
\lambda_{1}\left(s_{t}\right) & 0 & \cdots & 0 \\
0 & \lambda_{2}\left(s_{t}\right) & \cdots & 0 \\
\vdots & \vdots & \ddots & \vdots \\
0 & 0 & \cdots & \lambda_{m}\left(s_{t}\right)
\end{array}\right]
$$

which captures the difference in the intensity of volatility, and $v_{t}\left(s_{t}\right)$ is a vector of standard normal distribution, $v_{t}\left(s_{t}\right) \sim N\left(0, \Sigma\left(s_{t}\right)\right)$, where the covariance matrix is given by

$$
\Sigma\left(s_{t}\right)=\left[\begin{array}{cccc}
1 & r_{21}\left(s_{t}\right) & \cdots & r_{m 1}\left(s_{t}\right) \\
r_{12}\left(s_{t}\right) & 1 & \cdots & r_{m 2}\left(s_{t}\right) \\
\vdots & \vdots & \ddots & \vdots \\
r_{1 m}\left(s_{t}\right) & r_{2 m}\left(s_{t}\right) & \cdots & 1
\end{array}\right] .
$$


We also include an "atheoretical benchmark," which is the $\operatorname{AR}(q)$, i.e. an order- $q$ autoregressive process that is labelled as the Univariate, Single-regime Benchmark (USB). This is clearly motivated by the "efficient market hypothesis," which conjectures that all "relevant information" has been reflected in current (and potentially previous) period price whereby additional variables, such as those provided by the VAR, are considered insignificant. This could be the case of the stock return. On the other hand, the housing market is always being accused of not being as efficient as the stock market, and hence the housing market prediction can be improved with additional variables, including the stock return. Hence, a comparison of model performance with USB provides not only a form of "efficient market test," but also an indirect test of the "cross-market informational spillover." ${ }^{30}$ For the linear VAR model, we include all 7 variables. For the regimeswitching models, we can only afford to include 4 variables, which is a much shorter list than the linear model, as we need to estimate parameters in each regime, plus the transition probabilities. By design, it puts regime-switching models in a disadvantageous position. If, however, the regime-switching models still outperform the widely used linear model, then it suggests that regime changes may indeed be very important in the data. In addition, if models with certain variable(s) consistently outperform alternatives, then such variable(s) may be important to account for in the asset return movements. Thus, it may be important to include different combinations of our listed variables in different models and test for the performance of those models.

For the linear VAR model, we include all 7 variables. For the regime switching models, we can only afford to include 4 variables, which is a much shorter list than the linear model, as we need to estimate parameters in each regime, plus the transition probabilities. By design, this puts regime switching models in a disadvantageous position. If, however, the regime switching models still outperform the widely used linear model, then it suggests that regime changes may indeed be very important in the data. In addition, if models with certain variable(s) consistently outperform alternatives, then such variable(s) may be important to account for in the asset return movements. Thus, it may be important to include different combinations of our listed variables in different

\footnotetext{
${ }^{30}$ Even for the case of aggregate output, it may still be a good idea to use an uni-variate $\mathrm{AR}(\mathrm{p})$ as the benchmark. Among others, see Chauvet and Potter (2012) for more discussion.
} 
models and test for the performance of those models.

\subsection{Two-state Markov Process}

Being severely constrained by the sample size, we assume that there are only two states, i.e., $s_{t} \in S=\{1,2\}$. The procedure for the identification of the regime of the economy for a given period will be discussed below. The Markov switching process relates the probability that regime $j$ prevails in $t$ to the prevailing regime $i$ in $t-1, \operatorname{Pr}\left(s_{t}=j \mid\right.$ $\left.s_{t-1}=i\right)=p_{i j}$. The transition probabilities are assumed to be constant and the transition matrix is given by: ${ }^{31}$

$$
P=\left(\begin{array}{cc}
p_{11} & 1-p_{22} \\
1-p_{11} & p_{22}
\end{array}\right)
$$

Given that the economy can be either in state 1 or state 2 , the term $\alpha_{j}\left(s_{t}\right), j=$ $1, . ., m$, defined above, captures the difference in the intercept under different states. For convenience, we set $\alpha_{j}(1)=0$ for $s_{t}=1$, thus $\alpha_{j}(2)$ measures the difference in the intercept between state 2 and state 1. Furthermore, we set the diagonal element of $\Lambda\left(s_{t}\right)$ at state 1 to be unity, i.e., $\lambda_{j}(1)=1$, so that if $\lambda_{j}(2)>1$, then the intensity of volatility in state 2 is larger than that in state 1 , and vice versa. Since $v_{t}\left(s_{t}\right)$ is a vector of standard normal distribution and $\lambda_{j}(1)$ is set to be one, the variance of $y_{j, t}, j=1, . ., m$, at state 1 is $\sigma_{j}^{2}$, and the variance is $\lambda_{j}^{2}(2) \sigma_{j}^{2}$.

\subsection{Identification of Regimes}

Since the state of the economy is unobservable, we identify the regime for given a time period by Hamilton's $(1989,1994)$ smoothed probability approach, in which the probability of being state $s_{t}$ at time $t$ is given by $\pi\left(s_{t} \mid \Omega_{T}\right)$, where $\Omega_{T}=\left\{y_{1}, y_{2}, \ldots, y_{t}, \ldots, y_{T}\right\}$. The idea is that we identify the state of the economy from an ex post point of view, and thus the full set of information is utilized. Notice that we only allow for two regimes

\footnotetext{
${ }^{31}$ In principle, we could allow the transition probabilities to depend on the observed variables. However, the time series we have assess to are relatively short and hence we make compromise in the modelling choice.
} 
in this paper, i.e., $s_{t} \in S=\{1,2\}$. Thus, if $\pi\left(s_{t}=j \mid \Omega_{T}\right)>0.5$, then we identify the economy most likely to be in state $j, j=1,2 .{ }^{32}$

\section{$2.5 \quad$ Forecasting}

After we estimate all the above models, we use the calculated probabilities of regime switching for evaluating the forecasting performances of house and stock prices across various models, and then examine both in-sample and out-of-sample forecasting performances. We divide the sample into in-sample period 1975Q2-2005Q4, and out-of-sample period $2006 Q 1$ and after. In any econometric model assessment, the calculation of confidence interval is important, because it provides a quantitative sense on whether the point estimate of the coefficient and predicted path of variables are "off the mark." Clearly, there is a large body of literature on "predictive regression" in asset pricing which have applied different techniques to construct the confidence intervals. Phillips (2014) shows through an analytical method and simulations that some commonly used methods in that literature may be misleading. In particular, Phillips presents that "the commonly used Q test is biased towards accepting predictability and associated confidence intervals for the regressor coefficient asymptotically have zero converge probability in the stationary case." In light of these potential shortfalls, we conduct out-of-sample forecasting (OSF) in two different approaches. The first approach is the conventional conditional moment method. Given the estimation window $1975 Q 2-2005 Q 4$ and a forecasting horizon $h=1, \ldots, 4$, the estimated parameters are used to forecast house and stock prices $h$-step ahead outside the estimation window, using the smoothed transition probabilities. The $h$-step ahead forecasted value of $z_{t+h}$ based on model $i$ and information at time $t, \Omega_{t}$, is given by

$$
E^{i}\left(z_{t+h} \mid \Omega_{t}\right)=\sum_{j=1}^{2} E\left[z_{t+h} \mid s_{t+h}=j, \Omega_{t}\right] \times p\left(s_{t+h}=j \mid \Omega_{t}\right),
$$

where $j$ is the index for the state, and $z_{t} \in y_{t}$. The estimation window is then updated consecutively with one observation and the parameters are re-estimated. Again the $h$ step ahead forecasts of house and stock prices are computed outside the new estimation

\footnotetext{
${ }^{32}$ In addition, we follow Francq and Zakoian (2001) to use spectrual radius to determine the stationarity of the regime-switching models. Due to the space limit, we report the results in the appendix. We find that most models are stationary. Only Model B and C are marginally non-stationary.
} 
window. The procedure is iterated until the final observation. The forecasts based on this method is basically to compute the $h$-step ahead conditional expectations of the variable being predicted. Most existing (non-Bayesian) works follow this method.

The second approach is the simulation method. A merit of this approach is that we effectively simulate a "confidence interval" (CI) for ourselves and hence do not need employ other approximation technique to construct the CI. In a sense, we avoid the critique of Phillips (2013). The idea is simple. We simulate the path of the forecasted values by repeated drawings. The procedure is as follows.

- (Step 1) We estimate the model using the estimation window 1975Q2-2005Q4 and obtain the parameters, transition probabilities, and variance-covariance matrix. Given the estimation results we compute the smoothed probabilities to identify the regime at the period $2005 Q 4$.

- (Step 2) Given the regime at the period 2005Q4, we simulate the path of $h$-step ahead regimes by random drawing, $h=1, \ldots, 4 .^{33}$ Given this particular path of $h$-step ahead regimes, we can obtain the path of predicted values of $z_{t} \in y_{t}$ from (2).

- (Step 3) We iterate step 1 and 2 for 50,001 times to obtain the median of the $h$ step ahead forecasted values during 2006Q1 - 2006Q4 and their corresponding confidence intervals.

- We then update the sample with four more quarterly observations and repeat Step 1-3, including re-estimating the model, in order to simulate the path of predicted values for the subsequent four quarters. This procedure is repeated till the end of our sample.

An advantage of the second approach over the first one is that this method takes full account of the regime switching model by determining the path of future regimes using random drawing, rather than simply taking expectations over transition probabilities. Another advantage is that a confidence interval is naturally generated, which enhances

\footnotetext{
${ }^{33}$ For example, suppose the regime identified at the time $2005 Q 5$ is state 1 , we use the transition probabilities $p_{11}$ and $p_{12}$ to generate the state at the period 2006Q1. Specifically, we draw a value $v$ from a uniform distribution $U[0,1]$. The state at 2006Q1 is state 1 if $v \in\left(0, p_{11}\right)$, and is state 2 if otherwise. Suppose we have identified the state at $2006 Q 1$ to be state 2, then we use the transition probabilities $p_{21}$ and $p_{22}$ to generate the state at the period 2006Q2. Therefore, we will be able to simulate the path of $h$-step ahead regimes.
} 
the evaluation of different models' forecasting performance. It should be noticed that the regime-switching nature of the model implies that the future forecast is path-dependent and hence the conventional way to construct confidence interval may not be valid.

To evaluate the performances of in-sample and out-of-sample forecasts, we follow the literature to compute two widely-used loss function for $z_{t} \in y_{t}$, which are the square loss

function, $L\left(e_{t+h \mid t}^{i}\right)=\sum\left(e_{t+h \mid t}^{i}\right)^{2}$ and the absolute loss function, $L\left(e_{t+h \mid t}^{i}\right)=\sum\left|e_{t+h \mid t}^{i}\right|$, where $e_{t+h \mid t}^{i}$ be the $h$-step forecast error of model $i, e_{t+h \mid t}^{i} \equiv z_{t+h}-E^{i}\left(z_{t+h} \mid \Omega_{t}\right)$. For future reference, when we employ the square loss function as criteria to select models, we label it as "the square loss criterion" $(S L C)$. Similarly, when we use the absolute loss function as criteria to select models, we label it as "the absolute loss criterion" $(A L C)$. Clearly, the $S L C$ tends to penalize "big mistakes" more than the $A L C$. As it will be clear later, our main conclusions do not depend on which criteria is used. We will then combine these results with our newly proposed model comparison procedure, which will be explained in more details in the following section.

\subsection{Multi-lateral Model Comparison Procedures}

On top of computing the differences in the loss functions for each model on the prediction of both assets (housing and stock), we need a statistical procedure to compare whether those differences are significant. Before we explain our procedure, it would be helpful to provide a quick review of the current practice. The existing literature of applied works adopt the Diebold-Mariano test (henceforth DM test) and its variants to assess the "relative performance" of two models in a bilateral manner. ${ }^{34}$ While Diebold and Mariano (1995), Zivot (2004) provide the details, it is nevertheless instructive to outline the test here, as our procedure is closely related to the DM test. In our notations, the Diebold-Mariano (henceforth $D M$ ) test is based on the "loss differential" $d_{t}$,

$$
d_{t}=L\left(e_{t+h \mid t}^{1}\right)-L\left(e_{t+h \mid t}^{2}\right)
$$

\footnotetext{
${ }^{34}$ Diebold and Mariano test has been widely used in the literature. Among others, see Mariano and Preve (2011) for a review of the literature.
} 
where $L($.$) is some loss function. Clearly, if the two models have roughly the same$ predictive power, the expectation of the loss differential will be zero, $E\left[d_{t}\right]=0$. If, instead, Model 1 predicts better (worse) Model 2, the expected value of the loss differential will be negative (positive).$^{35}$ In practice, $d_{t}$ is unlikely to be exactly zero. The question is then how we can decide whether Model 1 is in fact "significantly better (or worse)" than Model 2. One of the contributions of DM test is that it shows that some function of $d_{t}$ follows the standard normal distribution. Hence, a test statistics can be constructed so that we can make judgement on models scientifically.

In application, researchers may need to choose among many alternatives. Typically, researchers need execute the DM test repeatedly, and therefore the issue of ordering naturally arises. For instance, consider the case of three competing models, A, B and C. One may compare A against B first, and then compare the "winner" with C. One may also compare A against $\mathrm{C}$ first and then compare the winner with B. Do these two slightly different ordering deliver the same final winner? Clearly, as the number of models increase, the number of possible ordering increases significantly and the importance of ordering in model comparison might matter. ${ }^{36}$ Hansen et al (2011) develop a procedure named as "model confidence set" (MCS). The idea is that we start with one model and put that in the MCS. One then applies the DM test to compare that model with an alternative. If both have the same predictive power in the sense that the "loss differential" $d_{t}$ is smaller than certain critical value, then both models will be kept in the MCS; otherwise, only the one with high predictive power will stay in the MCS. We repeat the procedure until we exhaust all the models we have. The models in the remaining MCS

\footnotetext{
${ }^{35}$ The DM statistics will depend $\bar{d}$, which is an average value of $d_{t}$, for different period $t$, and the co-variance of $d_{t}$ and $d_{t-j}, j=1,2,3, \ldots$ As shown by Zivot (2004), other things being equal, if model 1 which consistently over-predict in some sub-period and then consistently under-predict in other subperiod, it is more likely to get not only a lower value of $d_{t}$ in different period t, but also a higher value of co-variance $d_{t}$ and $d_{t-j}, j=1,2,3, \ldots$ As a result, model 1 is would be classified as under-perform the alternative model. See Zivot (2004) for more details.

${ }^{36}$ In fact, the situation is analogous to the old Condorcet Paradox, in which the candidate who wins in every pair-wise situation may not be the winner when all candidates can be selected in one time. In the present context, it means that the order of which model compares with which model would actually affect the final outcome. For more discussion, see Austen-Smith and Banks (2000), among others.
} 
will therefore have the same predictive power, and by construction they are better than the models that are not selected into the MCS. Hence, while we still compare models in a bilateral manner, we can still compare any finite set of models.

Mariano and Preve (2012), on the other front, generalize the idea of the DM test and compare several models simultaneously (MP test). The idea is simple. Consider the situation with $(K+1)$ models. We then define the " $j$-th loss differential" $d_{j, t}$

$$
d_{j, t}=L\left(e_{t+h \mid t}^{j}\right)-L\left(e_{t+h \mid t}^{j+1}\right), j=1,2, \ldots K
$$

where $L($.$) continues to denote some loss function. We collect these loss differential in a$ vector, $d_{t}=\left\{d_{j, t}\right\}, j=1,2, \ldots K$. We then take average of it,

$$
\bar{d} \equiv \frac{1}{P} \sum_{t=1}^{P} d_{t} .
$$

Mariano and Preve (2012) prove that $P(\bar{d}-\mu)^{\prime}(\widehat{\Omega})^{-1}(\bar{d}-\mu) \longrightarrow \chi_{k}^{2}$ (in distribution), where $\mu$ is the mean of the distribution, $\widehat{\Omega}$ is a consistent estimator of the population variance-covariance matrix $\Omega$, and $k$ is the degree of freedom. Thus, MP test enables us to test whether all models of concern have the same predictive power.

In this paper we differentiate competing theories of asset prices, which are represented by different econometrics models. Therefore, it is natural to use the MP test rather than the DM test. Moreover, we need to define a procedure which enable us to categorize the models into different "equivalent classes," each of them contains model with (statistically speaking) the same predictive power. The procedure needs to be "robust" in the sense that the final outcome (i.e. the ranking of different models) would not be affected by the ordering of which models are being compared first. Our procedures are similar to Hansen et al (2011) and here are the steps.

1. We consider $N$ models that make predictions on the same economic variable. We first rank models according to a criterion, such as $S L C$. Without loss of generality, we assume that according to the chosen criteria, the predictive performance of Model 1 is better than that of Model 2, which in turn is better than of Model 3, and so on. 
2. We conduct the MP test, in which the null hypothesis is that all models have the same predictive power. If the hypothesis is not rejected, then by definition, all $N$ models have the same predictive power on a particular variable according to the chosen criteria.

3. If the null hypothesis is rejected, then we eliminate the model with the least predictive power. It can be easily identified as the models have been ranked according to the predictive power in Step (1). We then repeat Step (2) until the null hypothesis of equal predictive power is accepted.

4. Assume that in Step (3), there are $N_{1}$ models which are found to possess the equal predictive power, $N_{1}>0$. For future reference, they are referred to as Class 1 among the $N$ models. By construction, there are $\left(N-N_{1}\right)$ models which do not have the same predictive power as the models in Class 1. We now repeat Step (1) on these $\left(N-N_{1}\right)$ models until the null of equal predictive power is not rejected. Assume that there are $N_{2}$ models, $N_{2}>0$, in the final list and they are identified as Class 2.

5. If $N=N_{1}+N_{2}$, then the procedure stops. The set of models are divided into two classes, and models within each class have the same predictive power. Every model in Class 1 has higher predictive power than any model in Class 2.

6. Now we consider the case that $N>N_{1}+N_{2}$. Again, by construction, there are $\left(N-N_{1}-N_{2}\right)$ models which do not have the same predictive power as the models in Class 1 or Class 2. We now repeat Step (1) on these $\left(N-N_{1}-N_{2}\right)$ models until the null of equal predictive power is not rejected. Assume that there are $N_{3}$ models, $N_{3}>0$, in the final list, and they are identified as Class 3.

7. If $N=N_{1}+N_{2}+N_{3}$, the the procedure stops.

8. If not, we repeat Step (6) and construct Class 4.

9. We repeat Step (8) until all $\mathrm{N}$ models are categorized into different classes. If there are totally $k$ class, then it must be that $N=N_{1}+N_{2}+\ldots+N_{k}$. 
10. We repeat the whole process with a change in the model evaluation criteria, e.g. $S L C$ being replaced by $A L C$.

Several remarks are in order. First, by definition, $N_{i}, i=1,2,3, \ldots$ must be positive. In other words, each "Equivalent Predictive Power Class" (EPPC) is non-empty. In addition, since models are first ranked according to a given criteria, our elimination

procedure is easy to implement. Second, by construction, all models within the same class have the same predictive power, and any model in Class $i$ will always have higher predictive power than any model in Class $j$, for any $i, j$, such that $i<j$. Third, it is possible that for the same set of $N$ models, the ranking will vary as the criteria changes (say, from $S L C$ to $A L C$ ), and hence the model can be categorized differently. In other words, the classification of EPPC is criteria-dependent. In case the same set of $N$ models have predictions on several economic variables (for instance, stock return and housing return in this paper), it is also possible that the ranking of models also varies with the variable we would like to predict. In other words, EPPC is also variabledependent. Notice also that this procedure still employs conventional criteria such as SLC and ALC, and hence it facilitates a comparison with the literature. On the other hand, our procedure allows us to compare a large number of competing models on a "fair ground." As computers become increasingly powerful and data availability improves over time, we believe that comparison among a large number of alternative models may be inevitable and the procedure we propose here can facilitate such a comparison. As we present our empirical results, these features will become clear.

\section{Estimation Results}

Limited by data availability, we keep the model as parsimonious as possible. The details of the estimation results for the whole sampling period 1975Q2-2012Q1 are presented in the appendix, and Table 4a provides a summary. In general, a model allowing for regime switching attains a lower value of Akaike's information criterion $(A I C)$ and a higher loglikelihood value. Among all these models, the regime switching model G (EFP, TED, 
SRET, HRET) has the best goodness of fit, i.e., a significantly lower value of $A I C$ than other models, suggesting that the credit market frictions and asset returns are indeed significantly inter-related.

(Table 4a about here)

For the Markov switching model, recall that we set the volatility at regime $1 \lambda_{j}(1)=1$, thus the element $\lambda_{j}(2)$ measures the relative volatility of regime 2 over regime 1 . In the appendix the figures show that the estimated values of relative volatility $\lambda_{j}(2)$ are all significantly less than one for $j=1$ and 2 , which means that for both federal funds rate and the spread the volatility in regime 2 is lower than in regime 1 . On the other hand, almost all of the $\lambda_{3}(2)$ and $\lambda_{4}(2)$ are insignificant, suggesting that for the quarterly stock and housing returns there is no significant difference in volatility across regimes. Thus, we identify two regimes for this monetary policy tool: a high volatility regime (regime 1) and a low volatility regime (regime 2). Table $4 \mathrm{~b}$ provides a summary of the estimated transition probabilities. It is clear that regimes are highly persistent, regardless the models. In particular, most models suggest $p_{11}$ to be close to 0.80 and all models suggest $p_{22}$ to be higher than 0.93 . They imply that the expected duration of regime 1 to be around $1 /(1-0.8)=5.0$ quarters and that for regime 2 is not less than $1 /(1-0.93)=$ 14.3 quarters.

(Table $4 \mathrm{~b}$ about here)

Given the estimated parameters, transition probabilities, and variance-covariance matrices, we estimate the classification of regimes under different models and report the results in Table 5. Basically, these models show similar classifications of the regimes. For those periods identified as regime 1, all models include the aftermath of the second oil crises and P. Volcker being appointed as Chairman of the Federal Reserve. ${ }^{37}$ Interestingly, when the TED spread (TED) is included in Model E, G and $\mathrm{H}$, the regime 1 also includes the stock market crash in the 1987, suggesting that TED picks up the volatility in the credit market after the stock market crash. It is also interesting that under Model

\footnotetext{
${ }^{37}$ Among others, Goodfriend and King (2005), Goodfriend (2007) provides a summary of the history of monetary policy during that period.
} 
E, which is like Model D except that EFP is replaced by the TED spread, the changes in regimes are much more frequent. In general, models that involve TED would experience more regime switching, suggesting higher variability of the risk premium faced by financial intermediations. We also compute the smoothed probabilities for all from Model B to Model H, as shown in Figure 2. It shows the probabilities of the economy being in regime 1 (high volatility regime) at a given period. Since there are only 2 regimes, the probabilities of being in regime 2 would be suppressed.

(Table 5, Figure 2 about here)

\section{Forecasting}

We now proceed to forecast stock and housing returns. As discussed above we first conduct in-sample forecasting for the period 1975Q2-2005Q4 and then examine the outof-sample forecasts for the period 2006Q1-2011Q4, using respectively the expectationsbased and simulation-based methods.

\subsection{In-Sample Forecasting}

We compute the loss functions based on $S L C$ and $A L C$ of in-sample $h$-step ahead forecasts, $h=1, \ldots, 4$, for each variable across all models. Several findings are in order. First, as shown in table 6a, the in-sample forecasts of asset returns are mixed. For the stock returns, the model C (FFR, SPR, SRET, HRET) has the best performance. For housing return, however, it is the Model E (FFR, TED, SRET, HRET) that out-perform all others. Notice that both models contain the monetary policy variable $F F R$. It is true for whether we use $S L C$ or $A L C$. On the other hand, it seems that the performances in predicting stock returns across models are similar. We therefore implement our multi-lateral model comparison procedures and attempt to categorize models into different "equivalent predictive power class" (EPPC). ${ }^{38}$ Table $6 \mathrm{~b}$ confirms our intuition. Whether we use $S L C$

\footnotetext{
${ }^{38}$ As a robustness check, we also use the conventional Diebold-Mariano test bilaterally and obtain very similar results. The details are in the appendix.
} 
or $A L C$, we find that all models have the same predictive power in terms of explaining the stock return during the in-sample period. In particular, no model has superior performance than an $\mathrm{AR}(1)$ process, which is the USB. It is consistent with the notion that the stock market is very efficient in reflecting all the relevant information that adding other variables in the statistical model does not provide any extra predictive power.

(Tables 6a, 6b about here)

For housing return, the situation is very different. Several observations are in order. First, whether we use $S L C$ or $A L C$, model $D, E, F, H$ have the same predictive power and they are always in Group 1, meaning that they are at least as good as the other models. Second, whether we use $S L C$ or $A L C$, model B (FFR, GDP, SRET, HRET) and USB are always in the lowest group. This suggests that using the monetary policy (FFR) and economic growth rate alone are not sufficient in understanding the housing market, at least for the in-sample period (1975Q2-2005Q4). Alternatively, we may say that the information in monetary policy and economic growth has been reflected in the housing return itself. The fact that AR(1) (which is also USB for the housing return) is always inferior to the four "good models" (Model D, E, F, H) suggests that there are important information in the financial market that enhances our ability to account for the housing market. Notice however that such "cross-market informational spillover" is very subtle. Table 6c also shows that Model G (EFP, TED, SRET, HRET) is always inferior to the four good models (Model D, E, F, H). However, Table 3 shows that Model F is simply Model G with TED spread replaced by the term spread (SPR), and Model H is simply Model $\mathrm{G}$ with the external finance premium (EFP) replaced by the term spread (SPR). Does it mean that the term spread is so crucial in understanding the housing return during that period? It does not seem to be the case, as both Model D and E, which have the same predictive power as model F and $\mathrm{H}$, do not contain SPR. Notice that financial variables are correlated and hence some other variables may also contain the information that is relevant in predicting future housing returns. To summarize, our estimations indicate that the fact that the "efficient market hypothesis" does not apply to the housing market during the in-sample period (1975 to 2005). The data are more 
consistent with models which emphasize on imperfect capital market, such as Christiano, Motto and Rostagno (2007), Davis (2010), Jin et al. (2012), among others.

\subsection{Out-of-Sample Forecasting via Conditional-Expectation Es- timation}

We now turn to the out-of-sample forecasting (OSF) of housing and stock returns beginning 2006Q1, at the time when the growth of housing returns began to decline and the sub-prime crisis started to unfold. Following the literature, we first conduct OSF by using the conditional-expectations predictions. The appendix provides details of the out-of-sample $h$-step ahead forecasts, $h=1, \ldots, 4$, for each variable across all models. Tables $6 \mathrm{c}$ summarize the results. In terms of forecasting stock returns, Model $\mathrm{H}(S P R$, TED, SRET, HRET) performs better than other models, both in terms of $S L C$ and $A L C$. In terms of forecasting housing returns, Model D (FFR, EFP, SRET, HRET) performs better than other models, also both in terms of $S L C$ and $A L C$. Naturally we ask whether the difference is statistically significant. Again, we adopt the same procedure and categorize models into different "equivalent predictive power class" (EPPC). Table $6 \mathrm{~d}$ reports the results, and several observations are in order. In terms of stock return forecasting, we find that (1) Model B, E, H and USB are always in Group 1, which means that they are at least as good as other models, and (2) Model D and F are always in the lower group. This is true whether we use $S L C$ or $A L C$. The ranking of Model A, C, and $\mathrm{G}$ will depend on which criteria is used, implying that there are models (especially D an F) which under-perform the USB, which is the simple $\mathrm{AR}(1)$, in the out-of-sampling forecasting of the stock return. Recall that for the in-sample forecasting, using the same set of procedures and same set of models, we have found that all models have the same predictive power. In other words, some models have actually deteriorated relative to the $U S B$ (i.e. $A R(1)$ ) in terms of the ability of predicting the stock return. Notice that

both model D and F involve EFP, it may suggest that the ability of EFP to track the aggregate stock return after the crisis is not as good as before.

(Tables 6c, 6d about here) 
The case of OSF for the housing return is perhaps equally interesting. Table $6 \mathrm{~d}$ clearly shows that whether we use $S L C$ or $A L C$, (1) Model C, D, F, G, H and USB are always in Group 1, meaning that they have better predictive power, and (2), Model A, B, E are always in Group 2, meaning that their predictive powers are not as good. Notice that for in-sample forecasting, whether we use $S L C$ or $A L C$, Model B (FFR, GDP, SRET, HRET) and USB are always in the lowest group. For the out-of-sample forecasting, Model B remains in the lowest group, yet the USB is "promoted" to the higher group. It means that whether for the linear VAR with 7 variables (Model A), or regime-switching VAR, no model in our list can out-perform the simple USB in terms of out-of-sample forecasting of the housing return. Similar to the case of stock return forecasting, this suggests that some models have deteriorated in terms of forecasting the housing return, at least relative to the simple AR(1) process. In particular, model A and $\mathrm{B}$ are the only models that involve GDP and yet they are always in group 2, suggesting that GDP may not be as useful in predicting the house price as before. Clearly, the model comparison here are far from conclusive and future research can revisit the issue with more rigorous tools.

Another interesting observation is that, perhaps the forecasting ability of a model has become more asset-specific for the out-of-sample forecast. ${ }^{39}$ For instance, while model $\mathrm{D}$ and $\mathrm{F}$ are always the inferior models for stock return out-of-sample forecasting, they are always in the Group 1 for the housing return forecasting. Similarly, while Model B and E are always the "better" models in terms of out-of-sample forecast for the stock return, they are always the "not-as-good" models in terms of out-of-sample forecast for the housing return. Future research may investigate further on this phenomenon of asset-dependent forecasting performance.

\footnotetext{
${ }^{39}$ Interestingly, this is also the case for structural models comparison. See Kwan et al. (2015), among others, for more details.
} 


\subsection{Out-of-Sample Forecasting via Simulation}

The results presented in the current section differ in at least two important dimensions from the results presented in the previous section. First, the previous sections provide only information of the "relative performance" of different models, as we use different statistical tools and procedures to assess whether some models have more superior predictive power than the others. In this section, we attempt to assess the "absolute performance" of different models by using simulation-based forecasting. Second, we aggregate the forecasting performance of each models during the whole out-of-sample period (2006 and after) into some statistics and then compare across models in the previous section. In the current section, we will compare the forecasting performance of different periods in each year, and then allow the model to be re-estimated with updated data, and then compare again in the subsequent year. Thus, we allow models to "learn and improve" and would like to see which model(s) are more successful in adjust the parameter with new data and hence provide more accurate forecasting over time.

We more specifically consider a forecasting window of 4 quarters starting 2006Q1, with $h$-quarter ahead forecasts, $h=1, \ldots, 4$. After simulating the out-of-sample path $2006 Q 1-2006 Q 4$ based on observations up to 2005Q4, the data are updated with four observations and the parameters are re-estimated. The procedure is repeated until we have updated the sample to include all observations from 1975 to 2010 to predict the asset returns in 2011. The purpose of this exercise is to see how the performances of the models change when information is updated. The simulated paths together with their 80-percent confidence intervals can be visualized in Figure 3 for stock returns and Figure 4 for housing returns. Table $7 \mathrm{a}$ and $7 \mathrm{~b}$ provide a summary of the performance of different models

(Figure 3 and 4, Table 7a, 7b about here)

As shown in Figure 3a and 3b, the actual stock return and the predicted paths by different models are well within the boundaries of the $80 \%$ confidence intervals for all five models. Thus, although the models do not predict what have actually happened in 2006 and 2007, the models' predictions are not that "far off the mark." Unfortunately, with the 
collapse of the Lehman Brothers, virtually all models are disappointing in the prediction of 2008 returns (Figure 3c). Among them, Model G (EFP, TED, SRET, HRET) performs worst in the sense that its 80-percent confidence interval does not even contain any of the actual quarterly return in 2008. As we include the data up to 2008Q4 and re-estimate the models, the prediction of 2009 by models significantly improve. As shown by Figure $3 \mathrm{~d}$, each model's confidence interval contains at least one quarter of stock return within the confidence interval. Among them, Model D (FFR, EFP, SRET, HRET), Model E (FFR, TED, SRET, HRET), Model F (EFP, SPR, SRET, HRET) and Model G contain almost the path of the whole year stock return. With the data of 2009 included and model updated, the prediction of 2010 is even better. As Figure 3e shows, each model's confidence interval contains at least one quarter of stock return. Interestingly, Model G, which has the worst performance in 2008, becomes the best model of 2010 in the sense that it is the only model whose confidence interval contains the whole path of quarterly return of the year. The prediction of 2011 is similar. As Figure $3 \mathrm{f}$ shows, virtually all models contain most of the year return, and all models unfortunately "miss" the drop of stock return in 2011Q3, as no model is able to generate a confidence interval which contains the stock return in 2011Q3.

As shown in Table 7b and Figure 4, the prediction of housing returns is worse than the stock counterpart. Figure 4a shows that every models generates a confidence interval that contains the path of the quarterly housing return of 2006,yet as early as 2007, Figure $4 \mathrm{~b}$ shows that the confidence intervals generated by our models fail to contain at least one quarter of housing return. It should be notice that the same set of models successfully contain the whole year path of stock return of the same year (2007). With 2007 data included and model updated, the failure of 2008 is in a sense unexpected. Both Table $7 \mathrm{~b}$ and Figure 4c show that the confidence intervals generated by more than half of our models - namely, Model A (linear VAR with all 7 variables), Model B (FFR, GDP, SRET, HRET), Model D (FFR, EFP, SRET, HRET), Model E (FFR, TED, SRET, HRET), Model G (EFP, TED, SRET, HRET) - fail to contain any quarterly housing return in 2008. The remaining 4 models all miss at least one quarterly return of housing of the year. Thus, while our models do not perform well in 2008 in predicting the stock return, 
the prediction of housing return in the same year is much worse. With the information of 2008 included and model updated again, the prediction of 2009 is improved but perhaps still disappointing. Recall that for the year 2009, the confidence interval generated by all our models all contain some quarterly return of stock, suggesting that the enlargement of the sample with model updating might improve the stock return forecasting. In the case of housing, Figure 4d shows that Model B continues to fail to contain any quarterly return of housing in 2009. While Model A, D, E, G make some improvements, the confidence interval generated by the Model F (EFP, SPR, SRET, HRET) fail to contain any quarterly housing return. And if the year 2008 and 2009 are disappointing year of housing return forecasting, the year 2010 is a year with positive surprises. As shown by Table $7 \mathrm{~b}$ and Figure 4e show that all models successfully contain some quarterly return of housing. Moreover, Model C (FFR, SPR, SRET, HRET), D, E and G are able to generate confidence intervals that contain the whole year housing return. For the case of stock return, only Model G contains the whole year of stock return in the confidence interval. In this sense, the prediction of housing returns in 2010 is a success. Unfortunately, Figure $4 \mathrm{f}$ shows that all models fail to contain the drop in housing return in 2011Q1, although they contain at least some quarterly return in the later part of the same year. It is comparable to the performance of stock return prediction of the same year (2011).

In sum, it seems that the OSF of asset returns is particularly difficult during this period. In the case of stock return, Table 7a suggest that since 2008, most models will miss at least one quarter of stock return, and while Model G "fails" in 2008, it becomes very successful in 2010. This confirms the intuition that regularly incorporating new data and re-estimating the model lead to better forecasting. In the case of the housing return, most of our models, namely, Model A, B, D, E, F, G all experience at least one "missing year" on either 2008 or 2009, i.e. a year in which the confidence interval generated by the model does not contain any quarterly return of the year. At the same time, when we re-estimate the model with data up to the end of 2009, model C, D, E, G successfully capture the year 2010. In this sense, model G (EFP, TED, SRET, HRET) seems to be the "best learner" in the sense that while it made mistakes in the 2008 or 2009, when it is 
re-estimated with the data up to the end of 2009, it successfully captures the movements in both stock return and housing return in 2010. Notice that according to table 7a and $7 \mathrm{~b}$, neither the USB for stock return nor the USB for the housing return enjoys a "perfect" year (i.e. the whole year asset return movement within the $80 \%$ confidence interval) since 2006, suggesting that while the USB may be classified in the same EPPC as other models during the out-of-sample period (2006 and after) as a whole, it may not "learn" as much and as fast as other models which incorporate other macroeconomic and financial variables.

\subsection{Some Robustness Checks}

Thus far, our analysis is based on using the data from 1975 to 2005 as in-sample, and the periods after as out-of-sample, and then we progressively update the in-sample. As a robustness check, we also re-estimate our models when we use the period from 1975 to 2006 as in-sample. Table 8 provides a summary and the details can be found in the appendix. Notice that Table 8 is constructed analogous to Table 6 in order to facilitate comparison. A few observations are in order. Table $8 \mathrm{a}$ shows that the best in-sample forecasting performance comes from model C (FFR, SPR, SRET, HRET) for stock and model E (FFR, TED, SRET, HRET) for housing, which is the same as the results in Table 6a. While the details of the model classifications in Table 8b slightly differ from Table 6b, some principal findings sustain. First, most, if not all, models are equally good in predicting stock return during the in-sample period. Second, in terms of predicting housing return, model B (FFR, GDP, SRET, HRET) and the USB are often the worst. Again, this supports the idea that GDP is not very helpful even for in-sample prediction of the housing return, and information about the future housing returns are reflected in economic variables other than the current housing return. Table $8 \mathrm{c}$ shows that the principal result of Table 6c also sustains, namely, model H (SPR, TED, SRET, HRET) out-performs other models in terms of out-of-sample forecasting of stock returns, and model D (FFR, EFP, SRET, HRET) out-performs other models in terms of out-ofsample forecasting of housing returns. Table 8d, which provides the model classification 
in terms of out-of-sample forecasts is also similar to Table 6d. More specifically, the model classification in terms of out-of-sample 4-quarter ahead forecasts of stock return are identical. In terms of the counterpart of housing returns forecast, model A (linear VAR with all 7 variables), model B which contains FFR and GDP and model E which contains FFR and TED are inferior to models C, D, F, G. A noticeable difference is that now model $\mathrm{H}$ which contains SPR and TED, and USB are also in the second class. Thus, it seems that while the choice of choosing 2005 as the end of the in-sample might not be the consensus among researchers, the results are not as sensitive as one may think. In addition, the previous section has also presented our results based on a recursive approach of allowing models to "update and re-estimate" in terms of the out-of-sample forecasting.

(Tables 8a, 8b, 8c, 8d about here)

\section{Concluding Remarks}

Dramatic movements in asset prices often occupy media headlines and carry implications in real economic activities, even political personnel changes. Yet in media and even academic circles are full of competing and sometimes even conflicting explanations. This paper attempts to bring some explanations for these events to formal testing. Notice that while an econometric model comparison is not equivalent to an explanation comparison, the exercise in this paper may provide us hints for future model development. It is especially true if models contain certain variables consistently out-perform other models which do not contain those variables. From a policy point of view, identifying the empirically more relevant model does not only satisfies intellectual curiosity, but may also assist governments making more appropriate policy decisions. Thus, this paper attempts to establish some stylized facts about the asset return dynamics in the aggregate level. In particular, this paper separates the data into the pre-crisis period 1975-2005 (in-sample) and the period after (2006-2011), and examines whether an estimated model based on the pre-crisis period can have reasonable forecasting for the crisis period (out-of-sample 
forecasting), with the effect of other variables such as GDP growth and monetary policy taken into consideration.

Our first contribution is to demonstrate how to categorize competing models into different "Equivalence Predictive Power Classes" (EPPC). We find that it can shed light on the Efficient Market Hypothesis (EMH) debate, as well as the structural-break discussion on the asset markets. During the in-sample period, all models have the same predictive power as the USB (Univariate, Single-regime Benchmark, i.e. AR $(q)$ ) on stock return. It is consistent with the EMH that all information about the future stock returns has been reflected in the current period stock return and hence additional variables do not enhance the forecasting. For the housing return, the situation is different. Model D, E, F, H consistently outperform the USB, suggest the existence of cross-market information flow and the value of multi-variate modeling. For the out-of-sample period as a whole, the picture changes. No model has superior predictive power than the USB on either the stock return of housing return forecast. Whether we use the "square loss criterion" $(S L C)$ or the "absolute loss criterion" $(A L C)$, and Model A, B and E are shown to have lower predictive power than the USB in the housing return forecast. Thus, these results seem to be consistent with the notion that there are some "structural changes" in the determinants of asset return dynamics since 2006. In particular, since both Model A and B are the only models which contain GDP as a variable in the dynamical system, the evidence then points to the possibility that GDP has lost its power in predicting the housing return after the crisis period, perhaps due to the deep recession. Obviously, it does not mean that "economic fundamentals" such as GDP is not important. One interpretation is that the information contained in the GDP has already been reflected in other financial variables that we include in the econometric model, such as TED spread. This is consistent with the theoretical result in Telmer and Zin (2002) that with incomplete markets, asset returns can predict (future) asset prices well.

Our second contribution shows that all models do not have the same capacity to "learn and update." Notice that the results based on EPPC clearly treat the model performance during the out-of-sample period as a whole. However, it is possible that some models make more mistake in the beginning of the financial crisis, and later improves significantly 
with new data is supplied. To investigate such possibility, we conduct out-of-sampling forecasting based on the simulation approach. We find that the USB of either the stock return or the housing return never enjoys a perfect year (i.e. a year that the asset return is totally inclusive within the confidence interval) since 2006. On the other hand, after revising with data by the end of 2009, Model G, which includes both the EFP and TED spread, can include the actual asset returns of 2010 in the confidence intervals. In other words, while uni-variate models may be as good as any model in predicting asset returns in the "long run," they may learn "slower" than multi-variate ones in the "short-run". It also suggests that macroeconomic models, which emphasize the role of imperfect capital market faced by non-financial firms as well as those faced by banks, may be promising in enhancing the understanding of the stock and housing returns. ${ }^{40}$

In addition,we also methodologically demonstrate a few things in terms of multivariate modeling. First, the widely used linear VAR model (i.e. single regime) with 7 variables can actually under-perform than the regime-switching counterparts with only 4 variables most of the time. Perhaps more importantly, we demonstrate that we can combine the multi-model comparison test of Mariano and Preve (2012) with the "Model Confidence set" procedure developed by Hansen et al. (2011) to classify models into different EPPC. We also demonstrate that such EPPC approach can be complemented by the simulation-based method used by Sargent, Williams and Zha (2006) and others to further distinguish the empirical performance of models within the same EPPC. Future research may want to further explore along these lines.

This research can clearly be extended in several dimensions. First, it would be interesting to apply the current econometric framework to other economies, such as the European Union countries. The current framework can also be applied to more disaggregate data. Also, it would be interesting to incorporate higher frequency variables and study the (potential) price discovery processes among different asset markets. Needless to say, one can re-examine the two asset markets with Bayesian econometrics. Finally, one could develop a theoretical framework that mimics the stylized facts found in this paper, which will further enhance our understanding of the interactions between the real

\footnotetext{
${ }^{40}$ Among others, see Gertler and Kiyotaki (2010), Davis (2010), Andres and Arce (2012), Jin et al. (2012).
} 
economy and the asset markets. 


\section{References}

[1] Andres, J. and O. Arce, 2012, Banking competition, housing prices and macroeconomic stability, Economic Journal, 122, 1346-372.

[2] Austen-Smith, D. and J. Banks, 2000, Positive Political Theory I: Collective Preference, Ann Arbor: University of Michigan Press.

[3] Bank for International Settlements, 2003, 73rd Annual Report, Basle.

[4] Bernanke, B. and M. Gertler,1995, Inside the black box: The credit channel of monetary policy transmission, Journal of Economic Perspectives 9, 27-48.

[5] Bernanke, B. and M. Gertler, 2001, Should central banks respond to movements in asset prices? American Economic Review, 91, 253-257.

[6] Bernanke, B., M. Gertler and S. Gilchrist, 1999, The Financial Accelerator in A Quantitative Business Cycle Framework, in John Taylor and Michael Woodford (ed.), Handbook of Macroeconomics, Vol. 1, New York: Elsevier.

[7] Bertay, A. C. and D. Gong, 2014, Securitization, financial stability and macroeconomy: Evidence from an international panel, mimeo.

[8] Campbell, J. Y. and J. F. Cocco, 2007, How do house prices affect consumption? Evidence from micro data, Journal of Monetary Economics, 54, 591-621.

[9] Case, K. E. and R. J. Shiller, 1990, Forecasting prices and excess returns in the housing market, Real Estate Economics, 18, 253-73.

[10] Case, K. E., J. Quigley and R. J. Shiller, 2005, Comparing wealth effects: the stock market versus the housing market, Advances in Macroeconomics, 5, 1235-1235.

[11] Cetorelli, N. and L. Goldberg, 2011, Global banks and international shock transmission: Evidence from the crisis, IMF Economic Review, 59, 41-76.

[12] Cetorelli, N. and L. Goldberg, 2012, Banking globalization and monetary transmission, Journal of Finance, 67, 1811-1843.

[13] Chang, K. L., N. K. Chen and C. K. Y. Leung, 2011, Monetary policy, term structure and real estate return: Comparing REIT, housing and stock, Journal of Real Estate Finance and Economics, 43, 221-257.

[14] Chang, K. L., N. K. Chen and C. K. Y. Leung, 2012, The dynamics of housing returns in Singapore: How important are the international transmission mechanisms? Regional Science and Urban Economics, 42, 516-530.

[15] Chang, K. L., N. K. Chen and C. K. Y. Leung, 2013, In the shadow of the United States: The international transmission effect of asset returns, Pacific Economic Review, 18(1), 1-40.

[16] Chauvet, M. and S. Potter, 2013, Forecasting output, G. Elliot and A. Timmenmann et., Handbook of Economic Forecasting, volume 2, part A, 141-194. 
[17] Chen, N. K., H. L. Cheng and C. S. Mao, 2014, Identifying and forecasting house prices: A macroeconomic perspective, Quantitative Finance, 14, 2105-2120.

[18] Chen, N. K. and C. K. Y. Leung, 2008, Asset price spillover, collateral and crises: With an application to property market policy, Journal of Real Estate Finance and Economics, 37, 351-385.

[19] Christiano, L., R. Motto and M. Rostagno, 2007, Financial factors in business cycles, Northwestern University, mimeo.

[20] Clapp, J. M. and C. Giaccotto, 1994, The influence of economic variables on local house price dynamics, Journal of Urban Economics 36, 161-83.

[21] Clark, T., 2011, Real-time density forecasts from Bayesian vector autoregressions with stochastic volatility, Journal of Business and Economic Statistics, 29, 327-341.

[22] Cochrane, J., 2001, Asset Pricing, Princeton: Princeton University Press.

[23] Cooley, T. and M. Dwyer, 1998. Business cycle analysis without much theory: A look at structural VARs. Journal of Econometrics, 83(1-2), 57-88.

[24] Davis, S., 2010, The adverse feedback loop and the real effects of financial sector uncertainty, Vanderbilt University, mimeo.

[25] De Walque, G., O. Pierrard and A. Rouabah, 2010, Financial (in)stability, supervision and liquidity injections: A dynamic general equilibrium approach, Economic Journal, 120(549), 1234-1261.

[26] Darrat, A. and J. Glascock, 1989, Real estate returns, money and fiscal deficits: Is the real estate market efficient? Journal of Real Estate Finance and Economics, 2, 197-208.

[27] Diebold, F. and R. Mariano, 1995, Comparing predictive accuracy, Journal of Business \& Economic Statistics, 13, 253-263.

[28] Emiris, M., 2006, The term structure of interest rates in a DSGE model, National Bank of Belgium, mimeo.

[29] Estrella, A., 2005, Why does the yield curve predict output and inflation? Economic Journal, 115, 722-44.

[30] Estrella, A. and M. R. Trubin, 2006, The yield curve as a leading indicator: Some practical issues, Current Issues in Economics and Finance 12, Federal Reserve Bank of New York.

[31] Fama, E., 1970, Efficient capital markets: A review of theory and empirical work, Journal of Finance, 25(2), 383-417.

[32] Ferreira, F., J. Gyourko and J. Tracy, 2010, Housing busts and household mobility, Journal of Urban Economics, 68(1), 34-45.

[33] Francq, C. and J. M. Zakoian, 2001, Stationary of multivariate Markov-switching ARMA models, Journal of Econometrics 10, 339-364.

[34] Gertler, M. and C. Lown, 1999, The information in the high-yield bond spread for the business cycle: Evidence and some implications, Oxford Review of Economic Policy, 15, 132-150. 
[35] Gertler, M. and N. Kiyotaki, 2010, Financial intermediation and credit policy in business cycle analysis, in B. M. Friedman and M. Woodford ed., Handbook of Monetary Economics, Vol. 3, 547-599.

[36] Goodhart, C., 2001, What weight should be given to asset prices in the measurement of inflation? Economic Journal 111, 335-356.

[37] Goodhart, C. and B. Hofmann, 2007, House Prices and the Macroeconomy: Implications for Banking and Price Stability, Oxford: Oxford University Press.

[38] Green, R., 2002, Stock prices and house prices in California: New evidence of a wealth effect? Regional Science and Urban Economics, 32, 775-783.

[39] De Graeve, F., 2007, The external finance premium and the macroeconomy: US Post-WWII evidence, working paper.

[40] Grishchenko, O. V. and M. Rossi, 2012, The role of heterogeneity in asset pricing: The effect of a clustering approach, Journal of Business and Economic Statistics, 30, 297-311.

[41] Hamilton, J., 1994, Time series analysis, Princeton: Princeton University Press.

[42] Hansen, P., A. Lunde and J. Nason, 2011, The model confidence set, Econometrica, $79(2), 453-497$.

[43] Hempel, C. G., 1942, The function of general laws in history, Journal of Philosophy, $39(2), 35-48$.

[44] Himmelberg, C., C. Mayer and T. Sinai, 2005, Assessing high house prices: Bubbles, fundamentals and misperceptions, Journal of Economic Perspective, 19, 67-92.

[45] Hott, C. and P. Monnin, 2008, Fundamental real estate prices: An empirical estimation with international data, Journal of Real Estate Finance and Economics, 36, 427-450.

[46] Huang, H., and Y. Tang, 2012, Residential land use regulation and the US housing price cycle between 2000 and 2009, Journal of Urban Economics, 71(1), 93-99.

[47] Huang, M., 2014, Bubble-like housing boom-bust cycles: Evidence from the predictive power of households' expectations, Quarterly Review of Economics and Finance, $54,2-16$

[48] Ibbotson, R. G. and L. B. Siegel, 1984, Real estate returns: A comparison with other investments, Journal of American Real Estate and Urban Economics Association, $12,219-242$.

[49] In't-Veld, J., R. Raciborski, M. Ratto and W. Roeger, 2011, The recent boom-bust cycle: The relative contribution of capital flows, credit supply and asset bubbles. European Economic Review, 55(3), 386-406.

[50] Jin, Y., C. K. Y. Leung and Z. Zeng 2012, Real estate, the external finance premium and business investment: A quantitative dynamic general equilibrium analysis, Real Estate Economics, 40(1), 167-195.

[51] Kan, K., S. K. S. Kwong and C. K. Y. Leung, 2004, The dynamics and volatility of commercial and residential property prices: Theory and evidence, Journal of Regional Science, 44(1), 95-123. 
[52] Kapetanios, G., A. Pagan and A. Scott, 2007, Making a match: Combining theory and evidence in policy-oriented macroeconomic modeling, Journal of Econometrics, $136,565-594$.

[53] Khandani, A. E., A. W. Lo and R. C. Merton, 2013, Systemic risk and the refinancing ratchet effect, Journal of Financial Economics, 108(1), 29-45.

[54] King, R., C. Plosser and S. Rebelo, 2002, Production, growth and business cycles: Technical appendix, Computational Economics, 20, 87-116.

[55] Kiyotaki, N. and J. Moore, 1997, Credit cycles, Journal of Political Economy, 105, 211-248.

[56] Kouwenberg, R. and R. Zwinkels, 2014, Forecasting the US housing market, International Journal of Forecasting, 30, 415-425.

[57] Kwan, Y. K., C. K.Y. Leung and J. Dong, 2015, Comparing consumption-based asset pricing models: The case of an Asian city, Journal of Housing Economics, 28, $18-41$.

[58] LeRoy, S., 1989, Efficient capital markets and Martingales, Journal of Economic Literature, 27(4), 1583-1621.

[59] Lettau, M. and S. C. Ludvigson, 2005, Expected returns and expected dividend growth, Journal of Financial Economics,76, 583-626.

[60] Leung, C., 2004, Macroeconomics and housing: a review of the literature, Journal of Housing Economics, 13, 249-267.

[61] Leung, C. K. Y., 2007, Equilibrium correlations of asset price and return, Journal of Real Estate Finance and Economics, 34, 233-256.

[62] Leung, C. K. Y., 2014, Error correction dynamics of house pice: An equilibrium benchmark, Journal of Housing Economics, 25, 75-95.

[63] Lubik, T., and F. Schorfheide, 2004, Testing for indeterminacy: An application to U.S. monetary policy, American Economic Review, 94(1), 190-217.

[64] Lustig, H. and S. Van Nieuwerburgh, 2005, Housing collateral, consumption insurance and risk premia: An empirical perspective, Journal of Finance, 60, 1167-1219.

[65] Lutz, B., R. Molloy, and H. Shan, 2011, The housing crisis and state and local government tax revenue: Five channels. Regional Science and Urban Economics, 41(4), 306-319.

[66] Maheu, J. and T. McCurdy, 2000, Identifying bull and bear markets in stock returns. Journal of Business and Economic Statistics 18, 100-112.

[67] Maheu, J., T. McCurdy, Y. Song, 2012, Components of Bull and Bear markets: Bull corrections and Bear rallies, Journal of Business and Economic Statistics 30, 391-403.

[68] Mariano, R. and D. Preve, 2012, Statistical tests for multiple forecast comparison, Journal of Econometrics, 169, 123-130.

[69] Menzly, L., T. Santos and P. Veronesi, 2004, Understanding predictability, Journal of Political Economy, 112, 1-47. 
[70] Mishkin, F., 2001, The transmission mechanism and the role of asset prices in monetary policy, NBER Working Paper 8617.

[71] Nichols, J. B., S. D. Oliner and M. R. Mulhall, 2013, Swings in commercial and residential land prices in the United States. Journal of Urban Economics, 73(1), $57-76$.

[72] Pagan, A. and T. Robinson, Methods for assessing the impact of financial effects on business cycles in macroeconometric models, Journal of Macroeconomics, 41, 94-106.

[73] Phillips, P., 2014, On confidence intervals for autoregressive roots and predictive regression, Econometrica, 82(3), 1177-1195.

[74] Piazzesi, M., M. Schneider and S. Tuzel, 2007, Housing, consumption, and asset pricing, Journal of Financial Economics, 83, 531-569.

[75] Plosser, C. and K. G. Rouwenhorst, 1994, International term structures and real economic growth, Journal of Monetary Economics, 33, 133-155.

[76] Quan, D. and S. Titman, 1997. Commercial real estate prices and stock market returns: An international analysis, Financial Analysts Journal, 53(3), 21-34.

[77] Quan, D. and S. Titman, 1999. Do real estate prices and stock prices move together? An international analysis, Real Estate Economics, 27, 183-207.

[78] Rigobon, R. and B. Sack, 2003. Measuring the reaction of monetary policy to the stock market, Quarterly Journal of Economics, 118, 639-669.

[79] Rosenberg, J. V. and S. Maurer, 2008, Signal or noise? Implications of the term premium for recession forecasting, FRBNY Economic Policy Review, 14(3), 1-11.

[80] Sargent, T., N. Williams and T. Zha, 2006, Shocks and government beliefs: The rise and fall of American inflation, American Economic Review, 96, 1193-1224.

[81] Shiller, R., 2007, Understanding recent trends in house prices and home ownership. http://www.kc.frb.org/publicat/sympos/2007/pdf/2007.09.27.shiller.pdf.

[82] Shiller, R., 2008, The Subprime Solution, Princeton: Princeton University Press.

[83] Sims, C., 1980a, Comparison of interwar and postwar business cycles: Monetarism reconsidered, American Economic Review, 70(2), 250-257.

[84] Sims, C., 1980b, Macroeconomics and reality, Econometrica, 48, 1-48.

[85] Sims, C. and T. Zha, 2006, Were there regime switches in U.S. monetary policy? American Economic Review, 96, 54-81.

[86] Sutton, G. D., 2002, Explaining changes in house prices, BIS Quarterly Review, September, 46-55.

[87] Telmer, C. and S. Zin, 2002, Prices as factors: Approximate aggregation with incomplete markets, Journal of Economic Dynamics and Control, 26, 1127-1157.

[88] Torous, W., R. Valkanov and S. Yan, 2004, On predicting stock returns with nearly integrated explanatory variables, Journal of Business, 77, 937-966. 
[89] Tsatsaronis, K. and H. Zhu, 2004, What dirves housing price dynamics: Crosscountry evidence, BIS Quarterly Review, March, 65-78.

[90] Welch, I. and A. Goyal, 2008, A comprehensive look at the empirical performance of equity premium prediction, Review of Financial Studies, 21(4), 1455-1508.

[91] Yoshida, J., 2008, Technology shocks and asset price dynamics: The role of housing in general equilibrium, University of Tokyo, mimeo.

[92] Zivot, E., 2004, Notes on forecasting, University of Washington at Seattle, mimeo. 
$\underline{\text { Tables }}$

Table 1. Statistical Summary of Federal Funds Rate, Term Spread, Gross Domestic Production Growth Rate, External Finance Premium, Market Liquidity, Stock Index Return and Housing Market Return (1975Q2-2012Q1)

\begin{tabular}{lrrrrrrr}
\hline & FFR & SPR & GDP & EFP & TED & SRET & HRET \\
\hline Mean & 5.808 & 1.634 & 0.699 & 1.125 & 0.867 & 1.910 & 1.123 \\
Median & 5.417 & 1.789 & 0.744 & 0.997 & 0.605 & 2.436 & 1.206 \\
Maximum & 17.780 & 3.611 & 3.859 & 3.023 & 3.333 & 18.952 & -26.431 \\
Minimum & 0.073 & -2.182 & -2.328 & 0.560 & 0.097 & -2.989 \\
Std. Dev. & 3.806 & 1.343 & 0.809 & 0.473 & 0.750 & 8.204 & 1.277 \\
Skewness & 0.785 & -0.707 & -0.536 & 1.596 & 1.643 & -0.787 & -0.490 \\
Kurtosis & 3.838 & 3.006 & 6.270 & 5.914 & 5.216 & 3.995 & 4.735 \\
Observations & 148.000 & 148.000 & 148.000 & 148.000 & 148.000 & 148.000 & 148.000 \\
\hline
\end{tabular}

Note: FFR denotes the federal funds rate, SPR denotes the term spread, GDP means the gross domestic production growth rate, EFP means the external finance premium, TED means the market liquidity, SRET means stock index return, and HRET means housing market return. 
Table 2. Correlation Coefficients (1975Q2-2012Q1)

\begin{tabular}{lcccrrrr}
\hline & FFR & SPR & GDP & EFP & TED & SRET & HRET \\
\hline FFR & 1.000 & -0.608 & 0.031 & 0.290 & 0.722 & 0.016 & 0.266 \\
SPR & & 1.000 & 0.050 & 0.097 & -0.410 & 0.011 & -0.251 \\
GDP & & 1.000 & -0.360 & -0.250 & 0.148 & 0.209 \\
EFP & & & 1.000 & 0.638 & -0.050 & -0.192 \\
TED & & & & 1.000 & -0.130 & -0.015 \\
SRET & & & & & & & \\
HRET & & & & & & & \\
\hline
\end{tabular}


Table 3a. List of Models

\begin{tabular}{|l|l|l|}
\hline Model & Model Structure & Variables \\
\hline A & Linear & FFR, SPR, TED, EFP, GDP, SRET, HRET \\
\hline B & Two-regime & FFR, GDP, SRET, HRET \\
\hline C & Two-regime & FFR, SPR, SRET, HRET \\
\hline D & Two-regime & FFR, EFP, SRET, HRET \\
\hline E & Two-regime & FFR, TED, SRET, HRET \\
\hline F & Two-regime & EFP, SPR, SRET, HRET \\
\hline G & Two-regime & EFP, TED, SRET, HRET \\
\hline H & Two-regime & SPR, TED, SRET, HRET \\
\hline USB & Linear & Uni-variate, Single-regime, Benchmark (i.e. AR(1)) \\
\hline
\end{tabular}

Key: (unless specified, all variables refer to quarterly data) FFR, Federal Fund Rate; SPR, term spread, which is equal to (10-year bond rate FFR); TED, TED spread, which is equal to (3-month Eurodollar deposit rate - 3-month T-bill rate), a measure of market liquidity; EFP, External Finance Premium, which is equal to corporate bond spread (Baa-Aaa), a measure of External Finance Premium; GDP, GDP growth rate; SRET, Stock Market Return; HRET, Housing Market Return. 
Table 3b. Choosing the Uni-variate, Single-regime Benchmark (USB) model

\begin{tabular}{lllll}
\hline & \multicolumn{2}{c}{ AIC } & \multicolumn{2}{c}{ SBC } \\
\hline & AR(1) & AR(2) & AR(1) & AR(2) \\
\cline { 2 - 5 } SRET & 7.0774 & 7.0902 & 7.1381 & 7.1712 \\
HRET & 2.7589 & 2.7464 & 2.8196 & 2.8274 \\
\hline
\end{tabular}

Note: AIC refers to the Akaike information criterion. SBC refers to the Schwartz Bayesian information criterion.

(1) For SRET, in terms of both AIC and SBC, AR(1) model performs better than AR(2).

(2) For HRET, in terms of AIC, AR(2) is the marginally better (2.746 versus 2.759). However, in terms of SBC, AR(1) is marginally better (2.820 versus 2.827). For parsimony purpose, we choose AR(1) specification. 
Table 4a. A Summary of Goodness of Fit for All Eight Models (1975Q2-2012Q1)

\begin{tabular}{lccc}
\hline & Models & AIC & SBC \\
Model A & Single-regime model (FFR, SPR, TED, EFP, GDP, SRET, HRET) & 12.1273 & 13.8284 \\
Model B & Two-regime model (FFR, GDP, SRET, HRET) & 13.8681 & 15.1237 \\
Model C & Two-regime model (FFR, SPR, SRET, HRET) & 12.7748 & 14.0304 \\
Model D & Two-regime model (FFR, EFP, SRET, HRET) & 11.0063 & 12.2619 \\
Model E & Two-regime model (FFR, TED, SRET, HRET) & 11.8574 & 13.1130 \\
Model F & Two-regime model (EFP, SPR, SRET, HRET) & 10.6150 & 11.8706 \\
Model G & Two-regime model (EFP, TED, SRET, HRET) & 9.2656 & 10.5212 \\
Model H & Two-regime model (SPR, TED, SRET, HRET) & 11.7468 & 13.0024 \\
Model USB & Uni-variate, Single-regime, Benchmark for (SRET) & 7.0774 & 7.1381 \\
Model USB & Uni-variate, Single-regime, Benchmark for (HRET) & 2.7589 & 2.8196 \\
\hline
\end{tabular}

Note: AIC refers to the Akaike information criterion. SBC refers to the Schwartz Bayesian information criterion. 
Table 4b. Estimated Persistence of Regimes among Models (1975Q2-2012Q1)

\begin{tabular}{|l|l|l|}
\hline & $p_{11}$ & $p_{22}$ \\
\hline Model B & 0.9427 & 0.9920 \\
\hline Model C & 0.9505 & 0.9914 \\
\hline Model D & 0.8060 & 0.9643 \\
\hline Model E & 0.7824 & 0.9386 \\
\hline Model F & 0.8226 & 0.9492 \\
\hline Model G & 0.7952 & 0.9370 \\
\hline Model H & 0.8478 & 0.9447 \\
\hline
\end{tabular}


Table 5. Identified periods of Regime 1

\begin{tabular}{|c|c|c|c|c|c|}
\hline \multirow{2}{*}{$\begin{array}{l}\text { Models } \\
\text { Model B }\end{array}$} & \multicolumn{5}{|c|}{ Regime 1} \\
\hline & 1978Q2-1982Q4 & & & & \\
\hline Model C & 1979Q4-1986Q2 & & & & \\
\hline \multirow[t]{2}{*}{ Model E } & 1975Q2-1976Q2 & 1978Q2-1978Q4 & 1979Q3-1982Q4 & 1984Q2-1984Q4 & 1987Q2-1987Q4 \\
\hline & 2007Q3-2008Q4 & 2009Q2 & & & \\
\hline \multirow[t]{2}{*}{ Model G } & 1975Q2 & 1976Q2 & 1978Q4 & 1979Q3-1984Q4 & 1987Q2-1987Q4 \\
\hline & 2007Q3-2008Q4 & 2009Q2-2009Q3 & & & \\
\hline \multirow[t]{2}{*}{ Model H } & 1975Q2-1976Q2 & 1978Q2-1982Q3 & 1984Q2 & 1987Q2-1988Q3 & 2001Q1-2001Q4 \\
\hline & 2007Q3-2009Q2 & & & & \\
\hline
\end{tabular}


Table 6a. A Summary of In-sample Forecasting Performances (4-Quarter Ahead Forecasts) (1975Q2-2005Q4)

\begin{tabular}{|c|c|c|c|c|c|}
\hline & & \multicolumn{2}{|c|}{ Stock Returns } & \multicolumn{2}{|c|}{ Housing Returns } \\
\hline & & SLC & ALC & SLC & ALC \\
\hline Model A & $\begin{array}{l}\text { Single-regime model (FFR, SPR, TED, EFP, GDP, } \\
\text { SRET, HRET) }\end{array}$ & 57.5866 & 5.6686 & 0.7577 & 0.6488 \\
\hline Model B & Two-regime model (FFR, GDP, SRET, HRET) & 57.8042 & 5.6453 & 0.8304 & 0.7053 \\
\hline Model C & Two-regime model (FFR, SPR, SRET, HRET) & 57.1605 & 5.6188 & 0.7356 & 0.6691 \\
\hline Model D & Two-regime model (FFR, EFP, SRET, HRET) & 58.7039 & 5.6662 & 0.7013 & 0.6364 \\
\hline Model E & Two-regime model (FFR, TED, SRET, HRET) & 58.2775 & 5.6553 & 0.6980 & 0.6204 \\
\hline Model F & Two-regime model (EFP, SPR, SRET, HRET) & 60.6847 & 5.7425 & 0.7331 & 0.6502 \\
\hline Model G & Two-regime model (EFP, TED, SRET, HRET) & 59.0501 & 5.7707 & 0.8295 & 0.6727 \\
\hline Model H & Two-regime model (SPR, TED, SRET, HRET) & 58.2623 & 5.6366 & 0.7308 & 0.6378 \\
\hline USB & Uni-variate, Single-regime Benchmark & 57.9966 & 5.6881 & 0.8400 & 0.6726 \\
\hline
\end{tabular}

Key: SLC: Square Loss Criteria; ALC: Absolute Loss Criteria. 
Table 6b. A Summary of EPPC (In-sample 4-Quarter Ahead Forecasts)

\begin{tabular}{|c|c|c|c|c|}
\hline & & Class 1 & Class 2 & Class 3 \\
\hline \multirow[t]{2}{*}{ Stock Return } & SLC & All models & 1 & 1 \\
\hline & ALC & All models & 1 & 1 \\
\hline \multirow[t]{2}{*}{ Housing Return } & SLC & D, E, F, H & A, C, G & $\mathrm{B}, \mathrm{USB}$ \\
\hline & ALC & $\mathrm{A}, \mathrm{C}, \mathrm{D}, \mathrm{E}, \mathrm{F}, \mathrm{H}$ & B, G, USB & l \\
\hline
\end{tabular}

Note: SLC: Squared Loss Criterion; ALC: Absolute Loss Criterion. Our convention is that if $i>j$, then any model in Class $i$ has less predictive power than any model in Class $j$. 
Table 6c. A Summary of Out-of-Sample Forecasting Performances (4-Quarter Ahead Forecasts) (2006Q4-2012Q1)

\begin{tabular}{|c|c|c|c|c|c|}
\hline & & \multicolumn{2}{|c|}{ Stock Returns } & \multicolumn{2}{|c|}{ Housing Returns } \\
\hline & & SLC & ALC & SLC & ALC \\
\hline Model A & $\begin{array}{l}\text { Single-regime model (FFR, SPR, TED, EFP, GDP, } \\
\text { SRET, HRET) }\end{array}$ & 126.3311 & 9.4671 & 4.8730 & 1.8844 \\
\hline Model B & Two-regime model (FFR, GDP, SRET, HRET) & 119.1706 & 9.0940 & 4.8658 & 1.8975 \\
\hline Model C & Two-regime model (FFR, SPR, SRET, HRET) & 122.2287 & 9.3329 & 3.7581 & 1.6619 \\
\hline Model D & Two-regime model (FFR, EFP, SRET, HRET) & 127.3973 & 9.5067 & 3.6938 & 1.6136 \\
\hline Model E & Two-regime model (FFR, TED, SRET, HRET) & 115.8617 & 8.8073 & 5.0151 & 1.9273 \\
\hline Model F & Two-regime model (EFP, SPR, SRET, HRET) & 133.7992 & 9.6332 & 3.8359 & 1.6712 \\
\hline Model G & Two-regime model (EFP, TED, SRET, HRET) & 127.3231 & 8.8930 & 4.0599 & 1.7108 \\
\hline Model H & Two-regime model (SPR, TED, SRET, HRET) & 109.6158 & 8.5835 & 4.2041 & 1.7652 \\
\hline USB & Uni-variate, Single-regime Benchmark & 113.6018 & 8.6529 & 4.5453 & 1.8221 \\
\hline
\end{tabular}

Key: SLC: Square Loss Criteria; ALC: Absolute Loss Criteria. 
Table 6d. A Summary of EPPC (Out-Of-Sample 4-Quarter Ahead Forecasts)

\begin{tabular}{|c|c|c|c|}
\hline \multirow{3}{*}{ Stock Return } & & Class 1 & Class 2 \\
\cline { 2 - 4 } & SLC & A, B, C, E, H, USB & D, F, G \\
\cline { 2 - 4 } Housing Return & ALC & B, E, G, H, USB & A, C, D, F \\
\cline { 2 - 4 } & SLC & C, D, F, G, H, USB & A, B, E \\
\cline { 2 - 4 } & ALC & C, D, F, G, H, USB & A, B, E \\
\hline
\end{tabular}

Note: SLC: Squared Loss Criterion; ALC: Absolute Loss Criterion. Our convention is that if $i>j$, then any model in Class $i$ has less predictive power than any model in Class $j$. 
Table 7a. Is the forecasted Stock return within the $80 \%$ confidence interval?

\begin{tabular}{|l|c|c|c|c|c|c|}
\hline Models & $\begin{array}{c}\text { Predicting 2006 } \\
\text { based on } \\
\text { 1975-2005 }\end{array}$ & $\begin{array}{c}\text { Predicting 2007 } \\
\text { based on 1975-2006 }\end{array}$ & $\begin{array}{c}\text { Predicting 2008 } \\
\text { based on } \\
1975-2007\end{array}$ & $\begin{array}{c}\text { Predicting 2009 } \\
\text { based on } \\
1975-2008\end{array}$ & $\begin{array}{c}\text { Predicting 2010 } \\
\text { based on } \\
1975-2009\end{array}$ & $\begin{array}{c}\text { Predicting 2011 } \\
\text { based on } \\
1975-2010\end{array}$ \\
\hline Model A & Yes & Yes & Partly & Partly & Partly & Partly \\
\hline Model B & Yes & Yes & Partly & Partly & Partly & Partly \\
\hline Model C & Yes & Yes & Partly & Partly & Partly & Partly \\
\hline Model D & Yes & Yes & Partly & Partly & Partly \\
\hline Model E & Yes & Yes & Partly & Partly & Yes & Partly \\
\hline Model F & Yes & Yes & No & Partly & Partly & Partly \\
\hline Model G & Yes & Yes & Partly & Partly & Partly & Partly \\
\hline Model H & Yes & Yes & Partly & &
\end{tabular}


Table $7 \mathrm{~b}$. Is the forecasted Housing return within the $80 \%$ confidence interval?

\begin{tabular}{|c|c|c|c|c|c|c|}
\hline Models & $\begin{array}{c}\text { Predicting } 2006 \\
\text { based on } \\
1975-2005\end{array}$ & $\begin{array}{c}\text { Predicting } 2007 \\
\text { based on 1975-2006 }\end{array}$ & $\begin{array}{c}\text { Predicting } 2008 \\
\text { based on } \\
\text { 1975-2007 }\end{array}$ & $\begin{array}{c}\text { Predicting } 2009 \\
\text { based on } \\
\text { 1975-2008 }\end{array}$ & $\begin{array}{c}\text { Predicting } 2010 \\
\text { based on } \\
1975-2009\end{array}$ & $\begin{array}{c}\text { Predicting } 2011 \\
\text { based on } \\
1975-2010\end{array}$ \\
\hline Model B & Yes & Partly & No & No & Partly & Partly \\
\hline Model C & Yes & Partly & Partly & Partly & Yes & Partly \\
\hline Model F & Yes & Partly & Partly & No & Partly & Partly \\
\hline Model G & Yes & Partly & No & Partly & Yes & Partly \\
\hline Model H & Yes & Partly & Partly & Partly & Partly & Partly \\
\hline USB & Yes & Partly & Partly & Partly & Partly & Partly \\
\hline
\end{tabular}


Table 8a. A Summary of In-sample Forecasting Performances (4-Quarter Ahead Forecasts) (1975Q2-2006Q4)

\begin{tabular}{|c|c|c|c|c|c|}
\hline \multirow{2}{*}{} & & \multicolumn{2}{c|}{ Stock Returns } & \multicolumn{2}{c|}{ Housing Returns } \\
\cline { 3 - 6 } & Single-regime model (FFR, SPR, TED, EFP, GDP, \\
SRET, HRET) & 56.1661 & 5.5860 & 0.7463 & 0.6412 \\
\hline Model B & Two-regime model (FFR, GDP, SRET, HRET) & 56.3073 & 5.5655 & 0.8174 & 0.7001 \\
\hline Model C & Two-regime model (FFR, SPR, SRET, HRET) & 55.6801 & 5.5256 & 0.7232 & 0.6599 \\
\hline Model D & Two-regime model (FFR, EFP, SRET, HRET) & 56.6837 & 5.5849 & 0.7252 & 0.6521 \\
\hline Model E & Two-regime model (FFR, TED, SRET, HRET) & 56.7498 & 5.5731 & 0.6995 & 0.6216 \\
\hline Model F & Two-regime model (EFP, SPR, SRET, HRET) & 58.9283 & 5.6407 & 0.7190 & 0.6447 \\
\hline Model G & Two-regime model (EFP, TED, SRET, HRET) & 58.2390 & 5.6850 & 0.7622 & 0.6450 \\
\hline Model H & Two-regime model (SPR, TED, SRET, HRET) & 57.7033 & 5.7300 & 0.7727 & 0.6579 \\
\hline USB & Uni-variate, Single-regime Benchmark & 56.4531 & 5.6016 & 0.8218 & 0.6636 \\
\hline
\end{tabular}

Key: SLC: Square Loss Criteria; ALC: Absolute Loss Criteria 
Table 8b. A Summary of EPPC (In-sample 4-Quarter Ahead Forecasts)

\begin{tabular}{|c|c|c|c|}
\hline \multirow{2}{*}{ Stock Return } & & Class 1 & Class 2 \\
\cline { 2 - 4 } & SLC & All models & $/$ \\
\cline { 2 - 4 } Housing Return & ALC & A, B, C, D, E, F, G, USB & H \\
\cline { 2 - 4 } & ALC & A, C, D, E, F, G, H & B, USB \\
\hline
\end{tabular}

Note: SLC: Squared Loss Criterion; ALC: Absolute Loss Criterion. Our convention is that if $i>j$, then any model in Class $i$ has less predictive power than any model in Class $j$. 
Table 8c. A Summary of Out-of-Sample Forecasting Performances (4-Quarter Ahead Forecasts) (2007Q4-2012Q1)

\begin{tabular}{|c|c|c|c|c|c|}
\hline & & \multicolumn{2}{|c|}{ Stock Returns } & \multicolumn{2}{|c|}{ Housing Returns } \\
\hline & & SLC & ALC & SLC & ALC \\
\hline Model A & $\begin{array}{l}\text { Single-regime model (FFR, SPR, TED, EFP, GDP, } \\
\text { SRET, HRET) }\end{array}$ & 152.4294 & 11.0135 & 5.3034 & 1.9487 \\
\hline Model B & Two-regime model (FFR, GDP, SRET, HRET) & 143.7629 & 10.5411 & 5.2328 & 1.9505 \\
\hline Model C & Two-regime model (FFR, SPR, SRET, HRET) & 147.2156 & 10.8114 & 3.9551 & 1.6780 \\
\hline Model D & Two-regime model (FFR, EFP, SRET, HRET) & 153.8418 & 11.0492 & 3.9000 & 1.6292 \\
\hline Model E & Two-regime model (FFR, TED, SRET, HRET) & 139.7478 & 10.2042 & 5.5364 & 2.0180 \\
\hline Model F & Two-regime model (EFP, SPR, SRET, HRET) & 161.8230 & 11.1754 & 4.1199 & 1.7119 \\
\hline Model G & Two-regime model (EFP, TED, SRET, HRET) & 153.6449 & 10.3014 & 4.3944 & 1.7674 \\
\hline Model H & Two-regime model (SPR, TED, SRET, HRET) & 132.4850 & 9.9965 & 4.6400 & 1.8598 \\
\hline USB & Uni-variate, Single-regime Benchmark & 137.1296 & 10.0236 & 5.0374 & 1.9263 \\
\hline
\end{tabular}

Key: SLC: Square Loss Criteria; ALC: Absolute Loss Criteria. 
Table 8d. A Summary of EPPC (Out-Of-Sample 4-Quarter Ahead Forecasts)

\begin{tabular}{|c|c|c|c|}
\hline \multirow{3}{*}{ Stock Return } & & Class 1 & Class 2 \\
\cline { 2 - 4 } & SLC & A, B, C, E, H, USB & D, F, G \\
\cline { 2 - 4 } Housing Return & ALC & B, E, G, H, USB & A, C, D, F \\
\cline { 2 - 4 } & SLC & C, D, F, G & A, B, E, H, USB \\
\cline { 2 - 4 } & C, D, F, G & A, B, E, H, USB \\
\hline
\end{tabular}

Note: SLC: Squared Loss Criterion; ALC: Absolute Loss Criterion. Our convention is that if $i>j$, then any model in Class $i$ has less predictive power than any model in Class $j$. 
Figure 1a Federal Funds Rate (FFR), Term Spread (SPR), Percentage Changes in Gross Domestic Production (GDP), External Finance Premium (EFP)
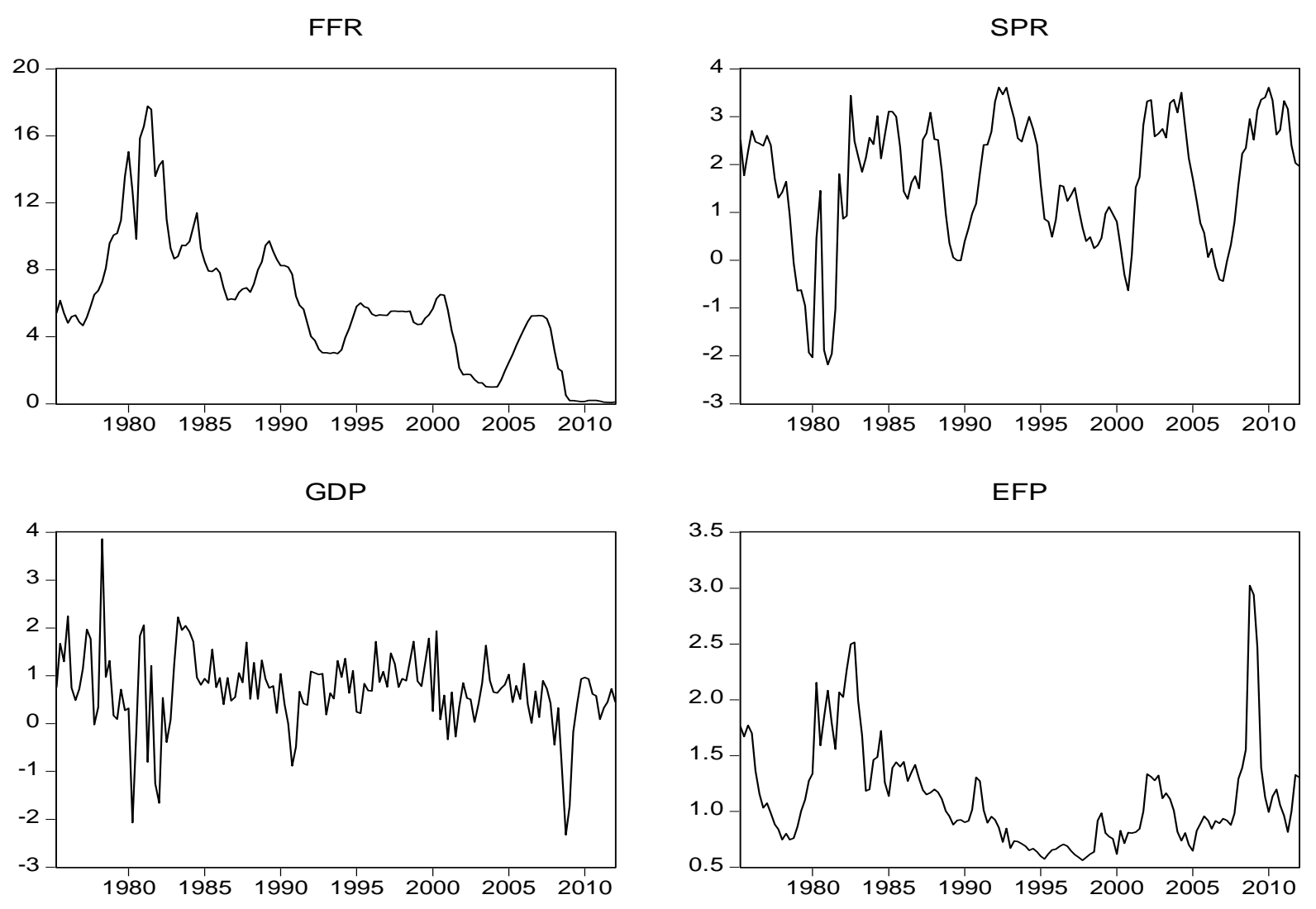
Figure 1b Market Liquidity (TED), Stock Index Return (SRET), Housing Market Return (HRET)
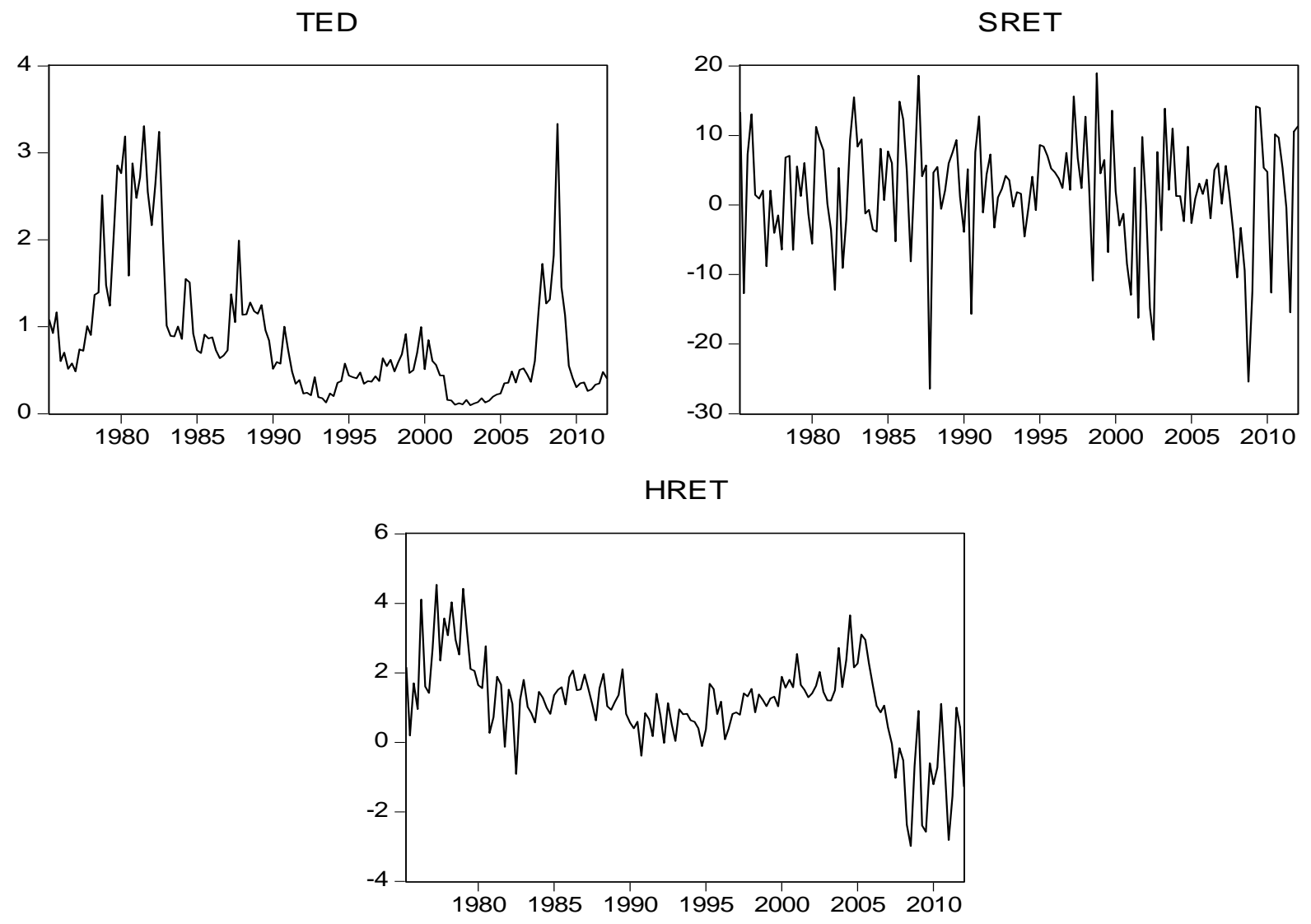
Figure 2a Smoothed Probabilities for Model B (FFR, GDP,SRET,HRET) (only the probability of Regime 1 will be shown)

Regime 1

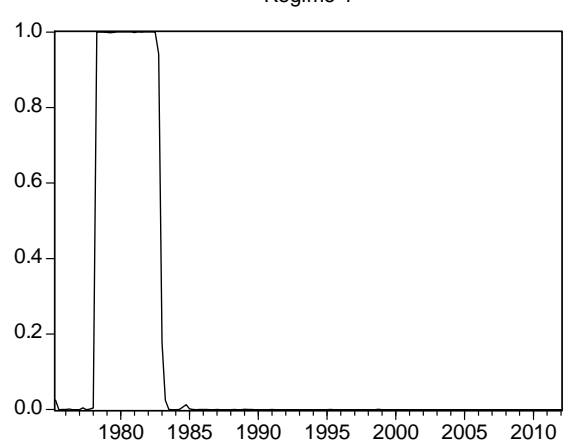

Figure 2b Smoothed Probabilities for Model C (FFR,SPR,SRET,HRET) Regime 1

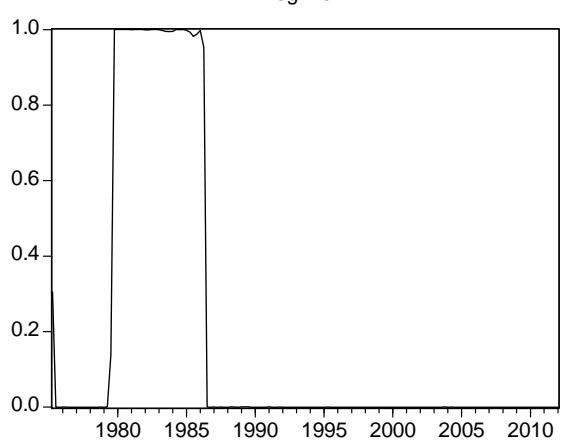

Figure 2c Smoothed Probabilities for Model D (FFR,EFP,SRET,HRET) Regime 1

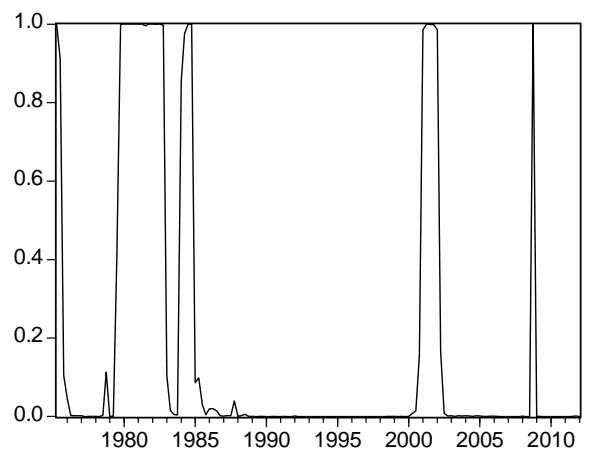

Figure 2d Smoothed Probabilities for Model E (FFR,TED,SRET,HRET)

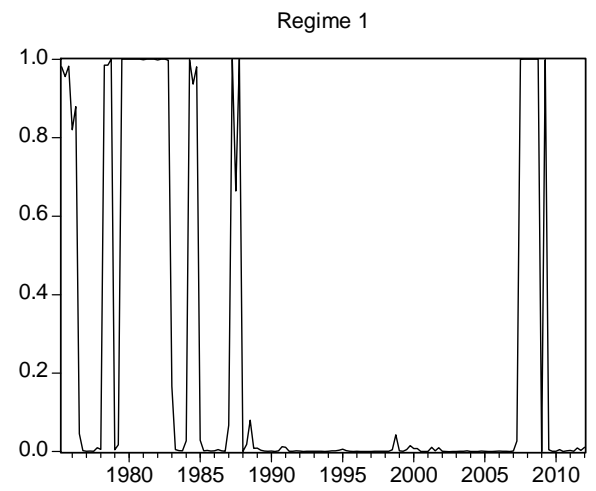


Figure 2e Smoothed Probabilities for Model F (EFP,SPR,SRET,HRET)

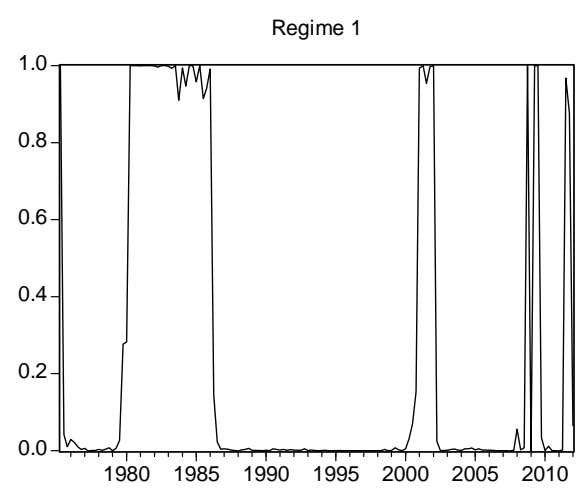

Figure 2f Smoothed Probabilities for Model G (EFP,TED,SRET,HRET)

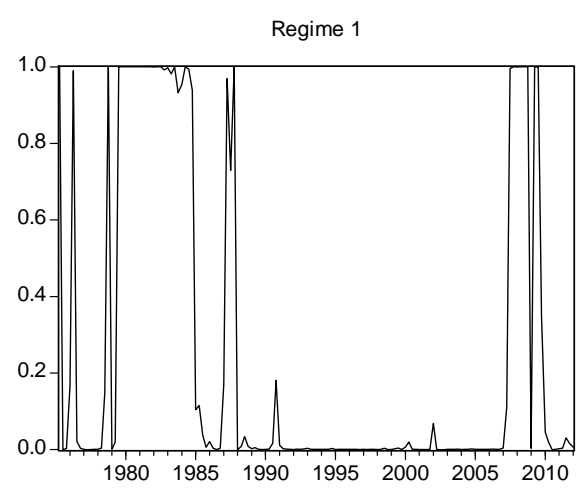

Figure 2g Smoothed Probabilities for Model H (SPR,TED,SRET,HRET)

Regime 1

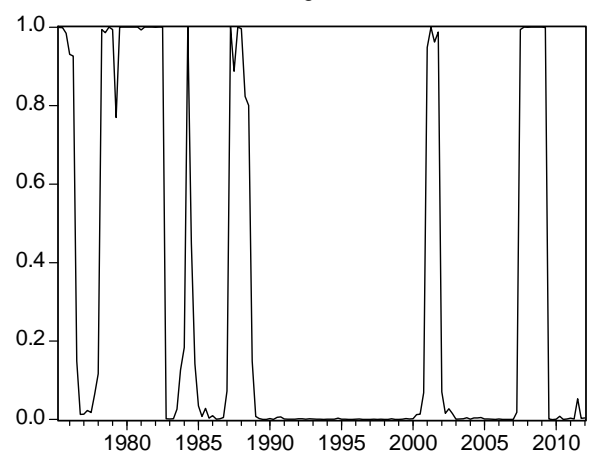


Figure 3a Simulation-Based Out-of-Sample Forecasts of Stock Returns with 80-Percent Confidence Interval (CI) from 2006Q1-2006Q4 Based on Information Available at 2005Q4

Model A: Single-Regime (FFR,SPR,TED,EFP,GDP,SRET,HRET); Model B: Two-Regime (FFR,GDP,SRET,HRET); Model C: Two-Regime (FFR,SPR,SRET,HRET); Model D: Two-Regime (FFR,EFP,SRET,HRET); Model E: Two-Regime (FFR,TED,SRET,HRET); Model F:

Two-Regime (EFP,SPR,SRET,HRET); Model G: Two-Regime (EFP,TED,SRET,HRET); Model H: Two-Regime (SPR,TED,SRET,HRET); Model SUB: Single-regime, Uni-variate AR(1) Benchmark
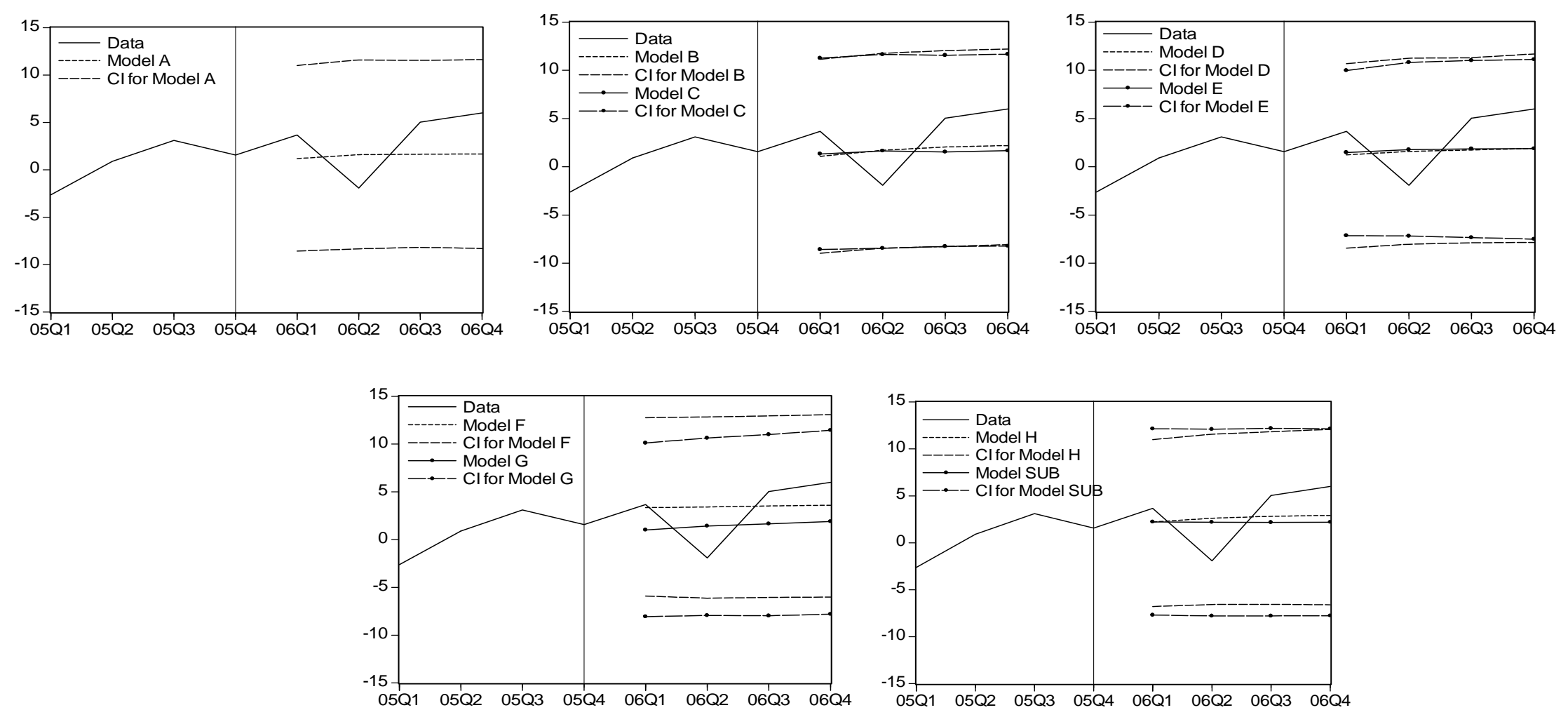
Figure 3b Simulation-Based Out-of-Sample Forecasts of Stock Returns with 80-Percent Confidence Interval (CI) from 2007Q1-2007Q4 Based on Information Available at 2006Q4

Model A: Single-Regime (FFR,SPR,TED,EFP,GDP,SRET,HRET); Model B: Two-Regime (FFR,GDP,SRET,HRET); Model C: Two-Regime (FFR,SPR,SRET,HRET); Model D: Two-Regime (FFR,EFP,SRET,HRET); Model E: Two-Regime (FFR,TED,SRET,HRET); Model F: Two-Regime (EFP,SPR,SRET,HRET); Model G: Two-Regime (EFP,TED,SRET,HRET); Model H: Two-Regime (SPR,TED,SRET,HRET); Model SUB: Single-regime, Uni-variate AR(1) Benchmark
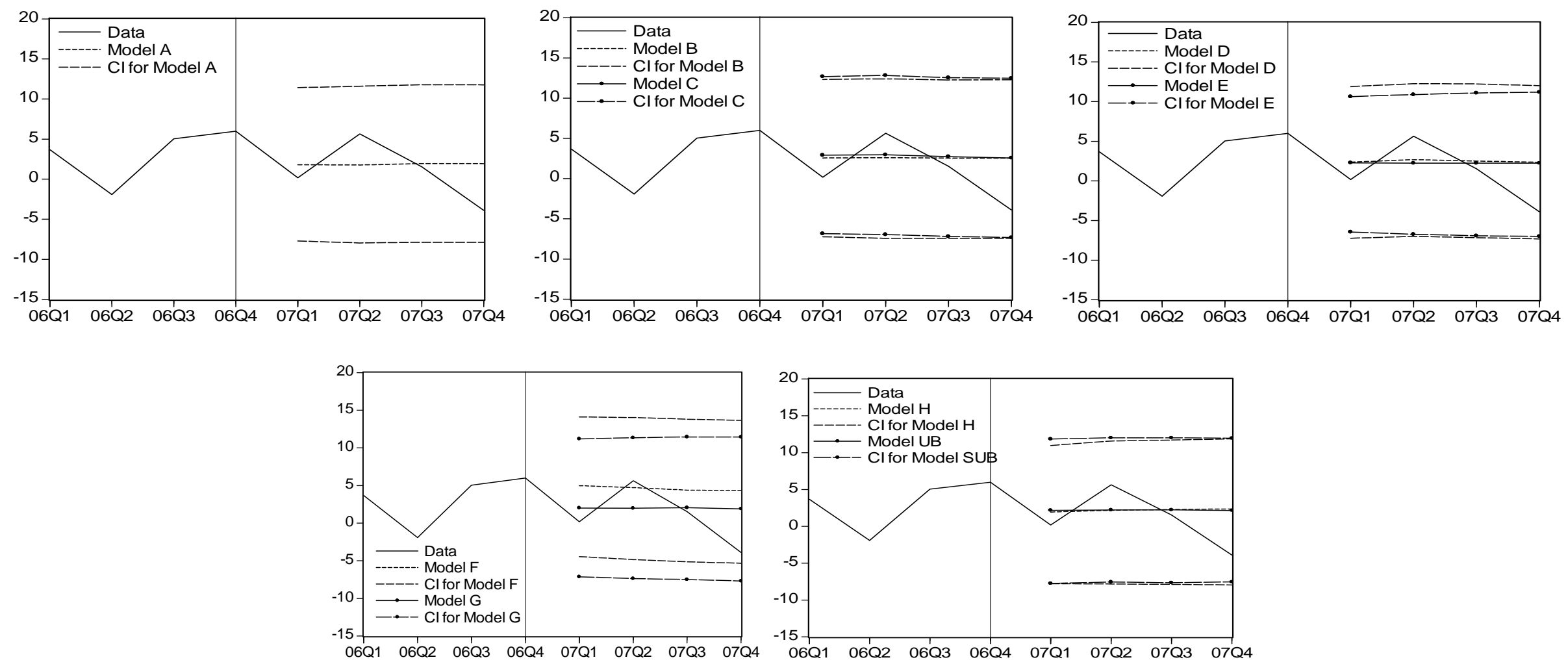
Figure 3c Simulation-Based Out-of-Sample Forecasts of Stock Returns with 80-Percent Confidence Interval (CI) from 2008Q1-2008Q4 Based on Information Available at 2007Q4

Model A: Single-Regime (FFR,SPR,TED,EFP,GDP,SRET,HRET); Model B: Two-Regime (FFR,GDP,SRET,HRET); Model C: Two-Regime (FFR,SPR,SRET,HRET); Model D: Two-Regime (FFR,EFP,SRET,HRET); Model E: Two-Regime (FFR,TED,SRET,HRET); Model F:

Two-Regime (EFP,SPR,SRET,HRET); Model G: Two-Regime (EFP,TED,SRET,HRET); Model H: Two-Regime (SPR,TED,SRET,HRET);

Model SUB: Single-regime, Uni-variate AR(1) Benchmark
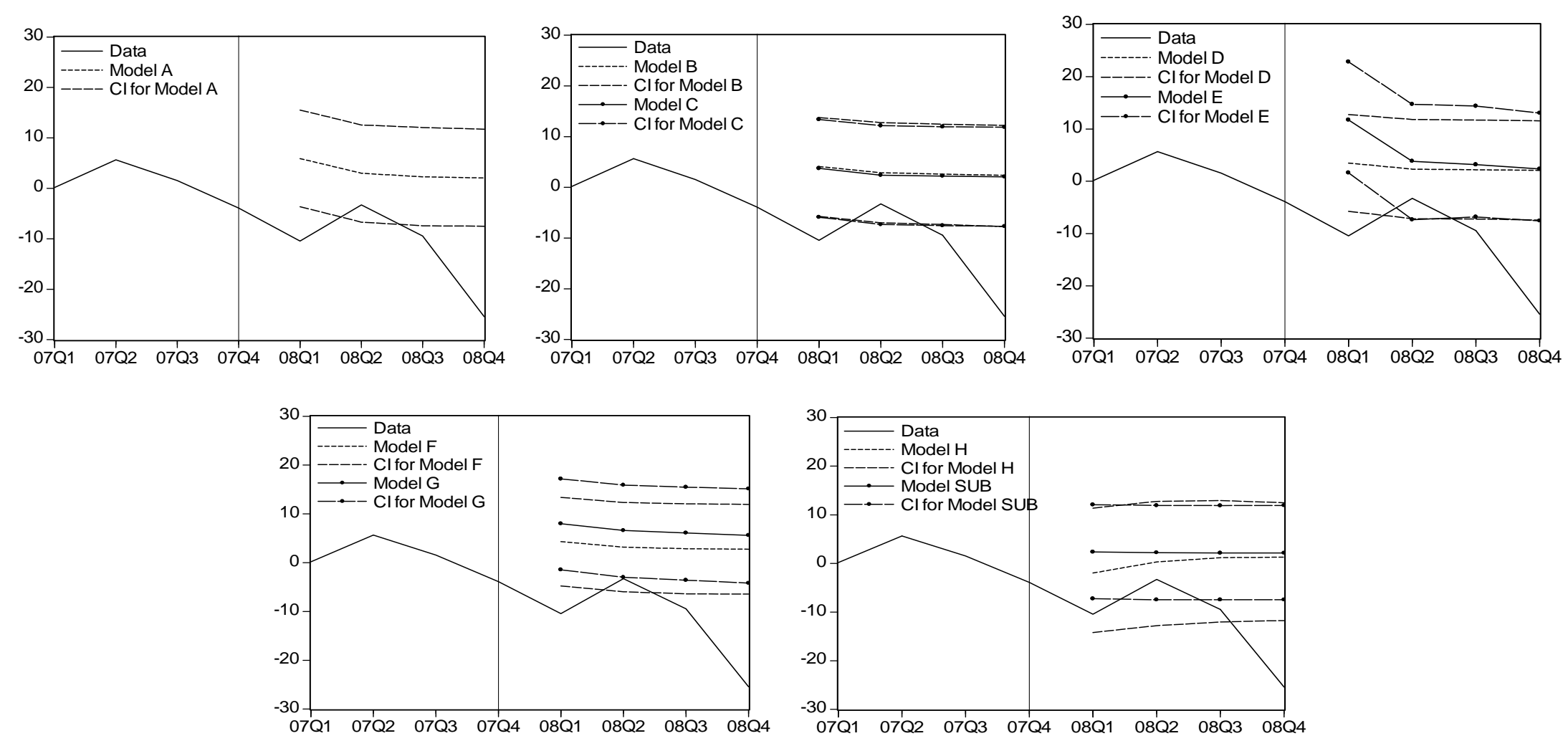
Figure 3d Simulation-Based Out-of-Sample Forecasts of Stock Returns with 80-Percent Confidence Interval (CI) from 2009Q1-2009Q4 Based on Information Available at 2008Q4

Model A: Single-Regime (FFR,SPR,TED,EFP,GDP,SRET,HRET); Model B: Two-Regime (FFR,GDP,SRET,HRET); Model C: Two-Regime (FFR,SPR,SRET,HRET); Model D: Two-Regime (FFR,EFP,SRET,HRET); Model E: Two-Regime (FFR,TED,SRET,HRET); Model F:

Two-Regime (EFP,SPR,SRET,HRET); Model G: Two-Regime (EFP,TED,SRET,HRET); Model H: Two-Regime (SPR,TED,SRET,HRET);

Model SUB: Single-regime, Uni-variate AR(1) Benchmark
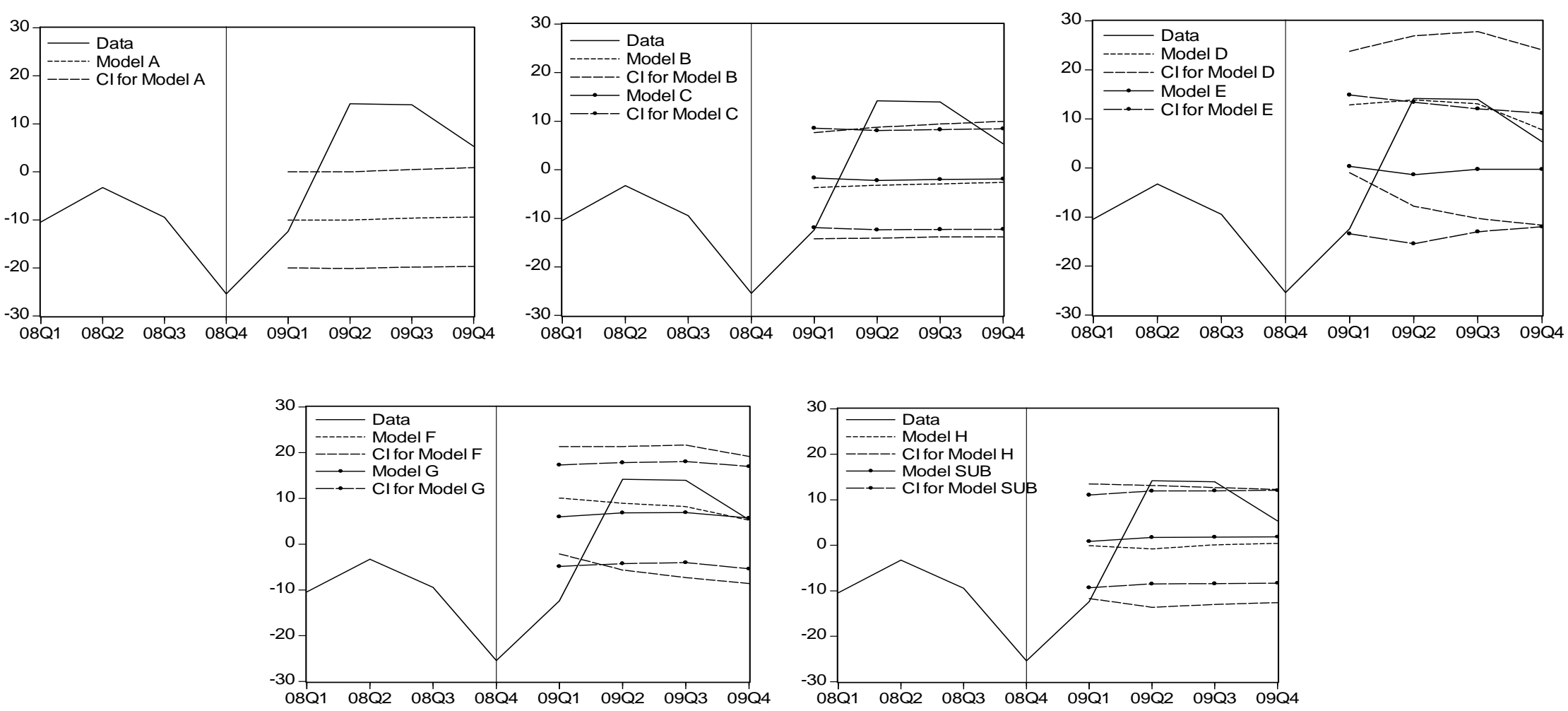
Figure 3e Simulation-Based Out-of-Sample Forecasts of Stock Returns with 80-Percent Confidence Interval (CI) from 2010Q1-2010Q4 Based on Information Available at 2009Q4

Model A: Single-Regime (FFR,SPR,TED,EFP,GDP,SRET,HRET); Model B: Two-Regime (FFR,GDP,SRET,HRET); Model C: Two-Regime (FFR,SPR,SRET,HRET); Model D: Two-Regime (FFR,EFP,SRET,HRET); Model E: Two-Regime (FFR,TED,SRET,HRET); Model F:

Two-Regime (EFP,SPR,SRET,HRET); Model G: Two-Regime (EFP,TED,SRET,HRET); Model H: Two-Regime (SPR,TED,SRET,HRET); Model SUB: Single-regime, Uni-variate AR(1) Benchmark
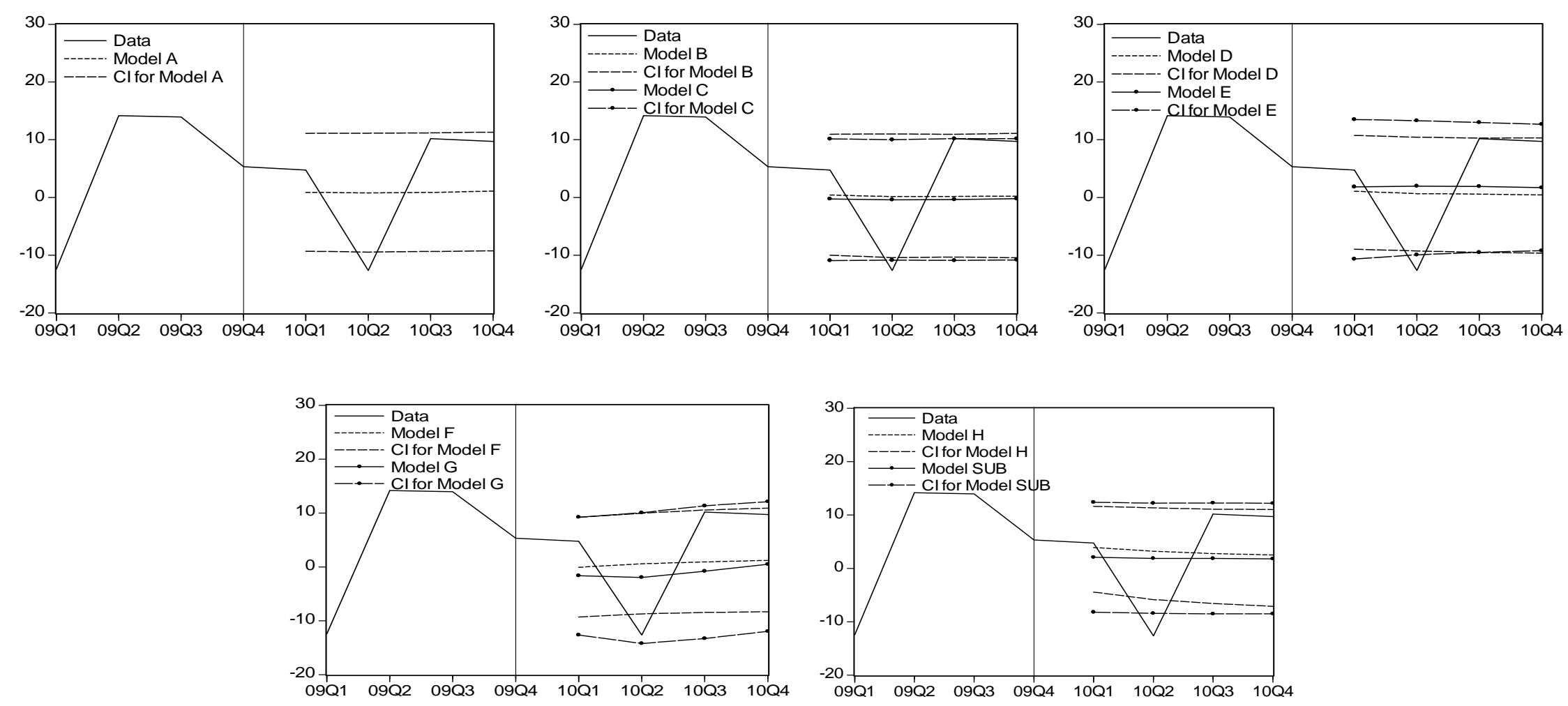
Figure 3f Simulation-Based Out-of-Sample Forecasts of Stock Returns with 80-Percent Confidence Interval (CI) from 2011Q1-2011Q4 Based on Information Available at 2010Q4

Model A: Single-Regime (FFR,SPR,TED,EFP,GDP,SRET,HRET); Model B: Two-Regime (FFR,GDP,SRET,HRET); Model C: Two-Regime (FFR,SPR,SRET,HRET); Model D: Two-Regime (FFR,EFP,SRET,HRET); Model E: Two-Regime (FFR,TED,SRET,HRET); Model F:

Two-Regime (EFP,SPR,SRET,HRET); Model G: Two-Regime (EFP,TED,SRET,HRET); Model H: Two-Regime (SPR,TED,SRET,HRET); Model SUB: Single-regime, Uni-variate AR(1) Benchmark
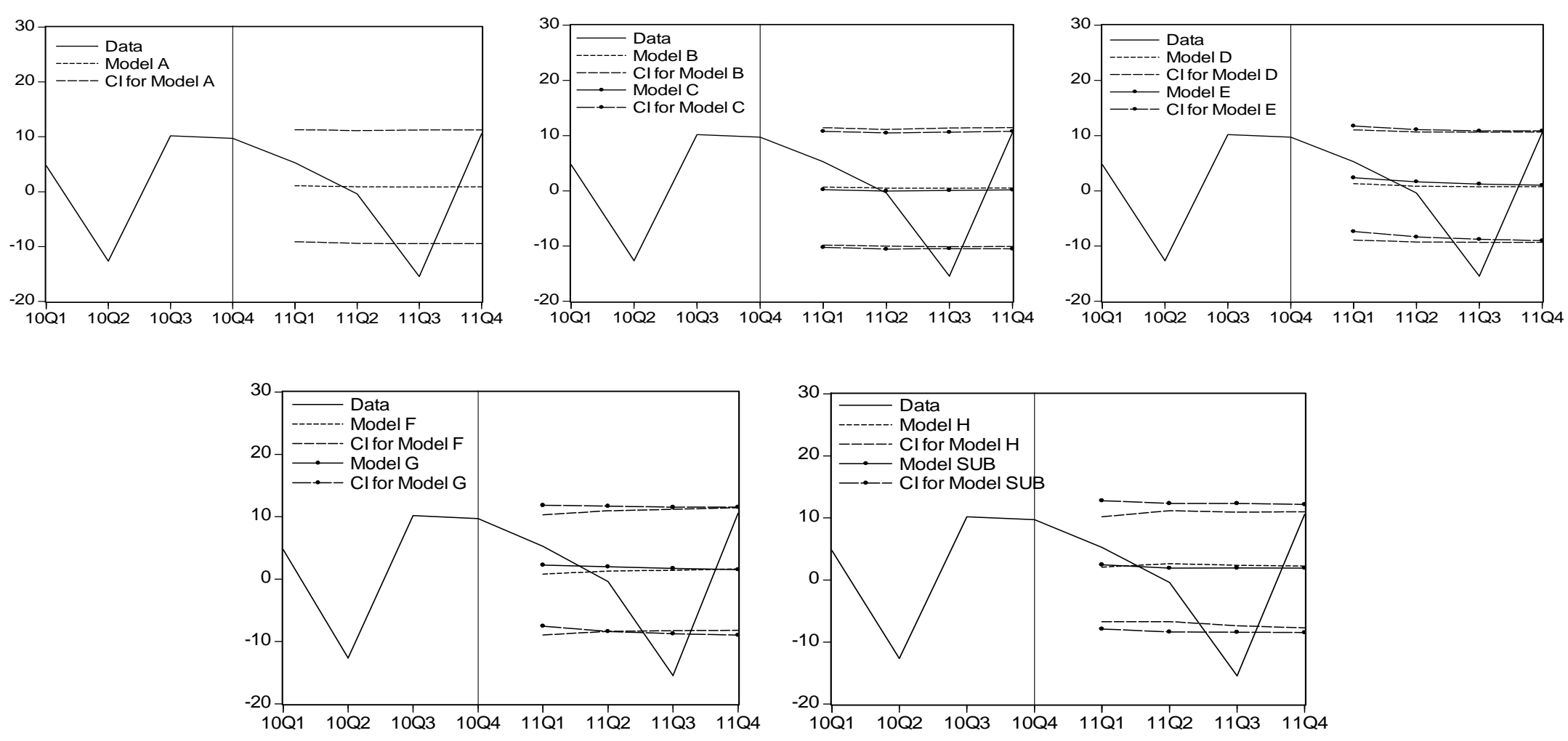
Figure 4a Simulation-Based Out-of-Sample Forecasts of Housing Returns with 80-Percent Confidence Interval (CI) from 2006Q1-2006Q4 Based on Information Available at 2005Q4

Model A: Single-Regime (FFR,SPR,TED,EFP,GDP,SRET,HRET); Model B: Two-Regime (FFR,GDP,SRET,HRET); Model C: Two-Regime (FFR,SPR,SRET,HRET); Model D: Two-Regime (FFR,EFP,SRET,HRET); Model E: Two-Regime (FFR,TED,SRET,HRET); Model F:

Two-Regime (EFP,SPR,SRET,HRET); Model G: Two-Regime (EFP,TED,SRET,HRET); Model H: Two-Regime (SPR,TED,SRET,HRET); Model SUB: Single-regime, Uni-variate AR(1) Benchmark
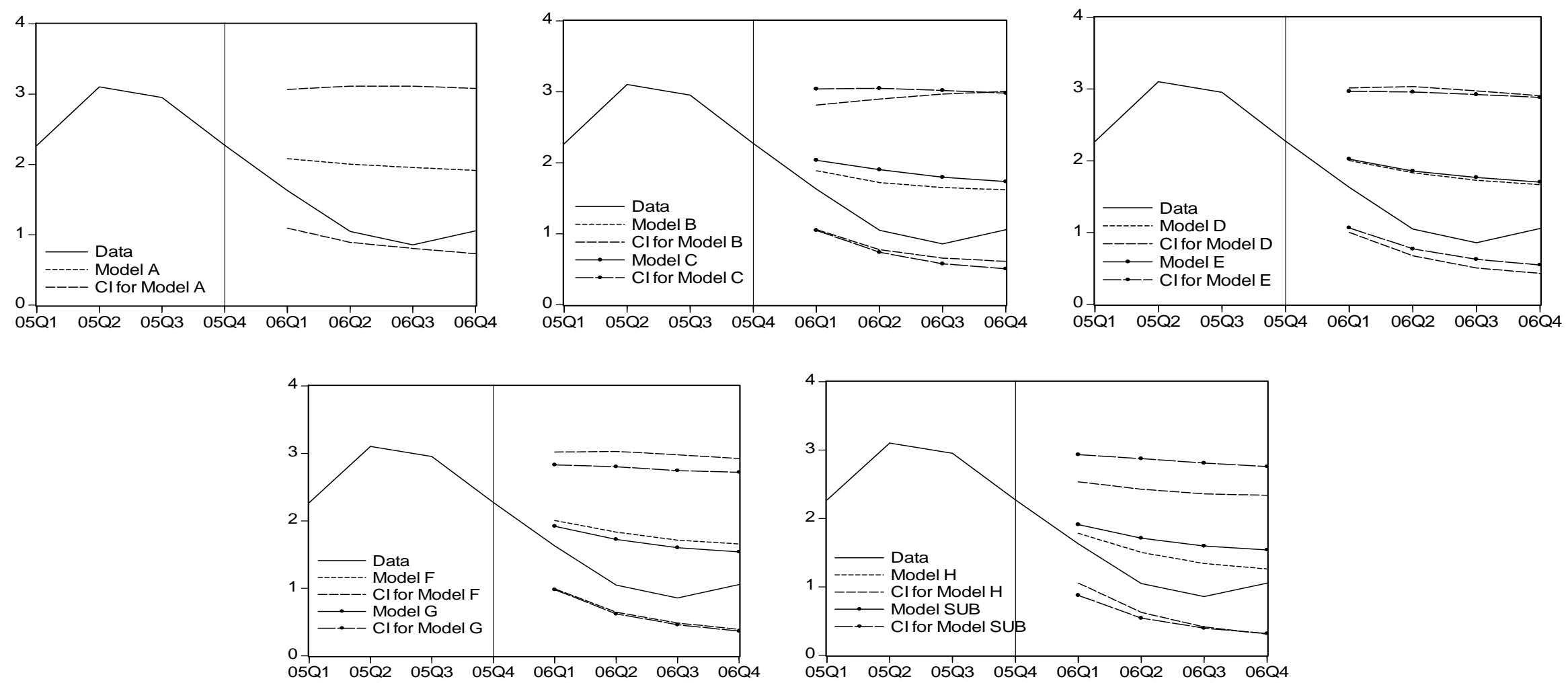
Figure 4b Simulation-Based Out-of-Sample Forecasts of Housing Returns with 80-Percent Confidence Interval (CI) from 2007Q1-2007Q4 Based on Information Available at 2006Q4

Model A: Single-Regime (FFR,SPR,TED,EFP,GDP,SRET,HRET); Model B: Two-Regime (FFR,GDP,SRET,HRET); Model C: Two-Regime (FFR,SPR,SRET,HRET); Model D: Two-Regime (FFR,EFP,SRET,HRET); Model E: Two-Regime (FFR,TED,SRET,HRET); Model F:

Two-Regime (EFP,SPR,SRET,HRET); Model G: Two-Regime (EFP,TED,SRET,HRET); Model H: Two-Regime (SPR,TED,SRET,HRET);

Model SUB: Single-regime, Uni-variate AR(1) Benchmark
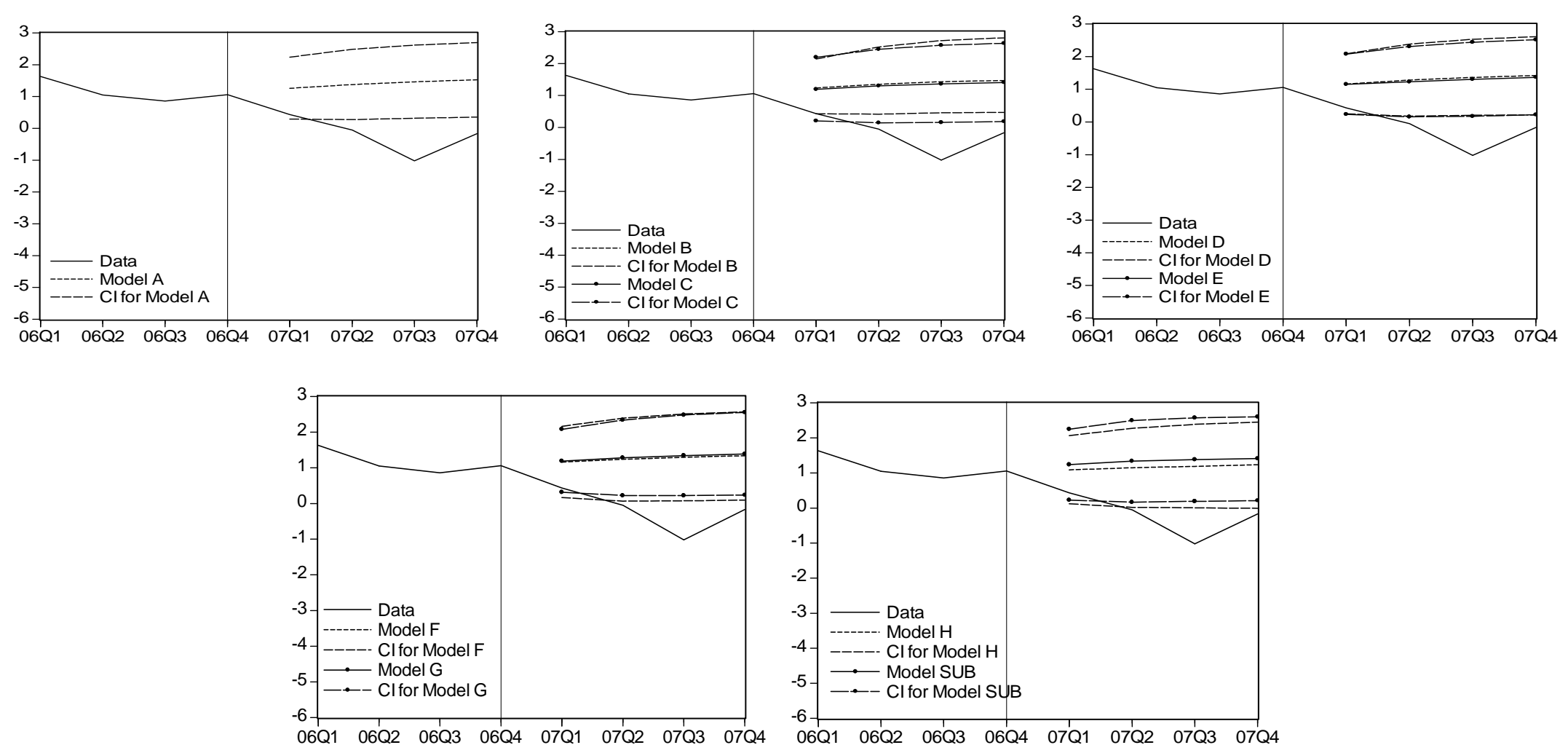
Figure 4c Simulation-Based Out-of-Sample Forecasts of Housing Returns with 80-Percent Confidence Interval (CI) from 2008Q1-2008Q4 Based on Information Available at 2007Q4

Model A: Single-Regime (FFR,SPR,TED,EFP,GDP,SRET,HRET); Model B: Two-Regime (FFR,GDP,SRET,HRET); Model C: Two-Regime (FFR,SPR,SRET,HRET); Model D: Two-Regime (FFR,EFP,SRET,HRET); Model E: Two-Regime (FFR,TED,SRET,HRET); Model F:

Two-Regime (EFP,SPR,SRET,HRET); Model G: Two-Regime (EFP,TED,SRET,HRET); Model H: Two-Regime (SPR,TED,SRET,HRET); Model SUB: Single-regime, Uni-variate AR(1) Benchmark
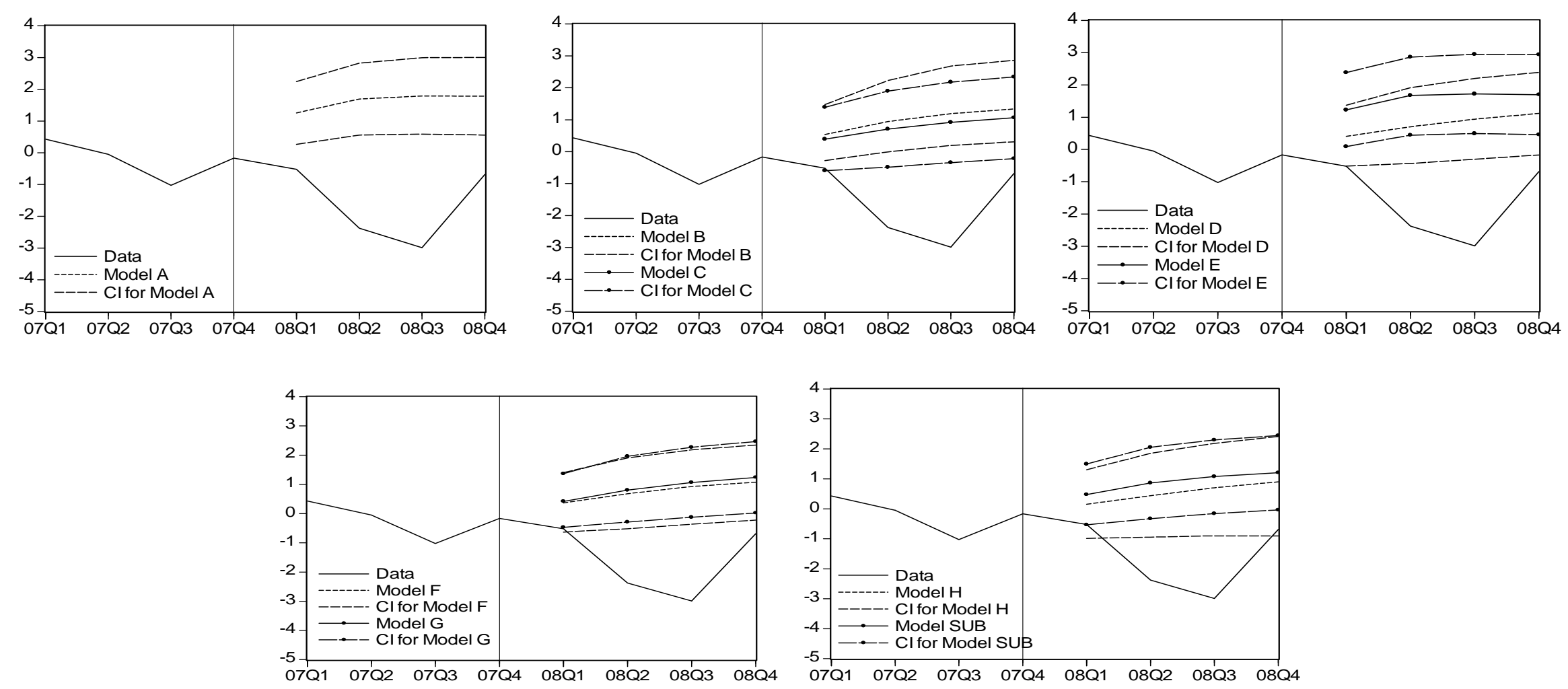
Figure 4d Simulation-Based Out-of-Sample Forecasts of Housing Returns with 80-Percent Confidence Interval (CI) from 2009Q1-2009Q4 Based on Information Available at 2008Q4

Model A: Single-Regime (FFR,SPR,TED,EFP,GDP,SRET,HRET); Model B: Two-Regime (FFR,GDP,SRET,HRET); Model C: Two-Regime (FFR,SPR,SRET,HRET); Model D: Two-Regime (FFR,EFP,SRET,HRET); Model E: Two-Regime (FFR,TED,SRET,HRET); Model F:

Two-Regime (EFP,SPR,SRET,HRET); Model G: Two-Regime (EFP,TED,SRET,HRET); Model H: Two-Regime (SPR,TED,SRET,HRET); Model SUB: Single-regime, Uni-variate AR(1) Benchmark
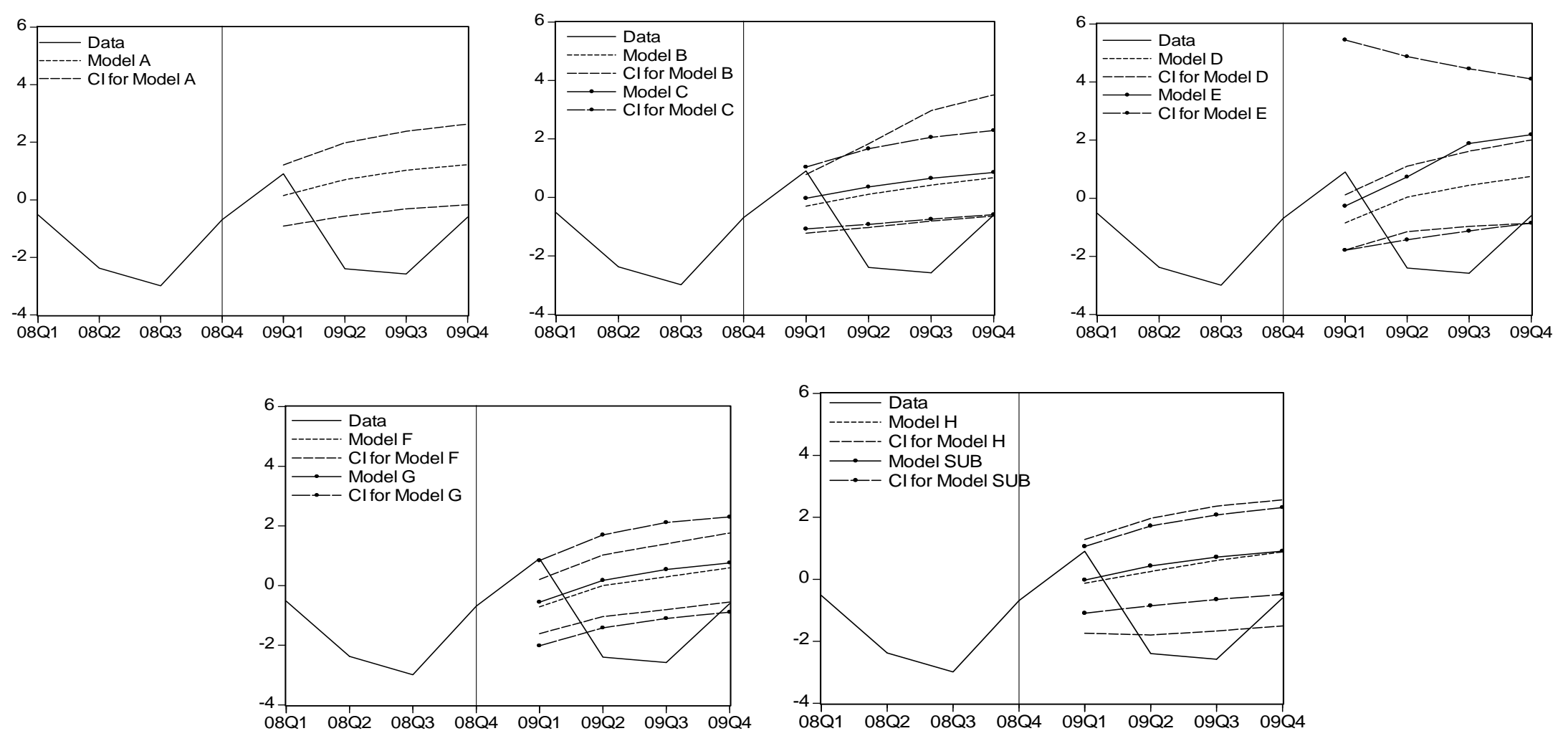
Figure 4e Simulation-Based Out-of-Sample Forecasts of Housing Returns with 80-Percent Confidence Interval (CI) from 2010Q1-2010Q4 Based on Information Available at 2009Q4

Model A: Single-Regime (FFR,SPR,TED,EFP,GDP,SRET,HRET); Model B: Two-Regime (FFR,GDP,SRET,HRET); Model C: Two-Regime (FFR,SPR,SRET,HRET); Model D: Two-Regime (FFR,EFP,SRET,HRET); Model E: Two-Regime (FFR,TED,SRET,HRET); Model F:

Two-Regime (EFP,SPR,SRET,HRET); Model G: Two-Regime (EFP,TED,SRET,HRET); Model H: Two-Regime (SPR,TED,SRET,HRET); Model SUB: Single-regime, Uni-variate AR(1) Benchmark
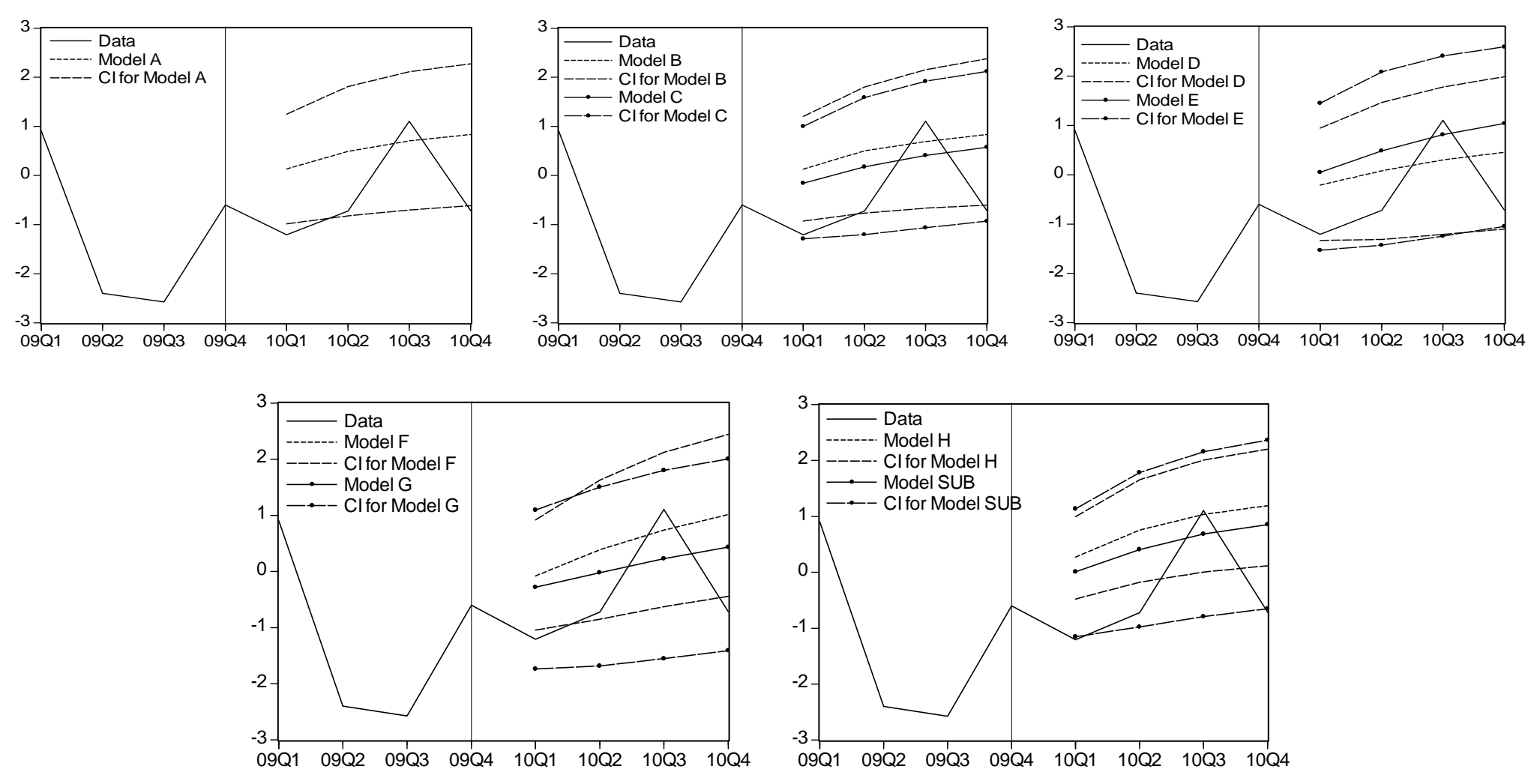
Figure 4f Simulation-Based Out-of-Sample Forecasts of Housing Returns with 80-Percent Confidence Interval (CI) from 2011Q1-2011Q4 Based on Information Available at 2010Q4

Model A: Single-Regime (FFR,SPR,TED,EFP,GDP,SRET,HRET); Model B: Two-Regime (FFR,GDP,SRET,HRET); Model C: Two-Regime (FFR,SPR,SRET,HRET); Model D: Two-Regime (FFR,EFP,SRET,HRET); Model E: Two-Regime (FFR,TED,SRET,HRET); Model F:

Two-Regime (EFP,SPR,SRET,HRET); Model G: Two-Regime (EFP,TED,SRET,HRET); Model H: Two-Regime (SPR,TED,SRET,HRET);

Model SUB: Single-regime, Uni-variate AR(1) Benchmark
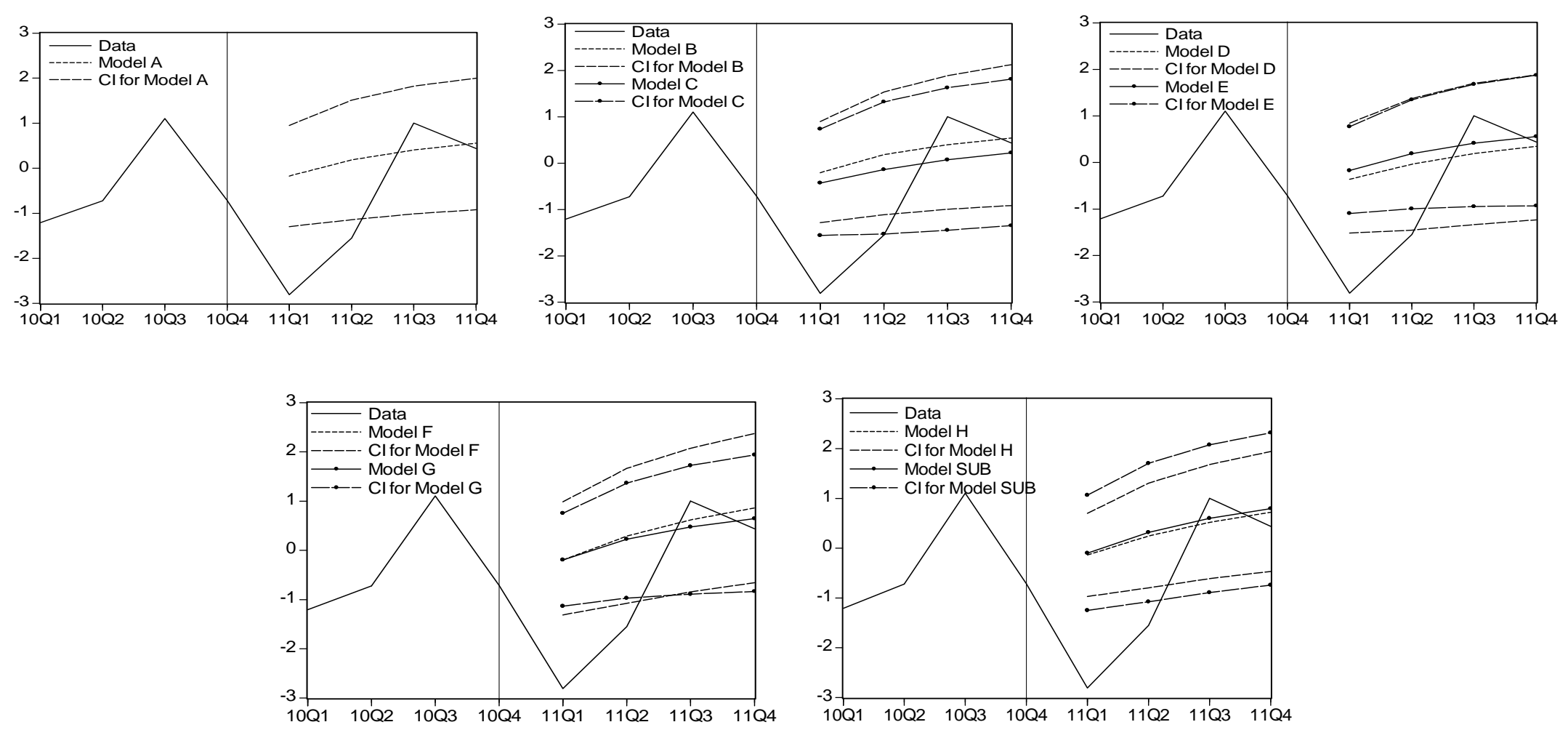


\section{Losing track of the asset markets: the case of housing and stock (April 2015) APPENDIX}

We are grateful to all suggestions and feedback. In response, we provide more details and some supplementary results in this appendix, which has different parts.

Appendix A provides the details of the estimation results.

Appendix B provides the non-stationarity test for the regime-switching models.

Appendix C provides the results of the Diebold-Mariano tests.

Appendix D provides the LM test results of the residuals from different models.

Appendix E discusses the suggestion of using Case-Shiller index.

Appendix F shows that the consideration of mortgage rate may not be necessary once our variables, such as FFR, and others are included.

Appendix G shows all the graphs of smoothed probabilities for different regimes in different models.

Appendix H provides the detailed results of the Mariano-Preve test.

Appendix I provides a simple review of the literature which chooses a similar boom-bust date as we do.

Appendix J provides the detailed results when the in-sample is chosen to be 1975 to 2006.

Appendix K provides the detailed results when the in-sample is chosen to be 1975 to 2007. 
Appendix A: Details of the Estimation Results

Table A-1 The Estimation Results for (FFR,SPR,TED,EFP,GDP,SRET,HRET) (1975Q2-2012Q1)

\begin{tabular}{|c|c|c|}
\hline Parameter & Estimate & S.E. \\
\hline$C_{1}$ & -0.0632 & 1.1167 \\
\hline$\phi_{1}^{(11)}$ & $0.9521^{* *}$ & 0.4351 \\
\hline$\phi_{1}^{(12)}$ & -0.0185 & 1.2775 \\
\hline$\phi_{1}^{(13)}$ & 0.0326 & 0.2616 \\
\hline$\phi_{1}^{(14)}$ & -0.0473 & 4.0180 \\
\hline$\phi_{1}^{(15)}$ & 0.1783 & 1.4650 \\
\hline$\phi_{1}^{(16)}$ & 0.0150 & 0.0187 \\
\hline$\phi_{1}^{(17)}$ & $0.1820 * *$ & 0.0779 \\
\hline$\sigma_{1}^{2}$ & $0.7801^{* * *}$ & 0.2694 \\
\hline$c_{2}$ & 0.1291 & 0.8810 \\
\hline$\phi_{1}^{(21)}$ & 0.0324 & 0.2168 \\
\hline$\phi_{1}^{(22)}$ & 0.8321 & 0.6291 \\
\hline$\phi_{1}^{(23)}$ & $-0.2874 *$ & 0.1704 \\
\hline$\phi_{1}^{(24)}$ & 0.3409 & 2.2504 \\
\hline$\phi_{1}^{(25)}$ & -0.0457 & 0.7291 \\
\hline$\phi_{1}^{(26)}$ & -0.0127 & 0.0119 \\
\hline$\phi_{1}^{(27)}$ & -0.1051 & 0.0692 \\
\hline$\sigma_{2}^{2}$ & $0.3765^{* * *}$ & 0.1049 \\
\hline$c_{3}$ & 0.1894 & 0.1954 \\
\hline$\phi_{1}^{(31)}$ & 0.0422 & 0.1003 \\
\hline$\phi_{1}^{(32)}$ & -0.0436 & 0.2949 \\
\hline$\phi_{1}^{(33)}$ & $0.6628 * * *$ & 0.1302 \\
\hline$\phi_{1}^{(34)}$ & -0.0316 & 0.7140 \\
\hline$\phi_{1}^{(35)}$ & 0.0018 & 0.5230 \\
\hline$\phi_{1}^{(36)}$ & -0.0055 & 0.0078 \\
\hline$\phi_{1}^{(37)}$ & -0.0264 & 0.0721 \\
\hline$\sigma_{3}^{2}$ & $0.1421^{* * *}$ & 0.0459 \\
\hline
\end{tabular}


Table A-1 The Estimation Results for (FFR,SPR,TED,EFP,GDP,SRET,HRET) (Continued)

\begin{tabular}{|c|c|c|}
\hline Parameter & Estimate & S.E. \\
\hline$C_{4}$ & $0.2517 * *$ & 0.1212 \\
\hline$\phi_{1}^{(41)}$ & 0.0046 & 0.0115 \\
\hline$\phi_{1}^{(42)}$ & 0.0094 & 0.0452 \\
\hline$\phi_{1}^{(43)}$ & $0.1281^{*}$ & 0.0748 \\
\hline$\phi_{1}^{(44)}$ & $0.6960 * * *$ & 0.0871 \\
\hline$\phi_{1}^{(45)}$ & -0.0224 & 0.0586 \\
\hline$\phi_{1}^{(46)}$ & $-0.0091 * *$ & 0.0038 \\
\hline$\phi_{1}^{(47)}$ & -0.0265 & 0.0339 \\
\hline$\sigma_{4}^{2}$ & $0.0384 * * *$ & 0.0117 \\
\hline$c_{5}$ & 0.0399 & 0.5192 \\
\hline$\phi_{1}^{(51)}$ & 0.0633 & 0.1028 \\
\hline$\phi_{1}^{(52)}$ & 0.1251 & 0.2307 \\
\hline$\phi_{1}^{(53)}$ & $-0.4813 * * *$ & 0.1595 \\
\hline$\phi_{1}^{(54)}$ & 0.1390 & 0.7788 \\
\hline$\phi_{1}^{(55)}$ & 0.2188 & 0.3100 \\
\hline$\phi_{1}^{(56)}$ & $0.0154^{*}$ & 0.0085 \\
\hline$\phi_{1}^{(57)}$ & $0.1457 * * *$ & 0.0570 \\
\hline$\sigma_{5}^{2}$ & $0.4258 * * *$ & 0.0777 \\
\hline$c_{6}$ & -1.9181 & 3.6237 \\
\hline$\phi_{1}^{(61)}$ & 0.1758 & 0.9594 \\
\hline$\phi_{1}^{(62)}$ & -0.1731 & 1.6097 \\
\hline$\phi_{1}^{(63)}$ & -2.1358 & 4.0102 \\
\hline$\phi_{1}^{(64)}$ & 3.3105 & 3.0779 \\
\hline$\phi_{1}^{(65)}$ & 0.9468 & 0.8978 \\
\hline$\phi_{1}^{(66)}$ & 0.0273 & 0.5652 \\
\hline$\phi_{1}^{(67)}$ & 0.4451 & 1.6590 \\
\hline$\sigma_{6}^{2}$ & $64.6998 * * *$ & 9.2548 \\
\hline
\end{tabular}


Table A-1 The Estimation Results for (FFR,SPR,TED,EFP,GDP,SRET,HRET) (Continued)

\begin{tabular}{|c|c|c|}
\hline Parameter & Estimate & S.E. \\
\hline$C_{7}$ & 0.2744 & 0.4664 \\
\hline$\phi_{1}^{(71)}$ & 0.0383 & 0.0692 \\
\hline$\phi_{1}^{(72)}$ & 0.1743 & 0.1238 \\
\hline$\phi_{1}^{(73)}$ & 0.3168 & 0.2622 \\
\hline$\phi_{1}^{(74)}$ & -0.6332 & 0.4330 \\
\hline$\phi_{1}^{(75)}$ & 0.0581 & 0.3275 \\
\hline$\phi_{1}^{(76)}$ & -0.0029 & 0.0398 \\
\hline$\phi_{1}^{(77)}$ & $0.6504 * * *$ & 0.0740 \\
\hline$\sigma_{7}^{2}$ & $0.8264^{* * *}$ & 0.1203 \\
\hline$\gamma_{12}$ & $-0.7719 * * *$ & 0.0692 \\
\hline$\gamma_{13}$ & 0.3969 & 0.3766 \\
\hline$\gamma_{14}$ & -0.0579 & 0.4058 \\
\hline$\gamma_{15}$ & $0.2686^{* *}$ & 0.1194 \\
\hline$\gamma_{16}$ & -0.1187 & 0.2400 \\
\hline$\gamma_{17}$ & -0.0001 & 1.0282 \\
\hline$\gamma_{23}$ & -0.0852 & 0.3400 \\
\hline$\gamma_{24}$ & 0.1092 & 0.3428 \\
\hline$\gamma_{25}$ & -0.1549 & 0.1105 \\
\hline$\gamma_{26}$ & 0.0144 & 0.3184 \\
\hline$\gamma_{27}$ & -0.1646 & 0.8197 \\
\hline$\gamma_{34}$ & $0.4720 * * *$ & 0.1359 \\
\hline$\gamma_{35}$ & 0.0689 & 0.1646 \\
\hline$\gamma_{36}$ & $-0.2184 *$ & 0.1145 \\
\hline$\gamma_{37}$ & -0.1768 & 0.4194 \\
\hline$\gamma_{45}$ & $-0.1759 *$ & 0.1030 \\
\hline$\gamma_{46}$ & -0.1324 & 0.1342 \\
\hline$\gamma_{47}$ & -0.0302 & 0.1633 \\
\hline$\gamma_{56}$ & 0.0885 & 0.0967 \\
\hline$\gamma_{57}$ & -0.0037 & 0.5499 \\
\hline$\gamma_{67}$ & -0.0764 & 0.3802 \\
\hline $\ln L$ & \multicolumn{2}{|c|}{-813.4167} \\
\hline AIC & \multicolumn{2}{|c|}{12.1273} \\
\hline
\end{tabular}

Notes:*, **, and $* * *$ represent the significance at $10 \%, 5 \%$, and $1 \%$, respectively. 
Table A-2 The Estimation Results for (FFR,GDP,SRET,HRET) and (FFR,SPR,SRET, HRET) (1975Q2-2012Q1)

\begin{tabular}{|c|c|c|c|c|c|c|c|c|}
\hline \multirow[b]{3}{*}{ Parameer } & \multicolumn{4}{|c|}{ Model B (FFR,GDP,SRET,HRET) } & \multicolumn{4}{|c|}{ Model C (FFR,SPR,SRET,HRET) } \\
\hline & \multicolumn{2}{|c|}{ Regime 1} & \multicolumn{2}{|c|}{ Regime 2} & \multicolumn{2}{|c|}{ Regime 1} & \multicolumn{2}{|c|}{ Regime 2} \\
\hline & Estimate & S.E. & Estimate & S.E. & Estimate & S.E. & Estimate & S.E. \\
\hline$c_{1}$ & 0.6459 & 5.4864 & 0.6459 & 5.4864 & 3.3709 & 10.2522 & 3.3709 & 10.2522 \\
\hline$\alpha_{1}(2)$ & & & -0.7967 & 5.4917 & & & -3.7369 & 10.1684 \\
\hline$\phi_{1}^{(11)}$ & $0.8869 * * *$ & 0.3217 & $0.9470 * * *$ & 0.0184 & 0.6805 & 0.6246 & $1.0043^{* * *}$ & 0.0261 \\
\hline$\phi_{1}^{(12)}$ & 0.0653 & 0.3550 & $0.3165 * * *$ & 0.0716 & -0.4163 & 0.7737 & 0.0814 & 0.0503 \\
\hline$\phi_{1}^{(13)}$ & 0.0983 & 0.1246 & 0.0037 & 0.0051 & 0.0169 & 0.1570 & $0.0130 * * *$ & 0.0050 \\
\hline$\phi_{1}^{(14)}$ & 0.3751 & 0.7392 & $0.0998 * * *$ & 0.0306 & 0.4475 & 1.4950 & $0.1530 * * *$ & 0.0326 \\
\hline$\sigma_{1}^{2}$ & $3.7607 * * *$ & 1.1723 & $3.7607 * * *$ & 1.1723 & $2.9799 * * *$ & 0.9583 & $2.9799 * * *$ & 0.9583 \\
\hline$\lambda_{1}(2)$ & & & $0.2331^{* * *}$ & 0.0400 & & & $0.2608^{* * *}$ & 0.0448 \\
\hline$C_{2}$ & 2.4118 & 4.6724 & 2.4118 & 4.6724 & -0.1800 & 6.0660 & -0.1800 & 6.0660 \\
\hline$\alpha_{2}(2)$ & & & -2.1901 & 4.7050 & & & 0.5318 & 5.9436 \\
\hline$\phi_{1}^{(21)}$ & -0.1814 & 0.2976 & 0.0110 & 0.0179 & 0.0680 & 0.3528 & -0.0204 & 0.0306 \\
\hline$\phi_{1}^{(22)}$ & 0.0062 & 0.1014 & $0.4137 * * *$ & 0.0818 & $0.9184^{*}$ & 0.4715 & $0.8897 * * *$ & 0.0537 \\
\hline$\phi_{1}^{(23)}$ & 0.0000 & 0.1247 & $0.0164^{* * *}$ & 0.0059 & -0.0649 & 0.0827 & 0.0006 & 0.0060 \\
\hline$\phi_{1}^{(24)}$ & 0.1086 & 0.4495 & $0.1271^{* * *}$ & 0.0486 & -0.1693 & 1.0029 & $-0.0765^{* * *}$ & 0.0289 \\
\hline$\sigma_{2}^{2}$ & $1.3203^{* * *}$ & 0.4182 & $1.3203^{* * *}$ & 0.4182 & $0.9795 * * *$ & 0.2850 & $0.9795^{* * *}$ & 0.2850 \\
\hline$\lambda_{2}(2)$ & & & $0.4697 * * *$ & 0.0799 & & & $0.4455^{* * *}$ & 0.0753 \\
\hline$C_{3}$ & 20.1490 & 16.2770 & 20.1490 & 16.2770 & 3.4849 & 41.7203 & 3.4849 & 41.7203 \\
\hline$\alpha_{3}(2)$ & & & -19.9915 & 16.2654 & & & -1.0281 & 37.9679 \\
\hline$\phi_{1}^{(31)}$ & -1.1545 & 0.9472 & 0.1053 & 0.2595 & -0.2134 & 3.2006 & -0.1091 & 1.0265 \\
\hline$\phi_{1}^{(32)}$ & 0.4739 & 0.9429 & 0.8703 & 1.3462 & 1.0294 & 3.1672 & -0.5515 & 1.3659 \\
\hline$\phi_{1}^{(33)}$ & -0.1306 & 0.2787 & 0.0357 & 0.1091 & 0.0927 & 0.6556 & 0.0214 & 0.1497 \\
\hline$\phi_{1}^{(34)}$ & -1.8127 & 2.2297 & 0.4312 & 0.8750 & 0.5422 & 2.3035 & 0.5266 & 1.0895 \\
\hline$\sigma_{3}^{2}$ & $44.4884^{* * *}$ & 10.6552 & $44.4884^{* * *}$ & 10.6552 & $46.0042^{* * *}$ & 11.5218 & $46.0042^{* * *}$ & 11.5218 \\
\hline$\lambda_{3}(2)$ & & & 1.2331 & 0.1727 & & & 1.2204 & 0.1890 \\
\hline
\end{tabular}


Table A-2 The Estimation Results for (FFR,GDP,SRET,HRET) and (FFR,SPR,SRET, HRET) (Continued)

\begin{tabular}{|c|c|c|c|c|c|c|c|c|}
\hline \multirow[b]{3}{*}{ Parameter } & \multicolumn{4}{|c|}{ Model B (FFR,GDP,SRET,HRET) } & \multicolumn{4}{|c|}{ Model C (FFR,SPR,SRET,HRET) } \\
\hline & \multicolumn{2}{|c|}{ Regime 1} & \multicolumn{2}{|c|}{ Regime 2} & \multicolumn{2}{|c|}{ Regime 1} & \multicolumn{2}{|c|}{ Regime 2} \\
\hline & Estimate & S.E. & Estimate & S.E. & Estimate & S.E. & Estimate & S.E. \\
\hline$C_{4}$ & $4.2564 * * *$ & 1.5149 & $4.2564 * * *$ & 1.5149 & $3.5685^{*}$ & 2.0665 & $3.5685^{*}$ & 2.0665 \\
\hline$\alpha_{4}(2)$ & & & $-4.1994 * * *$ & 1.5257 & & & $-3.9907^{*}$ & 2.4110 \\
\hline$\phi_{1}^{(41)}$ & $-0.2212 * *$ & 0.0955 & 0.0244 & 0.0338 & -0.1615 & 0.1256 & 0.1056 & 0.0700 \\
\hline$\phi_{1}^{(42)}$ & -0.0384 & 0.1887 & 0.2706 & 0.1837 & -0.2963 & 0.1937 & 0.1653 & 0.1363 \\
\hline$\phi_{1}^{(43)}$ & -0.0262 & 0.0493 & -0.0104 & 0.0104 & 0.0245 & 0.0223 & -0.0129 & 0.0134 \\
\hline$\phi_{1}^{(44)}$ & 0.1801 & 0.2060 & $0.6453 * * *$ & 0.0819 & -0.1584 & 0.3645 & $0.6856^{* * *}$ & 0.0757 \\
\hline$\sigma_{4}^{2}$ & $0.9707^{* * *}$ & 0.3314 & $0.9707^{* * *}$ & 0.3314 & $0.3865 * * *$ & 0.1206 & $0.3865 * * *$ & 0.1206 \\
\hline$\lambda_{4}(2)$ & & & 0.8945 & 0.1664 & & & $1.4978 *$ & 0.2676 \\
\hline$\gamma_{12}$ & $0.3477 * *$ & 0.1377 & 0.1335 & 0.0919 & $-0.9124 * * *$ & 0.0444 & $-0.6622 * * *$ & 0.0598 \\
\hline$\gamma_{13}$ & $-0.5269 * *$ & 0.2073 & -0.0201 & 0.0918 & $-0.4137 * *$ & 0.2043 & 0.0333 & 0.4014 \\
\hline$\gamma_{14}$ & -0.0587 & 0.3935 & -0.0565 & 0.0820 & -0.0705 & 0.3126 & 0.0660 & 0.1422 \\
\hline$\gamma_{23}$ & -0.2109 & 0.2778 & 0.1670 & 0.1126 & 0.2199 & 0.2753 & 0.0144 & 0.5934 \\
\hline$\gamma_{24}$ & -0.0523 & 0.1523 & -0.0783 & 0.0988 & -0.0476 & 0.3155 & -0.2153 & 0.1431 \\
\hline$\gamma_{34}$ & -0.2987 & 0.2067 & -0.1145 & 0.0986 & -0.1990 & 0.2056 & -0.0878 & 0.1497 \\
\hline$P_{11}$ & \multicolumn{4}{|c|}{$0.9427 * * *(0.0372)$} & \multicolumn{4}{|c|}{$0.9505 * * *(0.1053)$} \\
\hline$P_{22}$ & \multicolumn{4}{|c|}{$0.9920 * * *(0.0081)$} & \multicolumn{4}{|c|}{$0.9914 * * *(0.0086)$} \\
\hline $\ln L$ & \multicolumn{4}{|c|}{-964.2407} & \multicolumn{4}{|c|}{-883.3381} \\
\hline AIC & \multicolumn{4}{|c|}{13.8681} & \multicolumn{4}{|c|}{12.7748} \\
\hline
\end{tabular}

Note:*, ${ }^{* *}$, and $* * *$ represent the significance at $10 \%, 5 \%$, and $1 \%$, respectively. Values next to thee estimates of transition probability $P_{i i}$ are standard deviations. 
Table A-3 The Estimation Results for (FFR,EFP,SRET,HRET) and (FFR, TED,SRET, HRET) (1975Q2-2012Q1)

\begin{tabular}{|c|c|c|c|c|c|c|c|c|}
\hline \multirow[b]{3}{*}{ Parameter } & \multicolumn{4}{|c|}{ Model D (FFR,EFP,SRET,HRET) } & \multicolumn{4}{|c|}{ Model E (FFR, TED,SRET, HRET) } \\
\hline & \multicolumn{2}{|c|}{ Regime 1} & \multicolumn{2}{|c|}{ Regime 2} & \multicolumn{2}{|c|}{ Regime 1} & \multicolumn{2}{|c|}{ Regime 2} \\
\hline & Estimate & S.E. & Estimate & S.E. & Estimate & S.E. & Estimate & S.E. \\
\hline$c_{1}$ & 0.4042 & 1.7058 & 0.4042 & 1.7058 & 0.5411 & 0.6876 & 0.5411 & 0.6876 \\
\hline$\alpha_{1}(2)$ & & & -0.2192 & 1.7147 & & & -0.5605 & 0.6979 \\
\hline$\phi_{1}^{(11)}$ & $1.0196 * * *$ & 0.1052 & $0.9702 * * *$ & 0.0158 & $1.0290 * * *$ & 0.0869 & $0.9624^{* * *}$ & 0.0177 \\
\hline$\phi_{1}^{(12)}$ & -0.8414 & 1.3212 & $-0.1803^{* *}$ & 0.0836 & -0.7432 & 0.5670 & 0.1114 & 0.1272 \\
\hline$\phi_{1}^{(13)}$ & $0.0932 *$ & 0.0476 & 0.0022 & 0.0042 & 0.0419 & 0.0327 & 0.0051 & 0.0061 \\
\hline$\phi_{1}^{(14)}$ & 0.3035 & 0.4972 & $0.1415^{* * *}$ & 0.0304 & 0.3069 & 0.2198 & $0.0883 * * *$ & \\
\hline$\sigma_{1}^{2}$ & $3.2435 * * *$ & 1.0880 & $3.2435 * * *$ & 1.0880 & $2.3484 * * *$ & 0.8160 & $2.3484^{* * *}$ & 0.8160 \\
\hline$\lambda_{1}(2)$ & & & $0.2274^{* * *}$ & 0.0405 & & & $0.2827^{* * *}$ & 0.0542 \\
\hline$c_{2}$ & $0.8576 * * *$ & 0.2434 & $0.8576 * * *$ & 0.2434 & $0.7896 * * *$ & 0.2943 & $0.7896 * * *$ & 0.2943 \\
\hline$\alpha_{2}(2)$ & & & $-0.6579 * * *$ & 0.2488 & & & $-0.7080^{* *}$ & 0.2939 \\
\hline$\phi_{1}^{(21)}$ & 0.0043 & 0.0180 & 0.0080 & 0.0050 & 0.0633 & 0.0386 & $0.0434 * * *$ & 0.0058 \\
\hline$\phi_{1}^{(22)}$ & $0.6681^{* * *}$ & 0.1815 & $0.7648 * * *$ & 0.0449 & 0.3456 & 0.2357 & $0.4285 * * *$ & 0.0386 \\
\hline$\phi_{1}^{(23)}$ & -0.0114 & 0.0074 & $-0.0087 * * *$ & 0.0019 & -0.0180 & 0.0130 & -0.0031 & 0.0021 \\
\hline$\phi_{1}^{(24)}$ & $-0.2027 * * *$ & 0.0674 & -0.0054 & 0.0116 & -0.0403 & 0.0888 & 0.0033 & 0.0108 \\
\hline$\sigma_{2}^{2}$ & $0.0889 * * *$ & 0.0209 & $0.0889 * * *$ & 0.0209 & $0.3276^{* * *}$ & 0.0840 & $0.3276^{* * *}$ & 0.0840 \\
\hline$\lambda_{2}(2)$ & & & $0.4015 * * *$ & 0.0645 & & & $0.2549 * * *$ & 0.0370 \\
\hline$c_{3}$ & $-16.2521^{* *}$ & 8.2731 & $-16.2521^{* *}$ & 8.2731 & -4.1122 & 4.5255 & -4.1122 & 4.5255 \\
\hline$\alpha_{3}(2)$ & & & $15.7362 *$ & 8.7014 & & & 5.6720 & 4.9842 \\
\hline$\phi_{1}^{(31)}$ & -0.1352 & 0.6770 & 0.1844 & 0.2990 & -0.5253 & 0.6682 & 0.3363 & 0.4593 \\
\hline$\phi_{1}^{(32)}$ & 8.3846 & 6.6549 & 1.6192 & 2.2110 & 3.4809 & 4.1813 & -0.3749 & 2.9023 \\
\hline$\phi_{1}^{(33)}$ & -0.1241 & 0.2910 & 0.0436 & 0.1225 & -0.0370 & 0.3258 & 0.0337 & 0.2082 \\
\hline$\phi_{1}^{(34)}$ & $3.7744^{*}$ & 2.2008 & 0.2071 & 0.6802 & $3.0437 * *$ & 1.4118 & -0.5540 & 0.6514 \\
\hline$\sigma_{3}^{2}$ & $84.2574 * * *$ & 21.5064 & $84.2574 * * *$ & 21.5064 & $87.2822^{* * *}$ & 21.3439 & $87.2822^{* * *}$ & 21.3439 \\
\hline$\lambda_{3}(2)$ & & & 0.8236 & 0.1316 & & & $0.7869 *$ & 0.1130 \\
\hline
\end{tabular}


Table A-3 The Estimation Results for (FFR,EFP,SRET,HRET) and (FFR, TED,SRET, HRET) (Continued)

\begin{tabular}{|c|c|c|c|c|c|c|c|c|}
\hline \multirow[b]{3}{*}{ Paramete } & \multicolumn{4}{|c|}{ Model D (FFR,EFP,SRET,HRET) } & \multicolumn{4}{|c|}{ Model E (FFR, TED,SRET, HRET) } \\
\hline & \multicolumn{2}{|c|}{ Regime 1} & \multicolumn{2}{|c|}{ Regime 2} & \multicolumn{2}{|c|}{ Regime 1} & \multicolumn{2}{|c|}{ Regime 2} \\
\hline & Estimate & S.E. & Estimate & S.E. & Estimate & S.E. & Estimate & S.E. \\
\hline$C_{4}$ & $2.0783 * *$ & 0.8594 & $2.0783 * *$ & 0.8594 & -0.0424 & 1.1684 & -0.0424 & 1.1684 \\
\hline$\alpha_{4}(2)$ & & & $-1.6651 *$ & 0.9498 & & & 0.2578 & 1.2087 \\
\hline$\phi_{1}^{(41)}$ & 0.0517 & 0.0619 & 0.0509 & 0.0365 & 0.1300 & 0.0985 & 0.0130 & 0.0491 \\
\hline$\phi_{1}^{(42)}$ & -0.9692 & 0.7966 & -0.3145 & 0.3204 & -0.4374 & 0.8638 & 0.2737 & 0.2132 \\
\hline$\phi_{1}^{(43)}$ & 0.0313 & 0.0199 & -0.0097 & 0.0131 & 0.0465 & 0.0326 & -0.0156 & 0.0117 \\
\hline$\phi_{1}^{(44)}$ & 0.0719 & 0.2222 & 0.7005 & 0.0798 & $0.4447^{*}$ & 0.2385 & $0.6679 * * *$ & 0.0837 \\
\hline$\sigma_{4}^{2}$ & $0.5933 * * *$ & 0.1555 & $0.5933^{* * *}$ & 0.1555 & $1.3805^{* * *}$ & 0.3431 & $1.3805^{* * *}$ & 0.3431 \\
\hline$\lambda_{4}(2)$ & & & 1.1850 & 0.1884 & & & $0.6610 * * *$ & 0.1158 \\
\hline$\gamma_{12}$ & 0.1711 & 0.2826 & $-0.3211 * * *$ & 0.0878 & $0.4746 * * *$ & 0.1487 & $0.4847 * * *$ & 0.0704 \\
\hline$\gamma_{13}$ & $-0.2408 *$ & 0.1248 & -0.0517 & 0.1037 & -0.2376 & 0.1477 & -0.0350 & 0.1200 \\
\hline$\gamma_{14}$ & -0.0453 & 0.3667 & 0.0817 & 0.0796 & -0.0585 & 0.2470 & 0.0261 & 0.1079 \\
\hline$\gamma_{23}$ & 0.1878 & 0.1870 & $-0.1889 * *$ & 0.0951 & $-0.4594 * * *$ & 0.1466 & 0.1616 & 0.1015 \\
\hline$\gamma_{24}$ & $-0.5396 * * *$ & 0.1480 & -0.0083 & 0.0514 & -0.1012 & 0.2397 & -0.0629 & 0.1126 \\
\hline$\gamma_{34}$ & 0.1059 & 0.1863 & -0.0678 & 0.0985 & 0.0381 & 0.3192 & $-0.1594 *$ & 0.0946 \\
\hline$P_{11}$ & & 0.806 & $* * *(0.0675)$ & & & 0.782 & $k * *(0.0839)$ & \\
\hline$P_{22}$ & & 0.964 & $* * *(0.0160)$ & & & 0.938 & $k * *(0.0245)$ & \\
\hline $\ln L$ & & -752 & 4659 & & & & .4470 & \\
\hline AIC & & & 0063 & & & & .8574 & \\
\hline
\end{tabular}

Note:*, **, and *** represent the significance at $10 \%, 5 \%$, and $1 \%$, respectively. Values next to thee estimates of transition probability $P_{i i}$ are standard deviations. 
Table A-4 The Estimation Results for (EFP,SPR,SRET,HRET) and (EFP,TED,SRET, HRET) (1975Q2-2012Q1)

\begin{tabular}{|c|c|c|c|c|c|c|c|c|}
\hline \multirow[b]{3}{*}{ Parameter } & \multicolumn{4}{|c|}{ Model F (EFP,SPR,SRET,HRET) } & \multicolumn{4}{|c|}{ Model G (EFP,TED,SRET, HRET) } \\
\hline & \multicolumn{2}{|c|}{ Regime 1} & \multicolumn{2}{|c|}{ Regime 2} & \multicolumn{2}{|c|}{ Regime 1} & \multicolumn{2}{|c|}{ Regime 2} \\
\hline & Estimate & S.E. & Estimate & S.E. & Estimate & S.E. & Estimate & S.E. \\
\hline$c_{1}$ & $0.7296 * * *$ & 0.2636 & $0.7296 * * *$ & 0.2636 & $0.5626 * * *$ & 0.1730 & $0.5626^{* * *}$ & 0.1730 \\
\hline$\alpha_{1}(2)$ & & & $-0.5681^{* *}$ & 0.2657 & & & $-0.4569 * * *$ & 0.1729 \\
\hline$\phi_{1}^{(11)}$ & $0.6616^{* * *}$ & 0.1039 & $0.9043^{* * *}$ & 0.0251 & $0.5378 * * *$ & 0.0834 & $0.8877 * * *$ & 0.0305 \\
\hline$\phi_{1}^{(12)}$ & -0.0321 & 0.0340 & $-0.0329 * * *$ & 0.0077 & $0.1708^{* * *}$ & 0.0600 & 0.0112 & 0.0208 \\
\hline$\phi_{1}^{(13)}$ & $-0.0151^{* *}$ & 0.0071 & $-0.0065 * * *$ & 0.0012 & $-0.0217 * * *$ & 0.0070 & $-0.0046^{* * *}$ & 0.0017 \\
\hline$\phi_{1}^{(14)}$ & -0.0974 & 0.1045 & -0.0098 & 0.0075 & -0.0506 & 0.0575 & -0.0026 & 0.0101 \\
\hline$\sigma_{1}^{2}$ & $0.1204 * * *$ & 0.0334 & $0.1204^{* * *}$ & 0.0334 & $0.0854 * * *$ & 0.0269 & $0.0854 * * *$ & 0.0269 \\
\hline$\lambda_{1}(2)$ & & & $0.2456 * * *$ & 0.0365 & & & $0.3436 * * *$ & 0.0597 \\
\hline$c_{2}$ & 0.4976 & 0.8508 & 0.4976 & 0.8508 & $1.2040 * * *$ & 0.3525 & $1.2040 * * *$ & 0.3525 \\
\hline$\alpha_{2}(2)$ & & & -0.5735 & 0.8885 & & & $-0.9280 * *$ & 0.3642 \\
\hline$\phi_{1}^{(21)}$ & 0.1054 & 0.4325 & 0.1975 & 0.1679 & $-0.4471 * * *$ & 0.1503 & -0.1385 & 0.0891 \\
\hline$\phi_{1}^{(22)}$ & $0.7736 * * *$ & 0.1259 & $0.9450 * * *$ & 0.0444 & $0.7754 * * *$ & 0.1248 & $0.6267 * * *$ & 0.0647 \\
\hline$\phi_{1}^{(23)}$ & $-0.0465^{*}$ & 0.0261 & 0.0095 & 0.0058 & -0.0204 & 0.0133 & -0.0013 & 0.0031 \\
\hline$\phi_{1}^{(24)}$ & -0.0669 & 0.1764 & $-0.0967 * * *$ & 0.0290 & 0.0495 & 0.0822 & $0.0330 * *$ & 0.0145 \\
\hline$\sigma_{2}^{2}$ & $0.8517 * * *$ & 0.2923 & $0.8517 * * *$ & 0.2923 & $0.3048 * * *$ & 0.0665 & $0.3048 * * *$ & 0.0665 \\
\hline$\lambda_{2}(2)$ & & & $0.4228 * * *$ & 0.0835 & & & $0.3290 * * *$ & 0.0436 \\
\hline$C_{3}$ & $-17.0212 * * *$ & 5.1265 & $-17.0212^{* * *}$ & 5.1265 & $-12.7965 * *$ & 5.6932 & $-12.7965 * *$ & 5.6932 \\
\hline$\alpha_{3}(2)$ & & & $23.0667 * * *$ & 5.9987 & & & $17.6252 * * *$ & 6.3657 \\
\hline$\phi_{1}^{(31)}$ & $8.0003 * * *$ & 2.2391 & -3.5786 & 2.4561 & $9.1034^{* * *}$ & 2.0602 & -2.9172 & 3.3965 \\
\hline$\phi_{1}^{(32)}$ & $2.0457 * *$ & 0.8949 & -0.3452 & 0.6991 & -1.7698 & 2.0466 & 1.0652 & 1.9437 \\
\hline$\phi_{1}^{(33)}$ & -0.0338 & 0.3840 & -0.0114 & 0.1458 & 0.1551 & 0.2154 & -0.0219 & 0.1279 \\
\hline$\phi_{1}^{(34)}$ & $3.9087 * *$ & 1.7890 & -0.0885 & 0.4929 & $2.1608^{*}$ & 1.2348 & -0.2343 & 0.6194 \\
\hline$\sigma_{3}^{2}$ & $68.1342^{* * *}$ & 13.9435 & $68.1342^{* * *}$ & 13.9435 & $68.4217 * * *$ & 19.6088 & $68.4217^{* * *}$ & 19.6088 \\
\hline$\lambda_{3}(2)$ & & & 0.8930 & 0.1252 & & & 0.9030 & 0.1479 \\
\hline
\end{tabular}


Table A-4 The Estimation Results for (EFP,SPR,SRET,HRET) and (EFP,TED,SRET,HRET) (Continued)

\begin{tabular}{|c|c|c|c|c|c|c|c|c|}
\hline \multirow[b]{3}{*}{ Parameter } & \multicolumn{4}{|c|}{ Model F (EFP,SPR,SRET,HRET) } & \multicolumn{4}{|c|}{ Model G (EFP,TED,SRET, HRET) } \\
\hline & \multicolumn{2}{|c|}{ Regime 1} & \multicolumn{2}{|c|}{ Regime 2} & \multicolumn{2}{|c|}{ Regime 1} & \multicolumn{2}{|c|}{ Regime 2} \\
\hline & Estimate & S.E. & Estimate & S.E. & Estimate & S.E. & Estimate & S.E. \\
\hline$C_{4}$ & $2.4474 * * *$ & 0.5952 & $2.4474 * * *$ & 0.5952 & 0.2072 & 0.5430 & 0.2072 & 0.5430 \\
\hline$\alpha_{4}(2)$ & & & $-2.1522 * * *$ & 0.7166 & & & 0.5174 & 0.5835 \\
\hline$\phi_{1}^{(41)}$ & $-0.9926 * * *$ & 0.3252 & -0.0989 & 0.4520 & $-0.5901 *$ & 0.3463 & $-0.5057^{*}$ & 0.2762 \\
\hline$\phi_{1}^{(42)}$ & $-0.1516^{*}$ & 0.0828 & 0.0516 & 0.0764 & $0.4704 *$ & 0.2613 & $0.4723 * *$ & 0.1891 \\
\hline$\phi_{1}^{(43)}$ & $0.0497 * *$ & 0.0217 & -0.0174 & 0.0141 & $0.0782 * * *$ & 0.0243 & $-0.0223 * *$ & 0.0113 \\
\hline$\phi_{1}^{(44)}$ & 0.2981 & 0.1957 & $0.7640 * * *$ & 0.0833 & $0.5742 * * *$ & 0.1394 & $0.6261 * * *$ & 0.0742 \\
\hline$\sigma_{4}^{2}$ & $0.6971^{* * *}$ & 0.2153 & $0.6971^{* * *}$ & 0.2153 & $1.0832^{* * *}$ & 0.2912 & $1.0832^{* * *}$ & 0.2912 \\
\hline$\lambda_{4}(2)$ & & & 1.0585 & 0.2026 & & & $0.7435 * *$ & 0.1173 \\
\hline$\gamma_{12}$ & -0.0547 & 0.2167 & 0.1003 & 0.1228 & $0.4363 * *$ & 0.1707 & $0.1741^{*}$ & 0.0976 \\
\hline$\gamma_{13}$ & -0.0258 & 0.1456 & $-0.1884 * *$ & 0.0958 & 0.0179 & 0.1834 & -0.0249 & 0.1074 \\
\hline$\gamma_{14}$ & 0.0607 & 0.2749 & -0.1275 & 0.0968 & 0.2512 & 0.1932 & 0.0519 & 0.1162 \\
\hline$\gamma_{23}$ & 0.1780 & 0.1302 & 0.0046 & 0.1788 & $-0.4192 * * *$ & 0.1168 & $0.2075^{* *}$ & 0.0872 \\
\hline$\gamma_{24}$ & -0.0860 & 0.2871 & $-0.2094 * *$ & 0.0945 & -0.0595 & 0.2125 & 0.0019 & 0.0904 \\
\hline$\gamma_{34}$ & -0.1631 & 0.1787 & 0.0632 & 0.0859 & -0.1905 & 0.1616 & -0.1067 & 0.0908 \\
\hline$P_{11}$ & \multicolumn{4}{|c|}{$0.8226 * * *(0.0807)$} & \multicolumn{4}{|c|}{$0.7952 * * *(0.0789)$} \\
\hline$P_{22}$ & \multicolumn{4}{|c|}{$0.9492 * * *(0.0225)$} & \multicolumn{4}{|c|}{$0.9370 * * *(0.0300)$} \\
\hline $\ln L$ & \multicolumn{4}{|c|}{-723.5095} & \multicolumn{4}{|c|}{-623.6579} \\
\hline AIC & \multicolumn{4}{|c|}{10.6150} & \multicolumn{4}{|c|}{9.2656} \\
\hline
\end{tabular}

Note:*, ${ }^{* *}$, and $* * *$ represent the significance at $10 \%, 5 \%$, and $1 \%$, respectively. Values next to thee estimates of transition probability $P_{i i}$ are standard deviations. 
Table A-5 The Estimation Results for (SPR,TED,SRET,HRET)

\begin{tabular}{|c|c|c|c|c|}
\hline \multicolumn{5}{|c|}{ Model H (SPR,TED,SRET,HRET) } \\
\hline \multirow[b]{2}{*}{ Parameter } & \multicolumn{2}{|c|}{ Regime 1} & \multicolumn{2}{|c|}{ Regime 2} \\
\hline & Estimate & S.E. & Estimate & S.E. \\
\hline$C_{1}$ & $0.8605^{* *}$ & 0.3507 & $0.8605 * *$ & 0.3507 \\
\hline$\alpha_{1}(2)$ & & & $-0.6475^{*}$ & 0.3671 \\
\hline$\phi_{1}^{(11)}$ & $0.7534 * * *$ & 0.1014 & $0.9285 * * *$ & 0.0318 \\
\hline$\phi_{1}^{(12)}$ & -0.1560 & 0.2116 & $-0.2563 * * *$ & 0.0867 \\
\hline$\phi_{1}^{(13)}$ & -0.0285 & 0.0175 & $0.0119 * *$ & 0.0058 \\
\hline$\phi_{1}^{(14)}$ & $-0.1326^{*}$ & 0.0769 & -0.0532 & 0.0337 \\
\hline$\sigma_{1}^{2}$ & $0.8689 * * *$ & 0.2658 & $0.8689 * * *$ & 0.2658 \\
\hline$\lambda_{1}(2)$ & & & $0.3963 * * *$ & 0.0635 \\
\hline$c_{2}$ & $0.9804 * * *$ & 0.2697 & $0.9804 * * *$ & 0.2697 \\
\hline$\alpha_{2}(2)$ & & & $-0.7302 * * *$ & 0.2790 \\
\hline$\phi_{1}^{(21)}$ & $-0.1413^{* *}$ & 0.0666 & $-0.0393 * *$ & 0.0164 \\
\hline$\phi_{1}^{(22)}$ & $0.6087^{* *}$ & 0.1351 & $0.6601 * * *$ & 0.0593 \\
\hline$\phi_{1}^{(23)}$ & 0.0158 & 0.0096 & $-0.0092 * * *$ & 0.0027 \\
\hline$\phi_{1}^{(24)}$ & -0.0947 & 0.0801 & 0.0102 & 0.0138 \\
\hline$\sigma_{2}^{2}$ & $0.3418^{* * *}$ & 0.0756 & $0.3418^{* * *}$ & 0.0756 \\
\hline$\lambda_{2}(2)$ & & & $0.2434 * * *$ & 0.0308 \\
\hline$C_{3}$ & -5.5126 & 3.6041 & -5.5126 & 3.6041 \\
\hline$\alpha_{3}(2)$ & & & $7.4321 *$ & 4.2638 \\
\hline$\phi_{1}^{(31)}$ & 0.3514 & 1.2145 & -0.2685 & 0.6418 \\
\hline$\phi_{1}^{(32)}$ & 0.3968 & 1.7197 & $4.1531 * * *$ & 1.0871 \\
\hline$\phi_{1}^{(33)}$ & -0.1298 & 0.1506 & -0.0537 & 0.1230 \\
\hline$\phi_{1}^{(34)}$ & $3.0544 * * *$ & 0.8198 & -0.6950 & 0.6294 \\
\hline$\sigma_{3}^{2}$ & $78.2822 * * *$ & 16.5663 & $78.2822 * * *$ & 16.5663 \\
\hline$\lambda_{3}(2)$ & & & $0.7828 * * *$ & 0.1073 \\
\hline
\end{tabular}


Table A-5 The Estimation Results for (SPR,TED,SRET,HRET)

\begin{tabular}{|c|c|c|c|c|}
\hline \multirow[b]{3}{*}{ Parameter } & \multicolumn{4}{|c|}{ Model H (SPR,TED,SRET,HRET) } \\
\hline & \multicolumn{2}{|c|}{ Regime 1} & \multicolumn{2}{|c|}{ Regime 2} \\
\hline & Estimate & S.E. & Estimate & S.E. \\
\hline$C_{4}$ & 0.2028 & 0.5819 & 0.2028 & 0.5819 \\
\hline$\alpha_{4}(2)$ & & & -0.1368 & 0.6656 \\
\hline$\phi_{1}^{(41)}$ & -0.0221 & 0.2258 & 0.0773 & 0.0638 \\
\hline$\phi_{1}^{(42)}$ & 0.0652 & 0.1570 & $0.3256^{*}$ & 0.1778 \\
\hline$\phi_{1}^{(43)}$ & 0.0017 & 0.0346 & -0.0127 & 0.0135 \\
\hline$\phi_{1}^{(44)}$ & $0.6925^{* * *}$ & 0.1925 & $0.6871 * * *$ & 0.0912 \\
\hline$\sigma_{4}^{2}$ & $1.5297 * * *$ & 0.4401 & $1.5297 * * *$ & 0.4401 \\
\hline$\lambda_{4}(2)$ & & & $0.6229 * * *$ & 0.1214 \\
\hline$\gamma_{12}$ & -0.1347 & 0.2236 & -0.0801 & 0.1204 \\
\hline$\gamma_{13}$ & 0.2223 & 0.1448 & -0.0338 & 0.1339 \\
\hline$\gamma_{14}$ & -0.1356 & 0.2213 & $-0.2543 * * *$ & 0.0980 \\
\hline$\gamma_{23}$ & -0.1723 & 0.1719 & 0.0555 & 0.1070 \\
\hline$\gamma_{24}$ & -0.2133 & 0.1422 & 0.0061 & 0.1816 \\
\hline$\gamma_{34}$ & -0.1038 & 0.1396 & -0.1427 & 0.0905 \\
\hline$P_{11}$ & \multicolumn{4}{|c|}{$0.8478 * * *(0.0638)$} \\
\hline$P_{22}$ & \multicolumn{4}{|c|}{$0.9447 * * *(0.0230)$} \\
\hline $\ln L$ & \multicolumn{4}{|c|}{-807.2657} \\
\hline AIC & \multicolumn{4}{|c|}{11.7468} \\
\hline
\end{tabular}


Table A-6 The Estimation Results for Model SUB

\begin{tabular}{lcccc}
\hline \multicolumn{4}{c}{ Model SUB } \\
\hline \multicolumn{2}{c}{ Stock Return } & \multicolumn{2}{c}{ Housing Return } \\
\hline Parameter & Estimate & S.E. & Estimate & S.E. \\
\hline$c$ & $1.8024^{* *}$ & 0.7325 & $0.3476^{* * *}$ & 0.1203 \\
$\phi_{1}$ & 0.0584 & 0.0916 & $0.6807^{* * *}$ & 0.0723 \\
$\sigma^{2}$ & $66.6180^{* * *}$ & 9.3812 & $0.8874^{* * *}$ & 0.1377 \\
\hline $\ln L$ & -520.7270 & -201.1615 \\
AIC & \multicolumn{2}{c}{7.0774} & \multicolumn{2}{c}{2.7589} \\
\hline Note ** and *** represent the significance at 5\%, and 1\%,
\end{tabular}

Note: **, and $* * *$ represent the significance at $5 \%$, and $1 \%$, respectively. 
Appendix B: Stationarity of different Regime-Switching models

Table B-1 Stationarity Results of Francq and Zakoian (2001)

\begin{tabular}{|l|l|l|l|}
\hline Model & Model Structure & Variables & Spectral Radius \\
\hline B & Two-regime & FFR, GDP, SRET, HRET & 0.942 \\
\hline C & Two-regime & FFR, SPR, SRET, HRET & 1.013 \\
\hline D & Two-regime & FFR, EFP, SRET, HRET & 1.015 \\
\hline E & Two-regime & FFR, TED, SRET, HRET & 0.992 \\
\hline F & Two-regime & EFP, SPR, SRET, HRET & 0.834 \\
\hline G & Two-regime & EFP, TED, SRET, HRET & 0.769 \\
\hline H & Two-regime & SPR, TED, SRET, HRET & 0.852 \\
\hline
\end{tabular}

Key: (unless specified, all variables refer to quarterly data) FFR, Federal Fund Rate; SPR, term spread, which is equal to (10-year bond rate - FFR); TED, TED spread, which is equal to (3-month Eurodollar deposit rate - 3-month T-bill rate), a measure of market liquidity; EFP, External Finance Premium, which is equal to corporate bond spread (Baa-Aaa), a measure of External Finance Premium; GDP, GDP growth rate; SRET, Stock Market Return; HRET, Housing Market Return.

It is clear that Model B and C are (marginally) non-stationary. 


\section{Appendix C: Results from Diebold Mariano tests}

In the main text, we use the multi-lateral model comparison test of Mariano and Preve (2012). Since the literature is full of examples of using the more traditional bilateral model comparison test of Diebold and Mariano (1995), we also produce the corresponding results to facilitate the comparison.

Table C-1 A Summary of Diebold and Mariano (1995) Statistics (In-sample 4-Quarter Ahead Forecasts)

\begin{tabular}{|c|c|c|c|c|c|}
\hline & \multicolumn{2}{|c|}{ Stock Returns } & \multicolumn{2}{|c|}{ Housing Returns } \\
\hline & & SLC & ALC & SLC & ALC \\
\hline Model A & $\begin{array}{c}\text { Single-regime model (FFR, } \\
\text { SPR, TED, EFP, GDP, SRET, } \\
\text { HRET) }\end{array}$ & -0.3097 & -0.4418 & -0.9133 & -1.0650 \\
\hline Model B & $\begin{array}{c}\text { Two-regime model (FFR, GDP, } \\
\text { SRET, HRET) }\end{array}$ & -0.4282 & -0.2274 & $-1.9474 *$ & $-2.8435^{*}$ \\
\hline Model C & $\begin{array}{c}\text { Two-regime model (FFR, SPR, } \\
\text { SRET, HRET) }\end{array}$ & --- & --- & -0.7190 & $-2.5876 *$ \\
\hline Model D & $\begin{array}{c}\text { Two-regime model (FFR, EFP, } \\
\text { SRET, HRET) }\end{array}$ & -1.0046 & -0.4647 & -0.0825 & -0.8596 \\
\hline Model E & $\begin{array}{l}\text { Two-regime model (FFR, TED, } \\
\text { SRET, HRET) }\end{array}$ & -0.9847 & -0.3806 & --- & --- \\
\hline Model F & $\begin{array}{c}\text { Two-regime model (EFP, SPR, } \\
\text { SRET, HRET) }\end{array}$ & $-1.7738 *$ & -1.0419 & -0.6186 & -1.1555 \\
\hline Model G & $\begin{array}{l}\text { Two-regime model (EFP, TED, } \\
\text { SRET, HRET) }\end{array}$ & -1.3291 & $-1.7457^{*}$ & $-1.7517^{*}$ & -1.4553 \\
\hline Model H & $\begin{array}{l}\text { Two-regime model (SPR, TED, } \\
\text { SRET, HRET) }\end{array}$ & -0.7629 & -0.1499 & -0.7542 & -0.6536 \\
\hline SUB & $\begin{array}{c}\text { Single-regime, Uni-variate } \\
\text { AR(1) Benchmark }\end{array}$ & -0.5010 & -0.5293 & $-1.8833^{*}$ & -1.4664 \\
\hline
\end{tabular}

Key: SLC: Square Loss Criteria; ALC: Absolute Loss Criteria.

Note: For stock returns, the DM test is used to compare the forecasting ability for model $C$ and the competing model. For housing returns, the DM test is used to compare the forecasting ability for model $E$ and the competing model. * Significant at $10 \%$ level of significance.

For stock returns, (1)For SLC, Model C is better than Model F

(2)For ALC, Model C is better than Model G

For housing returns, (1)For SLC, Model E is better than Models B, G and SUB.

(2)For ALC, Model E is better than Models B and C. 
Table C-2 A Summary of Diebold and Mariano (1995) Statistics (Out-of-sample 4-Quarter Ahead Forecasts)

\begin{tabular}{|c|c|c|c|c|c|}
\hline & \multicolumn{2}{|c|}{ Stock Returns } & \multicolumn{2}{|c|}{ Housing Returns } \\
\hline & & SLC & ALC & SLC & ALC \\
\hline Model A & $\begin{array}{c}\text { Single-regime model (FFR, } \\
\text { SPR, TED, EFP, GDP, SRET, } \\
\text { HRET) }\end{array}$ & -1.5689 & $-1.6794 *$ & $-2.4232 *$ & $-2.3882 *$ \\
\hline Model B & $\begin{array}{c}\text { Two-regime model (FFR, GDP, } \\
\text { SRET, HRET) }\end{array}$ & $-1.9558 *$ & $-2.8362 *$ & $-3.2540 *$ & $-4.4689 *$ \\
\hline Model C & $\begin{array}{c}\text { Two-regime model (FFR, SPR, } \\
\text { SRET, HRET) }\end{array}$ & $-4.3008 *$ & $-3.6151^{*}$ & -0.9058 & $-2.1382 *$ \\
\hline Model D & $\begin{array}{c}\text { Two-regime model (FFR, EFP, } \\
\text { SRET, HRET) }\end{array}$ & $-1.8491^{*}$ & $-2.1131 *$ & --- & --- \\
\hline Model E & $\begin{array}{c}\text { Two-regime model (FFR, TED, } \\
\text { SRET, HRET) }\end{array}$ & -0.9668 & -1.1528 & $-1.8916^{*}$ & $-1.8734 *$ \\
\hline Model F & $\begin{array}{l}\text { Two-regime model (EFP, SPR, } \\
\text { SRET, HRET) }\end{array}$ & $-2.0955 *$ & $-2.3682 *$ & -0.5494 & -0.7063 \\
\hline Model G & $\begin{array}{c}\text { Two-regime model (EFP, TED, } \\
\text { SRET, HRET) }\end{array}$ & -1.3451 & -0.7321 & -1.5640 & -1.3771 \\
\hline Model H & $\begin{array}{c}\text { Two-regime model (SPR, TED, } \\
\text { SRET, HRET) }\end{array}$ & --- & --- & -1.3386 & -1.2733 \\
\hline SUB & $\begin{array}{l}\text { Single-regime, Uni-variate } \\
\text { AR(1) Benchmark }\end{array}$ & -0.8101 & -0.3555 & $-2.2557 *$ & $-1.8146^{*}$ \\
\hline
\end{tabular}

Key: SLC: Square Loss Criteria; ALC: Absolute Loss Criteria.

Note: For stock returns, the DM test is used to compare the forecasting ability for model $\mathrm{H}$ and the competing model. For housing returns, the DM test is used to compare the forecasting ability for model $D$ and the competing model. * Significant at $10 \%$ level of significance.

For stock returns,

(1)For SLC, Model H is better than Models B, C, D, F.

(2)For ALC, Model H is better than Models A, B, C, D, F.

For housing returns,

(1)For SLC, Model D is better than Models A, B, E, SUB.

(2)For ALC, Model D is better than Models A, B, C, E, SUB 


\section{Appendix D: LM test for the residuals}

In this appendix, we report the multivariate autocorrelation LM test (Johansen 1995: 22) for standardized residuals. The null hypothesis is "no serial correlation for standardized residuals".

Table ? A Summary of Residual Tests for All Eight Models (1975Q2-2012Q1)

\begin{tabular}{ccc}
\hline & Models & $\begin{array}{c}\text { LM test } \\
(\text { lag=10) }\end{array}$ \\
\hline Model A & Single-regime model (FFR, SPR, TED, EFP, GDP, SRET, HRET) & $64.014^{*}$ \\
Model B & Two-regime model (FFR, GDP, SRET, HRET) & 16.259 \\
Model C & Two-regime model (FFR, SPR, SRET, HRET) & 18.978 \\
Model D & Two-regime model (FFR, EFP, SRET, HRET) & 21.074 \\
Model E & Two-regime model (FFR, TED, SRET, HRET) & $24.779 *$ \\
Model F & Two-regime model (EFP, SPR, SRET, HRET) & 19.184 \\
Model G & Two-regime model (EFP, TED, SRET, HRET) & $24.992^{*}$ \\
Model H & Two-regime model (SPR, TED, SRET, HRET) & 19.550 \\
\hline
\end{tabular}

Note: The figure refers to the multivariate autocorrelation LM test of Johansen (1995) for standardized residuals. *represents the significance at $10 \%$.

\section{Reference:}

Johansen, S. 1995. Likelihood-based Inference in Cointegrated Vector Autoregressive Models. New York: Oxford University Press. 


\section{Appendix E: the suggestion of using Case-Shiller Index}

It has been suggested to us of employing the Case-Shiller Index (CSI) instead of the FHFA data series. First, we would like to plot the two series for a comparison. Clearly, Case-Shiller index tends to be more volatile, perhaps due to its focus on the top 30 cities, or even the top 10 cities. As discussed in Glaeser and Gyourko (2008), among others, conclusions being drawn from those "top cities” may not be the same as the one from studies using all 102 metropolitan areas.

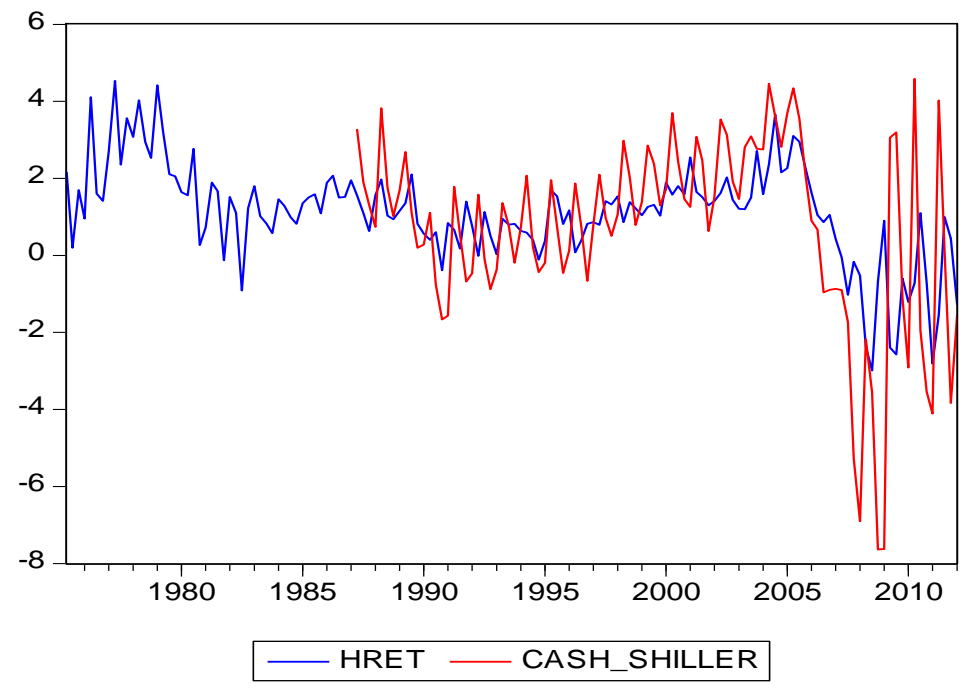

In principle, we would like to employ the CSI at least as a robustness check. Unfortunately, the CSI is available from 1987:Q1, which is much shorter than the FHFA series. And to employ much shorter time series for multivariate study probably involves a switch in econometric technique and therefore we leave that for future research.

We also find that the correlation coefficient between FHFA and S\&P Case-Shiller housing returns is 0.494 (1987:Q1-2012Q1), and thus the use of different indices may potentially generate different results.

\section{Reference:}

Glaeser, E. and J. Gyourko, 2008, Rethinking Federal Housing Policy: how to make housing plentiful and affordable, Washington, D.C.: American Enterprise Institute. 
Appendix F: the inclusion of Mortgage Rate may not be necessary once our listed variables are included.

It has been suggested to us that introducing the 30 year Mortgage Rate may improve the results. This appendix shows that it might not be the case. We first shows that the 30 Mortgage Rate, which is available from online, http://research.stlouisfed.org/fred2/series/MORTG, is highly correlated with other varibles.

The solid line represents the 30-Year Conventional Mortgage Rate (MORTG30) (Not Seasonally Adjusted) and the dotted line represents the FFR (Federal Fund Rate).

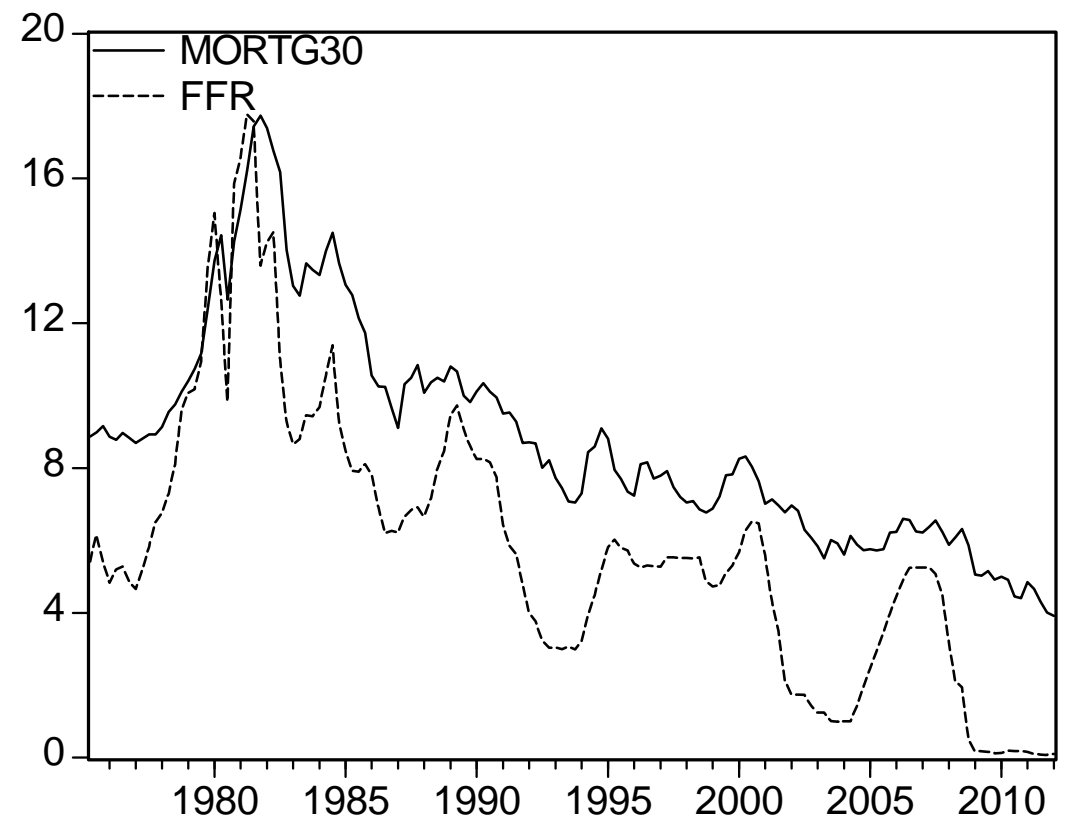

The correlation coefficient matrix

\begin{tabular}{|c|c|c|c|c|c|}
\hline & MORTG30 & FFR & EFP & SPR & TED \\
\hline MORTG30 & 1.000000 & 0.921546 & 0.441285 & -0.267886 & 0.686500 \\
\hline FFR & 0.921546 & 1.000000 & 0.289963 & -0.608354 & 0.722262 \\
\hline EFP & 0.441285 & 0.289963 & 1.000000 & 0.096856 & 0.638450 \\
\hline SPR & -0.267886 & -0.608354 & 0.096856 & 1.000000 & -0.410358 \\
\hline TED & 0.686500 & 0.722262 & 0.638450 & -0.410358 & 1.000000 \\
\hline
\end{tabular}

The correlation between FFR and MORTG30 is 0.921546.

Furthermore, we run a supplementary regression to show that Mortgage rate is mostly explained by our listed variables (FFR, EFP, SPR, TED). Hence, the introduction of it in the empirical analysis will not generate additional information.

More specifically, we run the following regression: 
$($ Mortgage Rate $)=a 0+a 1 *(S P R$, Term Spread $)+a 2^{*}($ TED Spread $)+a 3^{*}(E F P)+a 4 *(F F R)+$ (residual)

Table F1 Regression results Dependent Variable: MORTG30

Method: Least Squares

Date: 08/19/13 Time: 16:39

Sample: 1975Q2 2012Q1

Included observations: 148

\begin{tabular}{crlll}
\hline \hline \multicolumn{1}{c}{ Variable } & Coefficient & Std. Error & t-Statistic & Prob. \\
\hline \hline C & 1.186891 & 0.096209 & 12.33661 & 0.0000 \\
SPR & 0.971697 & 0.027584 & 35.22738 & 0.0000 \\
TED & -0.269824 & 0.069512 & -3.881673 & 0.0002 \\
EFP & 0.604615 & 0.085181 & 7.098020 & 0.0000 \\
FFR & 0.965193 & 0.011652 & 82.83384 & 0.0000 \\
\hline \hline R-squared & 0.989211 & Mean dependent var & 8.826689 \\
Adjusted R-squared & 0.988909 & S.D. dependent var & 3.055711 \\
S.E. of regression & 0.321806 & Akaike info criterion & 0.603462 \\
Sum squared resid & 14.80891 & Schwarz criterion & 0.704719 \\
Log likelihood & -39.65616 & F-statistic & 3277.810 \\
Durbin-Watson stat & 0.746341 & Prob(F-statistic) & 0.000000 \\
\hline \hline
\end{tabular}


Appendix G: The graphs of smoothed probabilities for different regimes in different models

Figure G-1 Smoothed Probabilities for Model B (FFR, GDP,SRET,HRET)

Regime 1

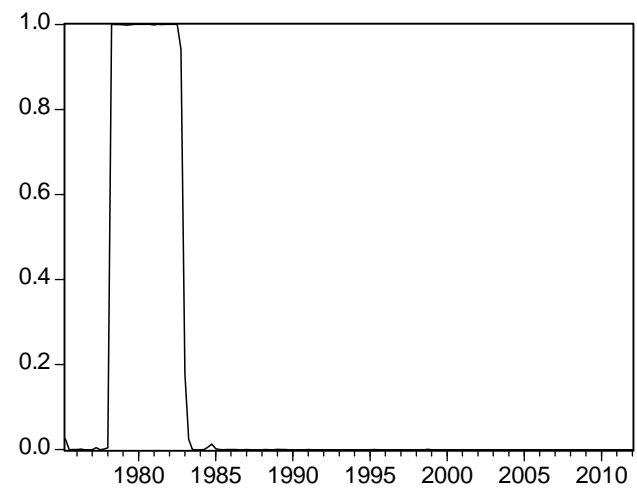

Regime 2

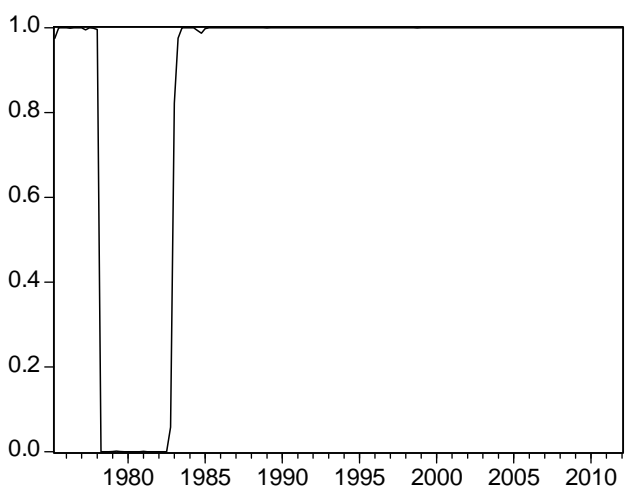

Figure G-2 Smoothed Probabilities for Model C (FFR,SPR,SRET,HRET)

Regime 1

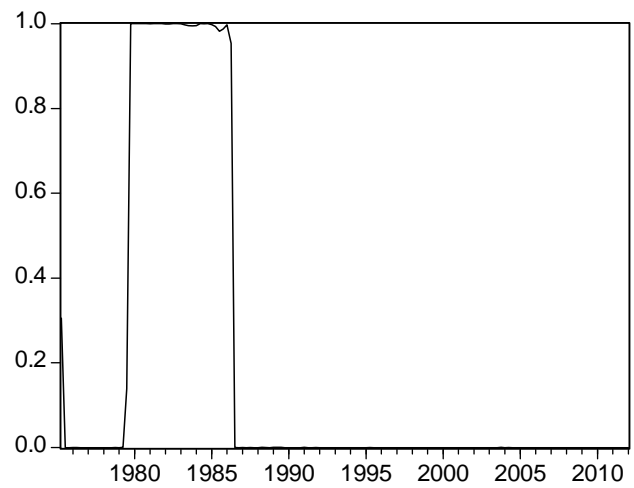

Regime 2

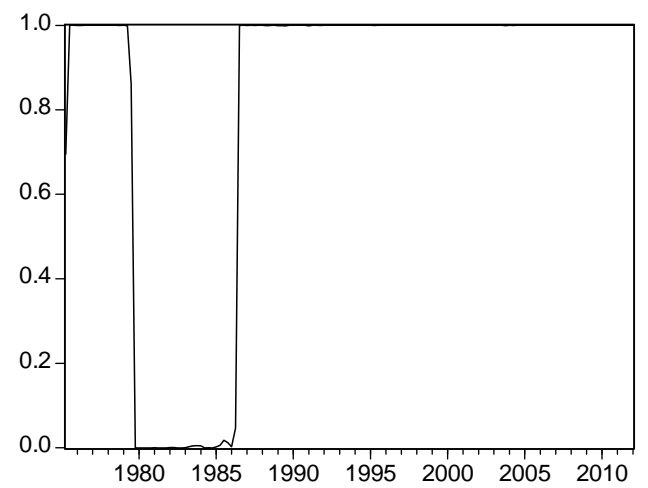

Figure G-3 Smoothed Probabilities for Model D (FFR,EFP,SRET,HRET)

Regime 1

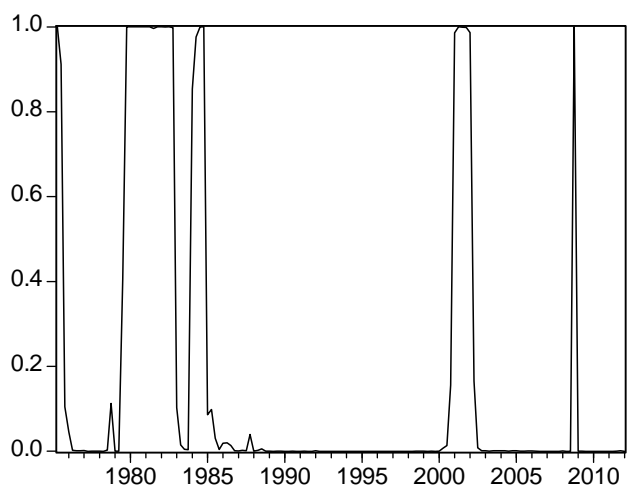

Regime 2

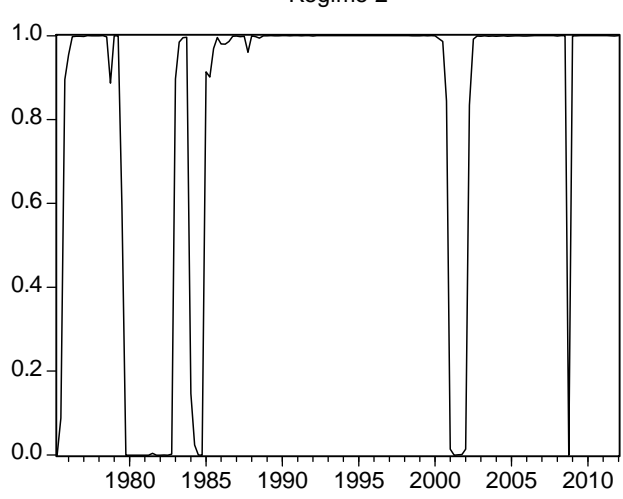


Figure G-4 Smoothed Probabilities for Model E (FFR,TED,SRET,HRET)
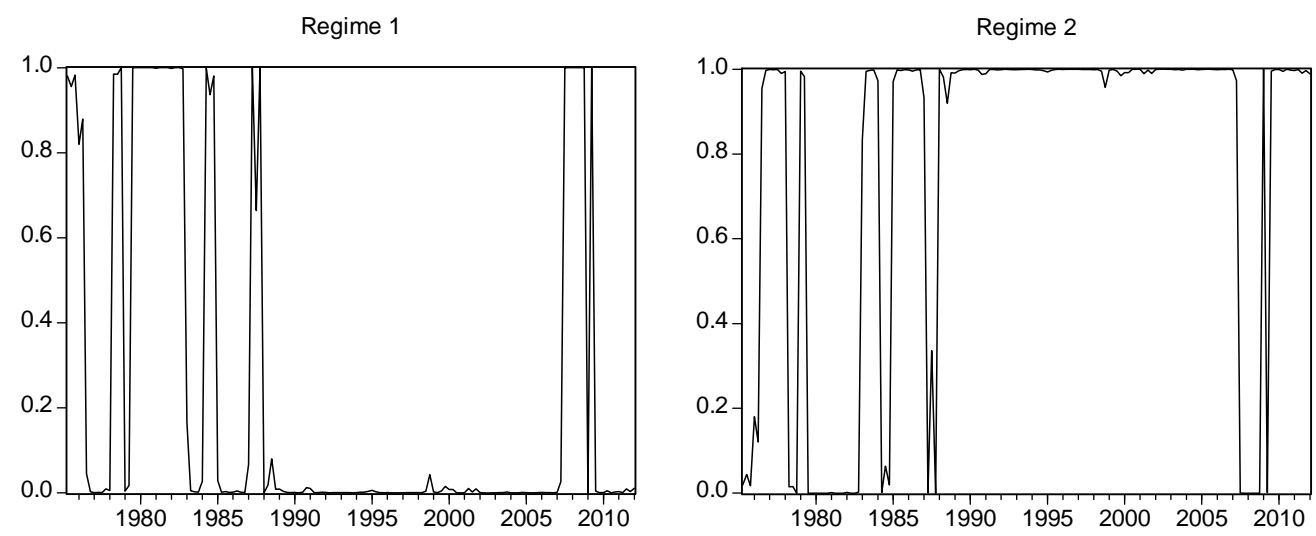

Figure G-5 Smoothed Probabilities for Model F (EFP,SPR,SRET,HRET)
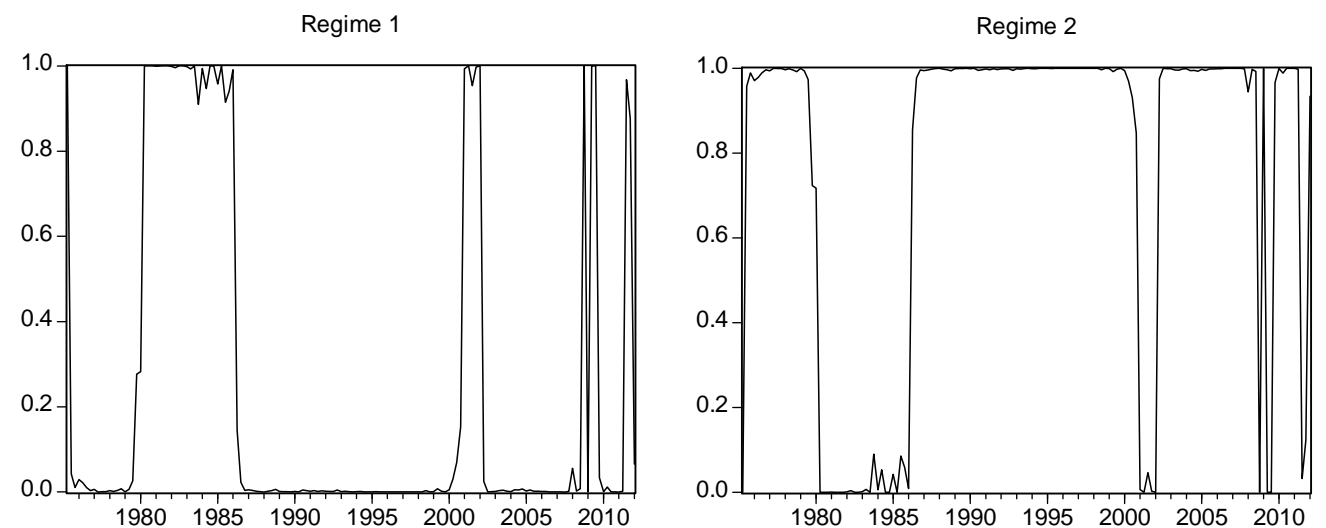

Figure G-6 Smoothed Probabilities for Model G (EFP,TED,SRET,HRET)
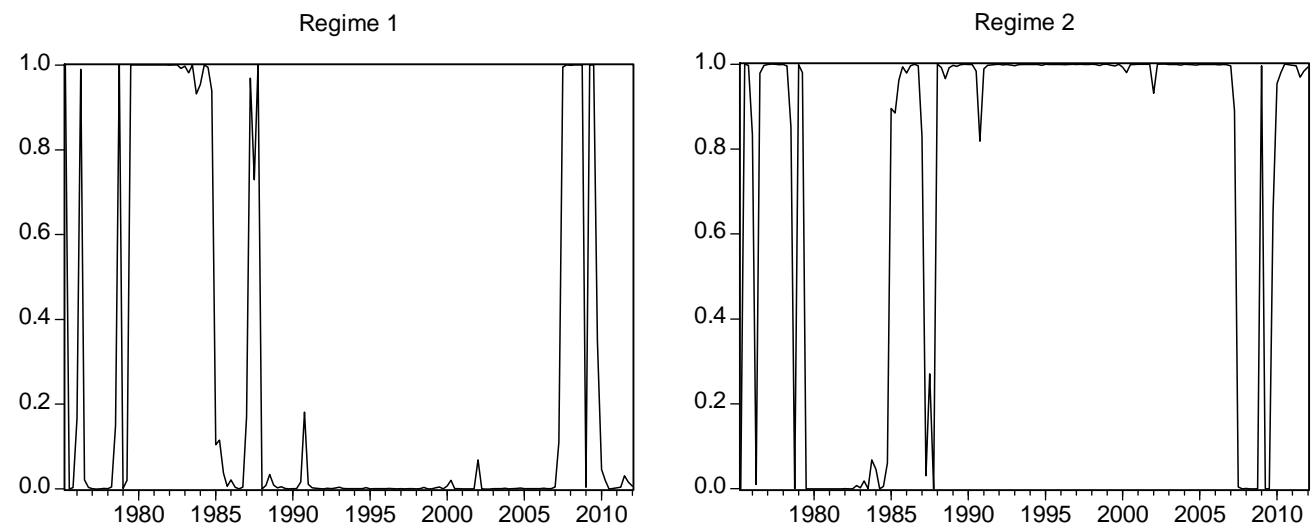
Figure G-7 Smoothed Probabilities for Model H (SPR,TED,SRET,HRET)
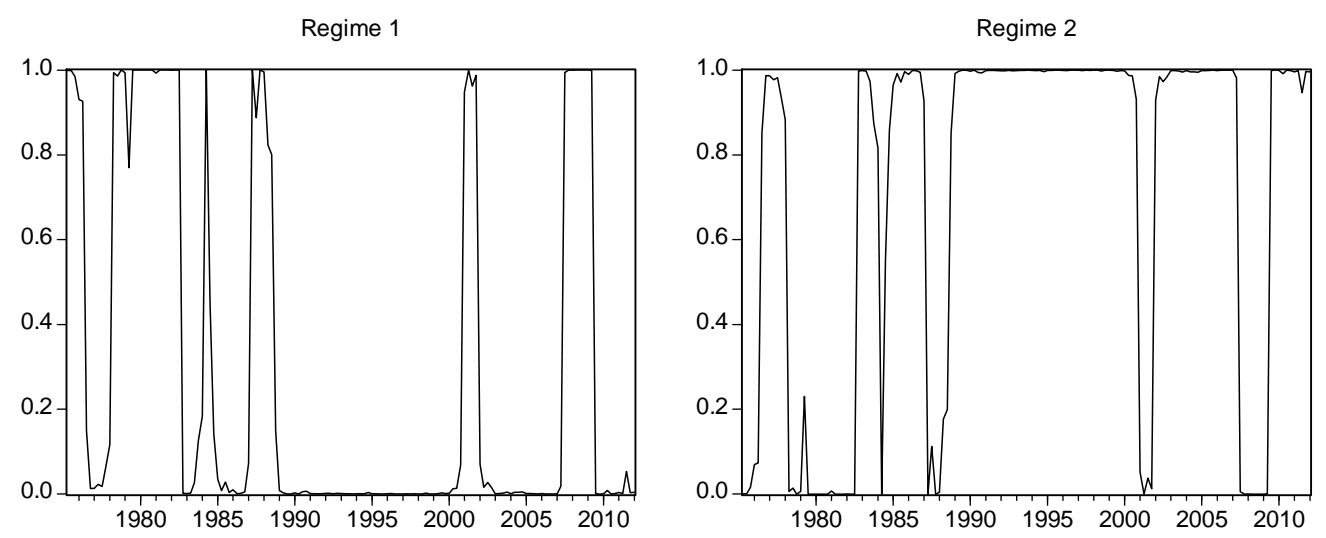
Appendix H:

This appendix provides more details of the results which have been summarized in the text.

Table H-1. A Summary of Mariano and Preve (2011) Statistics for Stock Returns (In-sample 4-Quarter Ahead Forecasts)

\begin{tabular}{lcc}
\hline \multicolumn{1}{c}{ Selected models } & $S$ statistic & $S_{c}$ statistic \\
\hline $\begin{array}{l}\text { Panel A: Squared loss criterion } \\
\text { A, B, C, D, E, F, G, H, USB }\end{array}$ & 7.2842 & 7.2230 \\
\hline $\begin{array}{l}\text { Panel B: Absolute loss criterion } \\
\text { A, B, C, D, E, F, G, H, USB }\end{array}$ & 7.9727 & 7.9057 \\
\hline $\begin{array}{l}\text { Note: The test statistics } S \text { and } \\
\text { competing models. * Significant at } 10 \% \text { level of significance. }\end{array}$ & \\
&
\end{tabular}


Table H-2. A Summary of Mariano and Preve (2011) Statistics for Housing Returns (In-sample 4-Quarter Ahead Forecasts)

\begin{tabular}{lcc}
\hline \multicolumn{1}{c}{ Selected models } & $S$ statistic & $S_{c}$ statistic \\
\hline Panel A: Squared loss criterion & & \\
A, B, C, D, E, F, G, H, USB & $59.4120^{*}$ & $58.9127^{*}$ \\
A, B, C, D, E, F, G, H & $42.3268^{*}$ & $41.9711^{*}$ \\
A, C, D, E, F, G, H & $14.7568^{*}$ & $14.6328^{*}$ \\
A, C, D, E, F, H & $12.6766^{*}$ & $12.5701^{*}$ \\
C, D, E, F, H & $12.6730^{*}$ & $12.5665^{*}$ \\
D, E, F, H & 5.7542 & 5.7059 \\
A, B, C, G, USB & $13.3869^{*}$ & $13.2744^{*}$ \\
A, B, C, G & $10.9644^{*}$ & $10.8722^{*}$ \\
A, C, G & 2.4697 & 2.4489 \\
B, USB & 0.0412 & 0.0408 \\
\hline Panel B: Absolute loss criterion & & \\
A, B, C, D, E, F, G, H, USB & $42.6523^{*}$ & $42.2939^{*}$ \\
A, C, D, E, F, G, H, USB & $17.0562^{*}$ & $16.9129^{*}$ \\
A, C, D, E, F, G, H & $12.1324^{*}$ & $12.0305^{*}$ \\
A, C, D, E, F, H & 6.6256 & 6.5698 \\
B, G, USB & 1.9334 & 1.9172 \\
\hline
\end{tabular}

Note: The test statistics $S$ and $S_{c}$ are used to compare the forecasting ability for various competing models. * Significant at $10 \%$ level of significance.

Conclusion: (1) For squared loss criterion:

Group 1: Models D, E, F, H have the same forecasting ability

Group 2: Models A, C, G have the same forecasting ability

Group 3: Models B, USB have the same forecasting ability

The order of forecasting performance: Group $1>$ Group $2>$ Group 3

(2) For absolute loss criterion:

Group 1: Models A, C, D, E, F, H have the same forecasting ability

Group 2: Models B, G, USB have the same forecasting ability

The order of forecasting performance: Group $1>$ Group 2 
Table H-3. A Summary of Mariano and Preve (2011) Statistics for Stock Returns (Out-of-sample 4-Quarter Ahead Forecasts)

\begin{tabular}{lcc}
\hline \multicolumn{1}{c}{ Selected models } & $S$ statistic & $S_{c}$ statistic \\
\hline Panel A: Squared loss criterion & & \\
A, B, C, D, E, F, G, H, USB & $50.5384^{*}$ & $48.2412^{*}$ \\
A, B, C, D, E, G, H, USB & $33.7668^{*}$ & $32.2319^{*}$ \\
A, B, C, E, G, H, USB & $26.6326^{*}$ & $25.4220^{*}$ \\
A, B, C, E, H, USB & 8.0183 & 7.6538 \\
D, F, G & 2.0174 & 1.9257 \\
\hline Panel B: Absolute loss criterion & & \\
A, B, C, D, E, F, G, H, USB & $67.7885^{*}$ & $64.7072^{*}$ \\
A, B, C, D, E, G, H, USB & $40.7105^{*}$ & $38.8600^{*}$ \\
A, B, C, E, G, H, USB & $23.9001^{*}$ & $22.8138^{*}$ \\
B, C, E, G, H, USB & $16.9517^{*}$ & $16.1812^{*}$ \\
B, E, G, H, USB & 4.8207 & 4.6016 \\
A, C, D, F & 0.4462 & 0.4259
\end{tabular}

Note: The test statistics $S$ and $S_{c}$ are used to compare the forecasting ability for various competing models. * Significant at $10 \%$ level of significance.

Conclusion: (1) For squared loss criterion:

Group 1: Models A, B, C, E, H, USB have the same forecasting ability

Group 2: Models D, F, G have the same forecasting ability

The order of forecasting performance: Group $1>$ Group 2

(2) For absolute loss criterion:

Group 1: Models B, E, G, H, USB have the same forecasting ability

Group 2: Models A, C, D, F have the same forecasting ability

The order of forecasting performance: Group $1>$ Group 2 
Table H-4. A Summary of Mariano and Preve (2011) Statistics for Housing Returns (Out-of-sample 4-Quarter Ahead Forecasts)

\begin{tabular}{lcc}
\hline \multicolumn{1}{c}{ Selected models } & $S$ statistic & $S_{c}$ statistic \\
\hline Panel A: Squared loss criterion & & \\
A, B, C, D, E, F, G, H, USB & $18.0523^{*}$ & $17.2317^{*}$ \\
A, B, C, D, F, G, H, USB & $15.5727^{*}$ & $14.8649^{*}$ \\
B, C, D, F, G, H, USB & $15.4347^{*}$ & $14.7331^{*}$ \\
C, D, F, G, H, USB & 7.0835 & 6.7615 \\
A, B, E & 0.2808 & 0.2680 \\
Panel B: Absolute loss criterion & & \\
A, B, C, D, E, F, G, H, USB & $23.1800^{*}$ & $22.1263^{*}$ \\
A, B, C, D, F, G, H, USB & $21.5041^{*}$ & $20.5266^{*}$ \\
A, C, D, F, G, H, USB & $13.5882^{*}$ & $12.9705^{*}$ \\
C, D, F, G, H, USB & 6.3011 & 6.0146 \\
A, B, E & 0.2911 & 0.2779
\end{tabular}

Note: The test statistics $S$ and $S_{c}$ are used to compare the forecasting ability for various competing models. * Significant at $10 \%$ level of significance.

Conclusion: (1) For squared loss criterion:

Group 1: Models C, D, F, G, H, USB have the same forecasting ability

Group 2: Models A, B, E have the same forecasting ability

(2) For absolute loss criterion:

Group 1: Models C, D, F, G, H, USB have the same forecasting ability

Group 2: Models A, B, E have the same forecasting ability

The order of forecasting performance: Group $1>$ Group 2. Thus, whether we useThe the squared loss criterion or absolute loss criterion, havethe same ranking is delivered. 
Appendix I:

This appendix provides a simple review of the literature which chooses a similar boom-bust date as we do.

AS it can be expected, the dating of bust regime varies across research papers, reflecting the difference in modelling techniques as well as research focuses. Nevertheless, there seems to be a collection of studies which also select the beginning of 2006 as the start of bust phase of the cycle.

1. Huang (2014) extends Galvão’s (2006) SBTVAR framework and shows that a persistent housing-bust phase in US begins in March 2006. This finding is in line with prior studies that identify 2006 as the starting period of the recent housing bust in the U.S.

2. Ferreira, Gyourko, and Tracy (2010) point out that loan-to-value ratios of some local housing markets are higher than 85\% in 2006, and specify that the housing bust starts in 2006.

3. Huang and Tang (2012) argue that tight housing supply constraints, which result in supply inelasticity, magnify the recent housing price bust since 2006.

4. In't-Veld, Raciborski, Ratto, and Roeger (2011) propose that the decline in residential investment since the early-2006 led to the economic recession, and identify the bust of the housing bubble in 2006.

5. Khandani, Lo, and Merton (2013) estimate the potential losses of the US housing market due to a housing price bust from 2006.

6. Lutz, Molloy, and Shan (2011) address five channels through which the US housing market influences state and local tax revenues. They provide estimates of a fall in sales tax revenue from 2006 to 2009 and find that housing prices peak in the first quarter of 2006, followed by a collapse of housing price growths.

7. Nichols, Oliner, and Mulhall (2013) show that residential and commercial land price indexes plunge after peaking in 2006.

8. Chen et al. (2014): According to FHFA house price index, the U.S. average house price has grown consecutively around $1.6 \%$ for the period 1995Q4 - 2005Q4, reaching a total of $89 \%$ in capital gains. The returns on housing started to decline around 2006q1 and then precipitated in the following quarters when the subprime mortgage problem aggravated. Using RW model, they identify the boom-bust regime capturing the periods where housing returns exhibited high volatility before mid-1980s and after 2005q4.

9. Kouwenberg and Zwinkels (2014): The real house price index reached a maximum in the first quarter of 2006, when it was $48 \%$ higher than the fundamental value estimate, and the prolonged period of overvaluation ended in the first quarter of 2009, as the price eventually dropped below the fundamental value.

10. Cetorelli and Goldberg (2012) show that internal capital markets of global banks also contribute to the international propagation of shocks. Using balance sheets data for chartered US banks over the period 1980-2009, the sample is split over two samples, a pre-crisis period using quarterly data on individual banks from "Call reports" from 1980Q1 to 2005Q4, and a crisis period sample using weekly series on aggregate Assets and Liabilities of Commercial Banks in the United States (Fed. H.8 Statistical Release).

11. Cetorelli and Goldberg (2010) confirm that global banks played a significant role in the crisis transmission to emerging market economies. Using banking statistics data from the BIS and IMF's International Financial Statistics for 17 source countries from the OECD and 94 destination countries from emerging Europe, Asia, and Latin from 2006 to 2009 they examine the relationships between adverse liquidity shocks on main developed-country banking systems to emerging markets, isolating loan supply from loan demand effects. The sample is split in to a pre-crisis period from 2006Q2 to 2007Q2 and a post-crisis period from 2008Q3 to 2009Q2, 
leaving out the crisis event period between 2007Q3 and 2008Q2 when market functioning was disrupted by the Lehman shock. Alternative datings were considered in robustness tests.

12. Bertay and Gong (2014) use an international panel to analyze the relationship between securitization and macroeconomic performance. Our findings suggest that economic growth is negatively related to country-level securitization activities, even before the 2007-2009 financial crisis. The annual sample is split into 1995-2006 and 2006-2012.

13. Shiller (2007): Between the bottom in the 4th quarter of 1996 and the peak in the first quarter of 2006, real home prices rose $86 \%$ nationally in the United States. 
Appendix J

This appendix provides the detailed results when 1975-2006 is chosen to be the in-sample period and the years after are categorized as out-of-sample.

Table J-1 A Summary of Mariano and Preve (2011) Statistics for Stock Returns (In-sample 4-Quarter Ahead Forecasts)

\begin{tabular}{|c|c|c|}
\hline Selected models & $S$ statistic & $S_{c}$ statistic \\
\hline $\begin{array}{l}\text { Panel A: Squared loss criterion } \\
\text { A, B, C, D, E, F, G, H, USB }\end{array}$ & 12.0249 & 11.9271 \\
\hline $\begin{array}{l}\text { Panel B: Absolute loss criterion } \\
\text { A, B, C, D, E, F, G, H, USB } \\
\text { A, B, C, D, E, F, G, USB }\end{array}$ & $\begin{array}{c}14.0797^{*} \\
7.1430 \\
\end{array}$ & $\begin{array}{c}13.9653 \\
7.0850 \\
\end{array}$ \\
\hline \multicolumn{3}{|c|}{$\begin{array}{l}\text { Note: The test statistics } S \text { and } S_{c} \text { are used to compare the forecasting ability for various } \\
\text { competing models. * Significant at } 10 \% \text { level of significance. }\end{array}$} \\
\hline $\begin{array}{l}\text { Conclusion: (1) For squared loss } \\
\text { All models he } \\
\qquad \begin{array}{r}\text { (2) For absolute los } \\
\text { Group 1: A, } \\
\text { Group 2: H }\end{array}\end{array}$ & forecasting & \\
\hline
\end{tabular}


Table J-2 A Summary of Mariano and Preve (2011) Statistics for Housing Returns (In-sample 4-Quarter Ahead Forecasts)

\begin{tabular}{|c|c|c|}
\hline Selected models & $S$ statistic & $S_{c}$ statistic \\
\hline \multicolumn{3}{|l|}{ Panel A: Squared loss criterion } \\
\hline A, B, C, D, E, F, G, H, USB & $21.6824^{*}$ & $21.5062 *$ \\
\hline A, B, C, D, E, F, G, H & $21.4527^{*}$ & $21.2782^{*}$ \\
\hline A, C, D, E, F, G, H & 7.9831 & 7.9182 \\
\hline $\mathrm{B}, \mathrm{USB}$ & 0.0099 & 0.0098 \\
\hline \multicolumn{3}{|l|}{ Panel B: Absolute loss criterion } \\
\hline \multicolumn{3}{|c|}{$\begin{array}{l}\text { Note: The test statistics } S \text { and } S_{c} \text { are used to compare the forecasting ability for various co } \\
\text { significance. } \\
\text { Conclusion: (1) For squared loss criterion: } \\
\text { Group 1: Models A, C, D, E, F, G, H have the same forecasting ability } \\
\text { Group 2: Models B, USB have the same forecasting ability } \\
\text { The order of forecasting performance: Group } 1 \text { > Group } 2 \\
\text { (2) For absolute loss criterion: } \\
\text { Group 1: Models A, C, D, E, F, G, H, USB have the same forecasting ability } \\
\text { Group 2: Model B } \\
\text { The order of forecasting performance: Group } 1>\text { Group } 2 \text {. }\end{array}$} \\
\hline
\end{tabular}


Table J-3 A Summary of Mariano and Preve (2011) Statistics for Stock Returns (Out-of-sample 4-Quarter Ahead Forecasts)

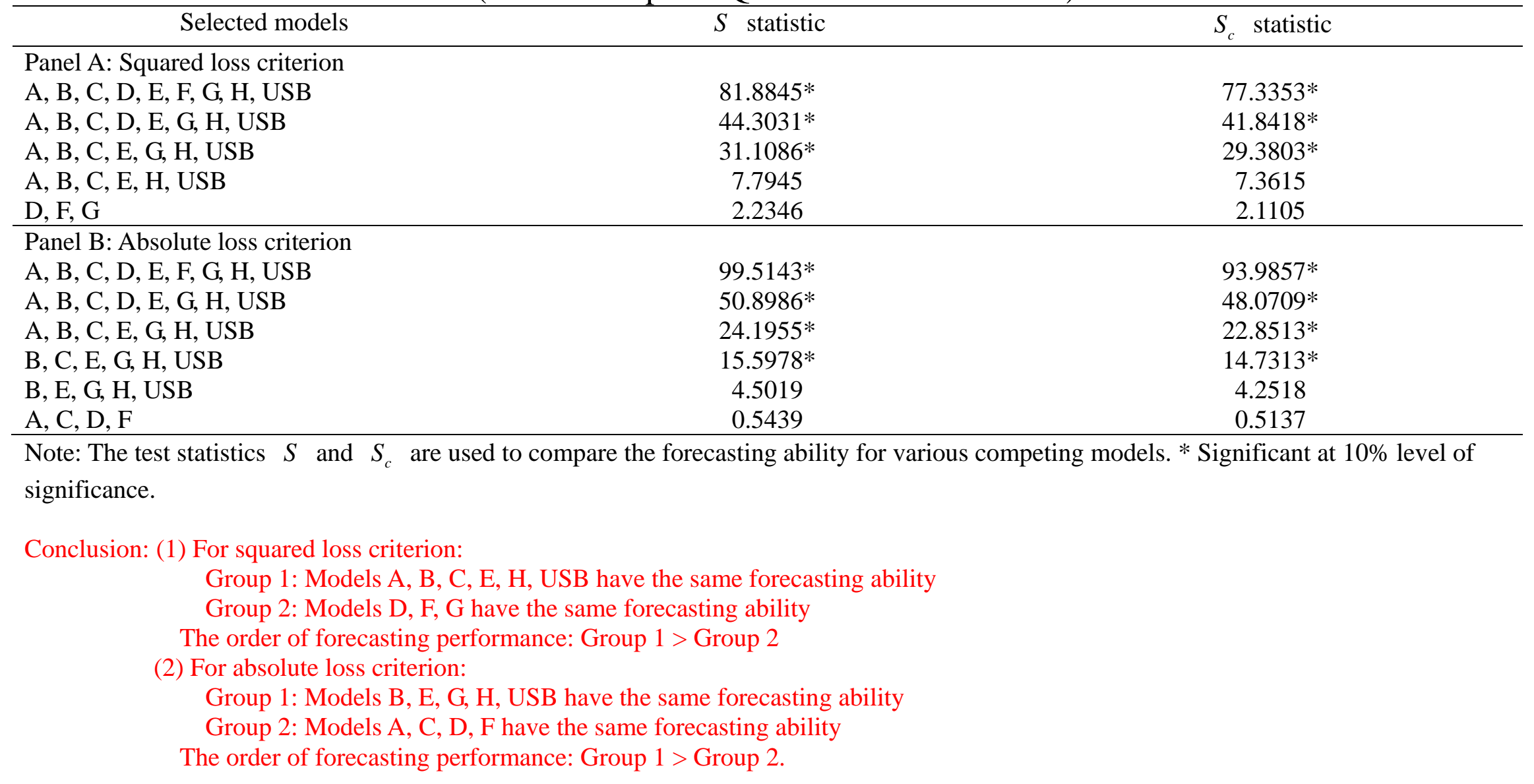


Table J-4 A Summary of Mariano and Preve (2011) Statistics for Housing Returns (Out-of-sample 4-Quarter Ahead Forecasts)

\begin{tabular}{lcc}
\hline \multicolumn{1}{c}{ Selected models } & $S$ statistic & $S_{c}$ statistic \\
\hline Panel A: Squared loss criterion & & \\
A, B, C, D, E, F, G, H, USB & $25.0090^{*}$ & $23.6196^{*}$ \\
A, B, C, D, F, G, H, USB & $16.8688^{*}$ & $15.9316^{*}$ \\
B, C, D, F, G, H, USB & $16.8638^{*}$ & $15.9270^{*}$ \\
C, D, F, G, H, USB & $12.8406^{*}$ & $12.1272^{*}$ \\
C, D, F, G, H & $11.1509^{*}$ & $10.5314^{*}$ \\
C, D, F, G & 4.7603 & 4.4958 \\
A, B, E, H, USB & 6.1248 & 5.7846 \\
Panel B: Absolute loss criterion & & \\
A, B, C, D, E, F, G, H, USB & $25.6580^{*}$ & $24.2326^{*}$ \\
A, B, C, D, F, G, H, USB & $25.4794^{*}$ & $24.0639^{*}$ \\
A, C, D, F, G, H, USB & $17.8622^{*}$ & $16.8699^{*}$ \\
C, D, F, G, H, USB & $15.8284^{*}$ & $14.9490^{*}$ \\
C, D, F, G, H & $11.9081^{*}$ & $11.2465^{*}$ \\
C, D, F, G & 3.2759 & 3.0939 \\
A, B, E, H, USB & 2.4058 & 2.2721 \\
\hline N
\end{tabular}

Note: The test statistics $S$ and $S_{c}$ are used to compare the forecasting ability for various competing models. * Significant at $10 \%$ level of significance.

Conclusion: (1) For squared loss criterion:

Group 1: Models C, D, F, G have the same forecasting ability

Group 2: Models A, B, E, H, USB have the same forecasting ability

(2) For absolute loss criterion:

Group 1: Models C, D, F, G have the same forecasting ability

Group 2: Models A, B, E, H, USB have the same forecasting ability. 
Appendix K

This appendix provides detailed results when the in-sample is chosen to be 1975 to 2007 . We start with some summary tables, followed by the details.

Table K-1 A Summary of In-sample Forecasting Performances (4-Quarter Ahead Forecasts) (1975Q2-2007Q4)

\begin{tabular}{|c|c|c|c|c|c|}
\hline & & \multicolumn{2}{|c|}{ Stock Returns } & \multicolumn{2}{|c|}{ Housing Returns } \\
\hline & & SLC & ALC & SLC & ALC \\
\hline Model A & $\begin{array}{l}\text { Single-regime model (FFR, SPR, TED, EFP, GDP, } \\
\text { SRET, HRET) }\end{array}$ & 54.8449 & 5.5073 & 0.8025 & 0.6615 \\
\hline Model B & Two-regime model (FFR, GDP, SRET, HRET) & 54.9900 & 5.4855 & 0.8683 & 0.7154 \\
\hline Model C & Two-regime model (FFR, SPR, SRET, HRET) & 54.1614 & 5.4408 & 0.7389 & 0.6629 \\
\hline Model D & Two-regime model (FFR, EFP, SRET, HRET) & 55.3647 & 5.5024 & 0.7755 & 0.6680 \\
\hline Model E & Two-regime model (FFR, TED, SRET, HRET) & 55.1031 & 5.5293 & 0.7726 & 0.6510 \\
\hline Model F & Two-regime model (EFP, SPR, SRET, HRET) & 57.3044 & 5.5994 & 0.7312 & 0.6520 \\
\hline Model G & Two-regime model (EFP, TED, SRET, HRET) & 56.1486 & 5.5662 & 0.8090 & 0.6634 \\
\hline Model H & Two-regime model (SPR, TED, SRET, HRET) & 56.1061 & 5.6180 & 0.7942 & 0.6620 \\
\hline USB & Uni-variate, Single-regime Benchmark & 55.0903 & 5.5222 & 0.8676 & 0.6835 \\
\hline
\end{tabular}

Key: SLC: Square Loss Criteria; ALC: Absolute Loss Criteria 
Table K-2. A Summary of EPPC (In-sample 4-Quarter Ahead Forecasts)

\begin{tabular}{|c|c|c|c|}
\hline \multirow{2}{*}{ Stock Return } & & Class 1 & Class 2 \\
& SLC & All models & $/$ \\
\cline { 2 - 4 } & ALC & All models & $/$ \\
\hline \multirow{2}{*}{ Housing Return } & SLC & A, C, D, E, F, G, H & B, USB \\
\cline { 2 - 4 } & ALC & A, C, D, E, F, G, H, USB & B \\
\hline
\end{tabular}

Note: SLC: Squared Loss Criterion; ALC: Absolute Loss Criterion. Our convention is that if $i<j$, then any model in Class $i$ has better predictive power than any model in Class $j$. 
Table K-3 A Summary of Out-of-Sample Forecasting Performances (4-Quarter Ahead Forecasts) (2008Q4-2012Q1)

\begin{tabular}{|c|c|c|c|c|c|}
\hline \multicolumn{2}{|c|}{} & \multicolumn{2}{c|}{ Stock Returns } & \multicolumn{2}{c|}{ Housing Returns } \\
\cline { 3 - 6 } & Single-regime model (FFR, SPR, TED, EFP, GDP, & SLC & ALC & \multicolumn{2}{c|}{ SLC } \\
Sodel A & SRET, HRET) & 170.5441 & 11.6253 & 4.0734 & \multirow{2}{*}{1.6796} \\
\hline Model B & Two-regime model (FFR, GDP, SRET, HRET) & 157.0917 & 10.8966 & 3.7355 & 1.6366 \\
\hline Model C & Two-regime model (FFR, SPR, SRET, HRET) & 161.3897 & 11.2335 & 2.7891 & 1.3927 \\
\hline Model D & Two-regime model (FFR, EFP, SRET, HRET) & 169.8544 & 11.5395 & 2.6515 & 1.3177 \\
\hline Model E & Two-regime model (FFR, TED, SRET, HRET) & 153.8335 & 10.5620 & 4.4722 & 1.7894 \\
\hline Model F & Two-regime model (EFP, SPR, SRET, HRET) & 172.0982 & 11.2934 & 3.1779 & 1.4685 \\
\hline Model G & Two-regime model (EFP, TED, SRET, HRET) & 166.1691 & 10.4612 & 3.3197 & 1.5039 \\
\hline Model H & Two-regime model (SPR, TED, SRET, HRET) & 142.7175 & 10.2122 & 3.6399 & 1.6368 \\
\hline USB & Uni-variate, Single-regime Benchmark & 150.2610 & 10.3168 & 3.8935 & 1.6767 \\
\hline
\end{tabular}

Key: SLC: Square Loss Criteria; ALC: Absolute Loss Criteria. 
Table K-4 A Summary of EPPC (Out-Of-Sample 4-Quarter Ahead Forecasts)

\begin{tabular}{|c|c|c|c|}
\hline \multirow{3}{*}{ Stock Return } & & Class 1 & Class 2 \\
\cline { 2 - 4 } & SLC & B, C, E, H, USB & A, D, F, G \\
\hline \multirow{2}{*}{ Housing Return } & ALC & B, E, G, H, USB & A, C, D, F \\
\cline { 2 - 4 } & ALC & C, D, F, G & A, B, E, H, USB \\
\hline
\end{tabular}

Note: SLC: Squared Loss Criterion; ALC: Absolute Loss Criterion. Our convention is that if $i<j$, then any model in Class $i$ has better predictive power than any model in Class $j$.

We will now present all the details which support the previous summary tables. 
Table K-5 A Summary of In-sample Forecasting Performances (4-Quarter Ahead Forecasts) (1975Q2-2007Q4)

\begin{tabular}{|c|c|c|c|c|c|}
\hline \multicolumn{2}{|c|}{} & \multicolumn{2}{c|}{ Stock Returns } & \multicolumn{2}{c|}{ Housing Returns } \\
\cline { 3 - 6 } & & MSE & MAE & MSE & MAE \\
\hline \multirow{2}{*}{ Model A } & Single-regime model (FFR, SPR, TED, EFP, GDP, & \multirow{2}{*}{54.8449} & 5.5073 & 0.8025 & 0.6615 \\
& SRET, HRET) & 54.9900 & 5.4855 & 0.8683 & 0.7154 \\
\hline Model B & Two-regime model (FFR, GDP, SRET, HRET) & 54.1614 & 5.4408 & 0.7389 & 0.6629 \\
\hline Model C & Two-regime model (FFR, SPR, SRET, HRET) & 55.3647 & 5.5024 & 0.7755 & 0.6680 \\
\hline Model D & Two-regime model (FFR, EFP, SRET, HRET) & 55.1031 & 5.5293 & 0.7726 & 0.6510 \\
\hline Model E & Two-regime model (FFR, TED, SRET, HRET) & 57.3044 & 5.5994 & 0.7312 & 0.6520 \\
\hline Model F & Two-regime model (EFP, SPR, SRET, HRET) & 56.1486 & 5.5662 & 0.8090 & 0.6634 \\
\hline Model G & Two-regime model (EFP, TED, SRET, HRET) & 56.1061 & 5.6180 & 0.7942 & 0.6620 \\
\hline Model H & Two-regime model (SPR, TED, SRET, HRET) & 55.0903 & 5.5222 & 0.8676 & 0.6835 \\
\hline USB & Uni-variate, Single-regime Benchmark & & & \multicolumn{2}{c}{} \\
\hline
\end{tabular}


Table K-6 A Summary of Mariano and Preve (2011) Statistics for Stock Returns (In-sample 4-Quarter Ahead Forecasts)

\begin{tabular}{|c|c|c|}
\hline Selected models & $S$ statistic & $S_{c}$ statistic \\
\hline $\begin{array}{l}\text { Panel A: Squared loss criterion } \\
\text { A, B, C, D, E, F, G, H, USB }\end{array}$ & 10.8690 & 10.7834 \\
\hline $\begin{array}{l}\text { Panel B: Absolute loss criterion } \\
\text { A, B, C, D, E, F, G, H, USB }\end{array}$ & 7.7257 & 7.6648 \\
\hline
\end{tabular}

Conclusion: All models have the same forecasting ability. 
Table K-7 A Summary of Mariano and Preve (2011) Statistics for Housing Returns (In-sample 4-Quarter Ahead Forecasts)

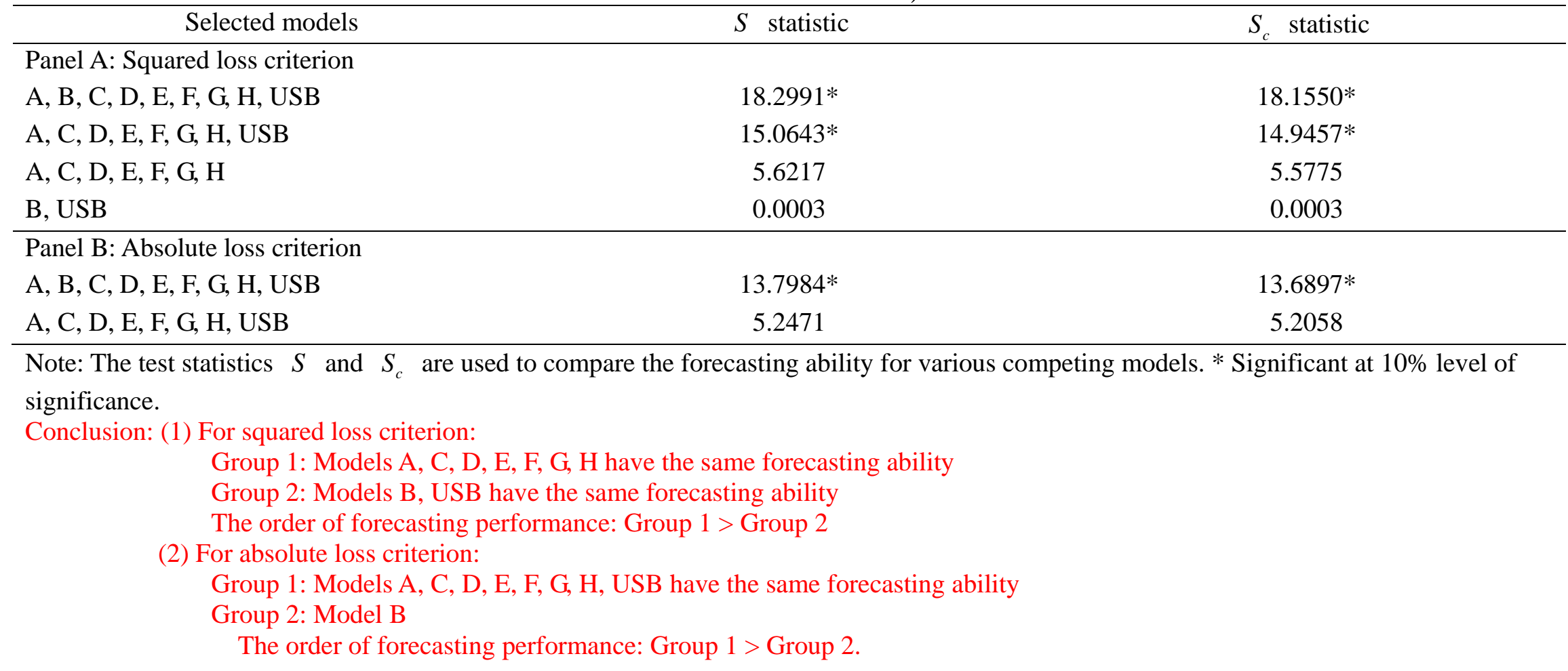


Table K-8 A Summary of Out-of-Sample Forecasting Performances (4-Quarter Ahead Forecasts) (2008Q4-2012Q1)

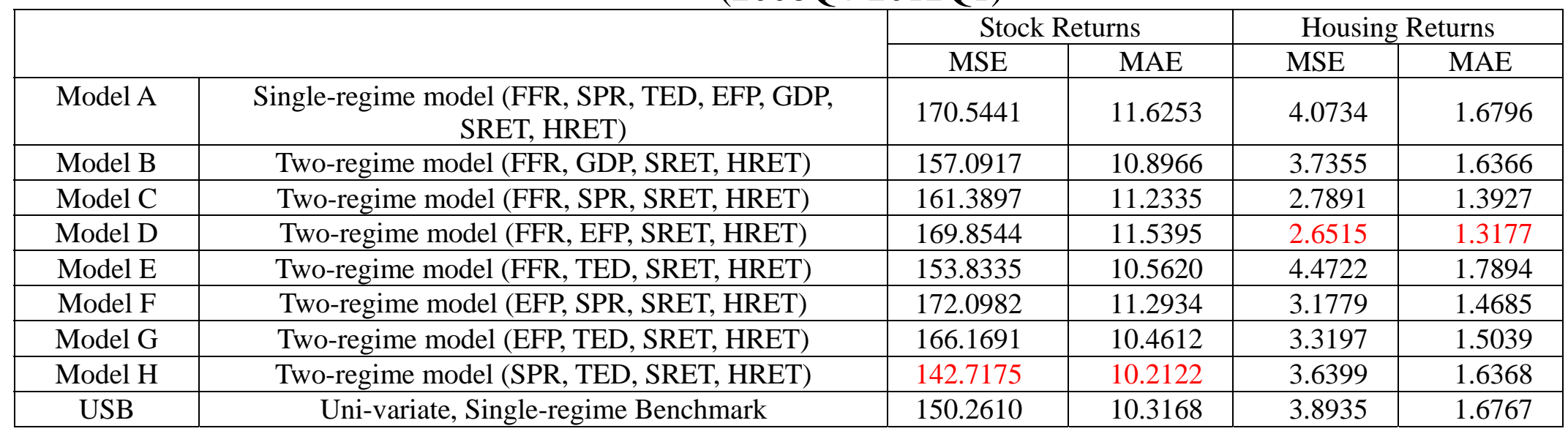


Table K-9 A Summary of Mariano and Preve (2011) Statistics for Stock Returns (Out-of-sample 4-Quarter Ahead Forecasts)

\begin{tabular}{lcc}
\hline \multicolumn{1}{c}{ Selected models } & $S$ statistic & $S_{c}$ statistic \\
\hline Panel A: Squared loss criterion & & \\
A, B, C, D, E, F, G, H, USB & $71.2009^{*}$ & $66.1151^{*}$ \\
A, B, C, D, E, G, H, USB & $55.4084^{*}$ & $51.4507^{*}$ \\
B, C, D, E, G, H, USB & $41.2602^{*}$ & $38.3131^{*}$ \\
B, C, E, G, H, USB & $15.5858^{*}$ & $14.4735^{*}$ \\
B, C, E, H, USB & 7.2440 & 6.7266 \\
A, D, F, G & 0.3807 & 0.3535 \\
\hline Panel B: Absolute loss criterion & & \\
A, B, C, D, E, F, G, H, USB & $68.1230^{*}$ & $63.2570^{*}$ \\
B, C, D, E, F, G, H, USB & $44.8673^{*}$ & $41.6625^{*}$ \\
B, C, E, F, G, H, USB & $27.5887^{*}$ & $25.6180^{*}$ \\
B, C, E, G, H, USB & $12.2081^{*}$ & $11.3361^{*}$ \\
B, E, G, H, USB & 2.9030 & 2.6957 \\
A, C, D, F & 5.9929 & 5.5649 \\
\hline
\end{tabular}

Note: The test statistics $S$ and $S_{c}$ are used to compare the forecasting ability for various competing models. * Significant at $10 \%$ level of significance.

Conclusion: (1) For squared loss criterion:

Group 1: Models B, C, E, H, USB have the same forecasting ability

Group 2: Models A, D, F, G have the same forecasting ability

The order of forecasting performance: Group $1>$ Group 2.

(2) For absolute loss criterion:

Group 1: Models B, E, G, H, USB have the same forecasting ability

Group 2: Models A, C, D, F have the same forecasting ability

The order of forecasting performance: Group 1 > Group 2. 
Table K-10 A Summary of Mariano and Preve (2011) Statistics for Housing Returns (Out-of-sample 4-Quarter Ahead Forecasts)

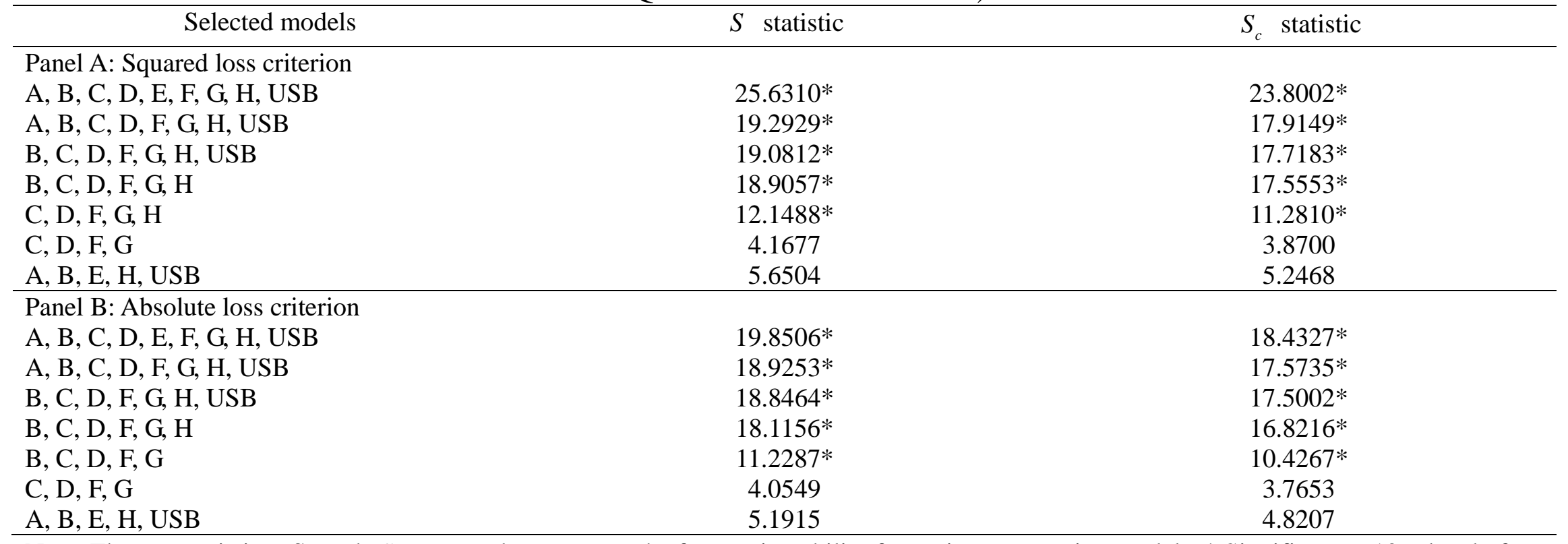

Note: The test statistics $S$ and $S_{c}$ are used to compare the forecasting ability for various competing models. * Significant at $10 \%$ level of significance.

Conclusion: (1) For squared loss criterion:

Group 1: Models C, D, F, G have the same forecasting ability

Group 2: Models A, B, E, H, USB have the same forecasting ability.

(2) For absolute loss criterion:

Group 1: Models C, D, F, G have the same forecasting ability

Group 2: Models A, B, E, H, USB have the same forecasting ability.

The order of forecasting performance: Group $1>$ Group 2. 